Florida International University FIU Digital Commons

12-11-2009

\title{
Managing Small-Medium Cities in a Time of Globalization: Experiences and Evidence from Florida's Public Managers
}

Nadine V. Wedderburn

Florida International University, nadzjam@yahoo.com

DOI: $10.25148 /$ etd.FI10112002

Follow this and additional works at: https://digitalcommons.fiu.edu/etd

Part of the Other Public Affairs, Public Policy and Public Administration Commons, Public Administration Commons, Public Affairs Commons, Recreation, Parks and Tourism Administration Commons, and the Urban Studies Commons

\section{Recommended Citation}

Wedderburn, Nadine V., "Managing Small-Medium Cities in a Time of Globalization: Experiences and Evidence from Florida's Public Managers" (2009). FIU Electronic Theses and Dissertations. 308.

https://digitalcommons.fiu.edu/etd/308 


\section{FLORIDA INTERNATIONAL UNIVERSITY}

Miami, Florida

MANAGING SMALL-MEDIUM CITIES IN A TIME OF GLOBALIZATION:

EXPERIENCES AND EVIDENCE FROM FLORIDA'S PUBLIC MANAGERS

A dissertation submitted in partial fulfillment of the

requirements for the degree of DOCTOR OF PHILOSOPHY

in

PUBLIC AFFAIRS

by

Nadine Vanessa Wedderburn 
To: $\quad$ Dean Kenneth Furton

College of Arts and Sciences

This dissertation, written by Nadine Vanessa Wedderburn, and entitled Managing Small-Medium Cities in a Time of Globalization: Experiences and Evidence from Florida's Public Managers, having been approved in respect to style and intellectual content, is referred to you for judgment.

We have read this dissertation and recommend that it be approved.

$\begin{array}{r}\text { Sukumar Ganapati } \\ \hline \text { Keith Revell } \\ \hline \text { John F. Stack, Jr. } \\ \hline \text { Howard A. Frank, Major Professor }\end{array}$

Date of Defense: December 11, 2009

The dissertation of Nadine Vanessa Wedderburn is approved.

\begin{tabular}{r}
$\begin{array}{r}\text { Dean Kenneth Furton } \\
\text { College of Arts and Sciences }\end{array}$ \\
\hline Interim Dean Kevin O'Shea \\
University Graduate School
\end{tabular}

Florida International University, 2010 
(C) Copyright 2010 by Nadine Vanessa Wedderburn

All rights reserved. 


\section{DEDICATION}

I dedicate this dissertation to my parents, Bing and Dorothy Wedderburn.

Their deep, undying love for each other inspired me to complete this task.

Their patience and unwavering support sustained my efforts.

Their lessons of discipline kept me focused.

This work is a tribute to their timeless example. 


\section{ACKNOWLEDGMENTS}

The completion of this work signifies the generous support and invaluable guidance of the members of my dissertation committee. Many thanks to Dr. John F. Stack, Jr. for stirring my interest in the phenomenal topic of globalization and for being mentor extraordinaire during the preparation of this document; to Dr. Sukumar Ganapati for his intelligent insights on the intersection of public management and globalization and his calm and steady direction during this process; to Dr. Keith Revell for his keen sense of quality and the infectious energy and enthusiasm that he brings to the adventure of learning every day. It motivates me to continuously aim high; and to Dr. Howard Frank, my chairperson, who is a constant guiding light and exemplary model of what it means to be the consummate teacher, adviser and leader.

I am grateful for the support of the Department of Public Administration at FIU for fostering a thriving community of learning and scholastic collegiality. I especially mention Dr. Meredith Newman for her outstanding leadership as Professor and Chair of the department and for her commitment to exceptionally high standards for the field of public administration.

I am thankful for the many wholesome friendships formed at FIU. My academic colleagues consistently inspire me to be the best, in teaching and in learning. 
I am truly indebted to the participants in this study. Their cooperation has helped me realize the ending of a mission and the beginning of exciting times to come. Their dedication to promoting a better life for those whom they serve is not nearly recognized enough.

Finally, I am deeply appreciative of the love, support and prayers of extended family and friends who championed me along this journey. To my brothers, Weyden, Christopher and Kevin, I love you all. Thank you for all you do to encourage and uplift me. 


\begin{abstract}
OF THE DISSERTATION
MANAGING SMALL-MEDIUM CITIES IN A TIME OF GLOBALIZATION:

EXPERIENCES AND EVIDENCE FROM FLORIDA'S PUBLIC MANAGERS
\end{abstract}

by

Nadine Vanessa Wedderburn

Florida International University, 2009

Miami, Florida

Professor Howard A. Frank, Major Professor

This study examines how public management practitioners in small and medium-sized Florida cities perceive globalization and its impact on public management practice. Using qualitative analysis, descriptive statistics and factor analysis methods, data obtained from a survey and semistructured interviews were studied to comprehend how public managers view the management and control of their municipalities in a time of globalization. The study shows that the public managers' perceptions of globalization and its impact on public management in Florida's small-medium cities are nuanced.

Whereas some public managers feel that globalization has significant impacts on municipalities' viability, others opine that globalization has no local impact. The study further finds that globalization processes are perceived as altering the public management functions of decision-making, economic development and service delivery in some small-medium cities in 
Florida as a result of transnational shifts, rapidly changing technologies, and municipalities' heightened involvement in the global economy. The study concludes that the globalization discourse does not resonate among some public managers in Florida's small-medium cities in ways implied in extant literature. 


\section{TABLE OF CONTENTS}

CHAPTER

PAGE

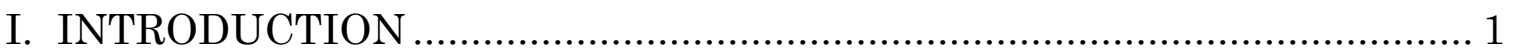

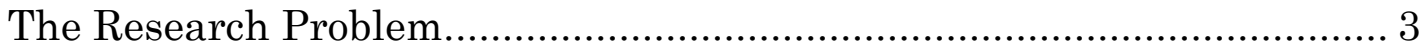

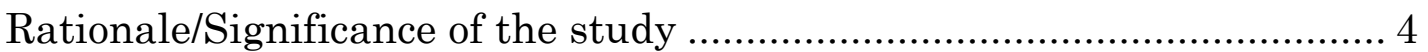

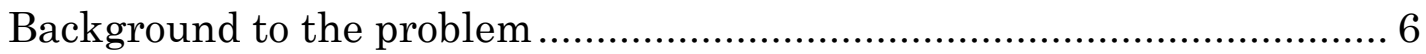

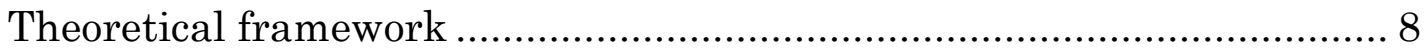

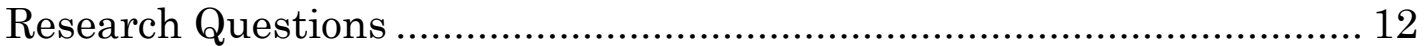

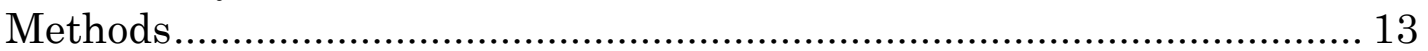

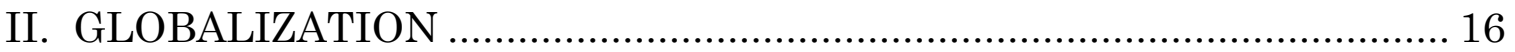

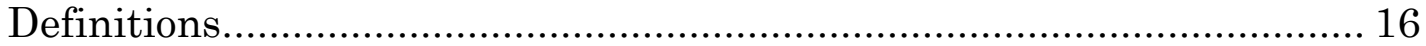

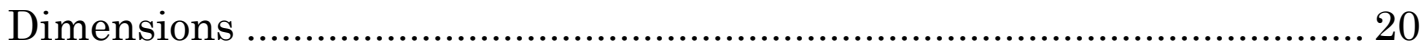

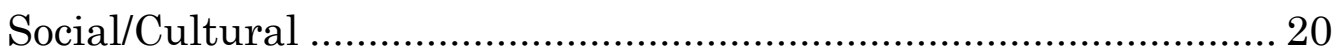

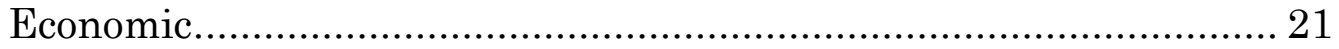

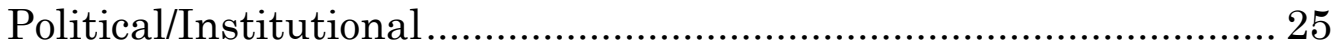

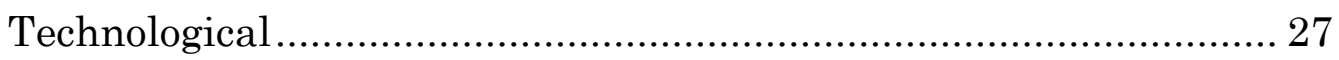

Interactions between the global and the local........................................ 29

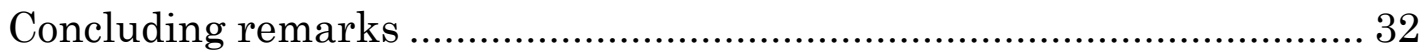

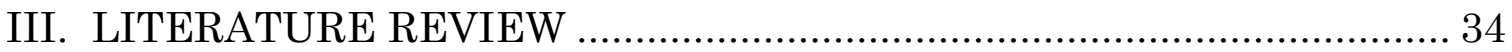

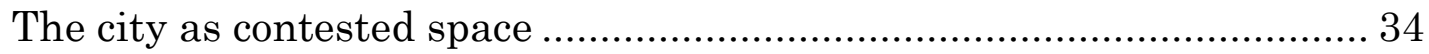

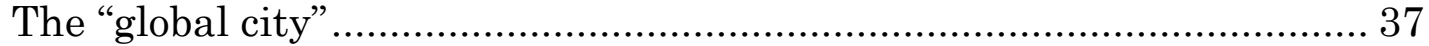

The Metropolitan Statistical Area …........................................................ 40

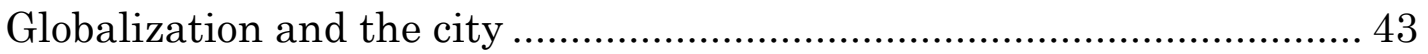

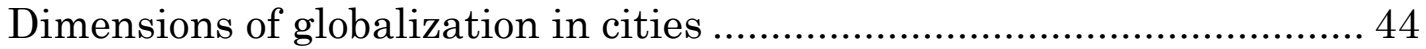

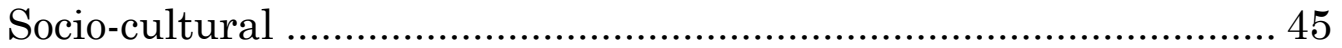

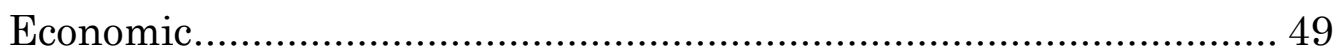

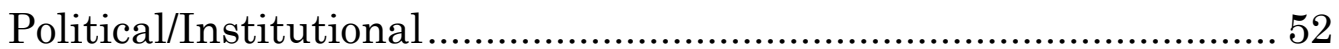

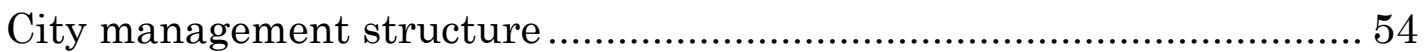

City management as public management ............................................. 57

Public management functions................................................................. 59

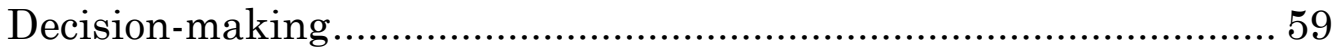

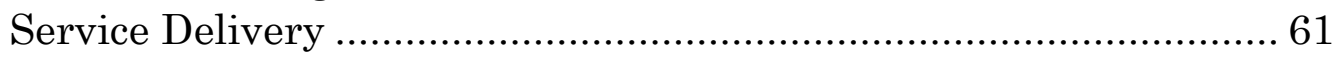

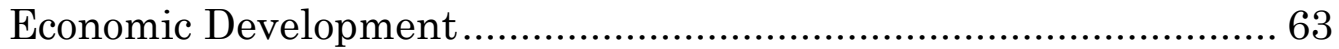

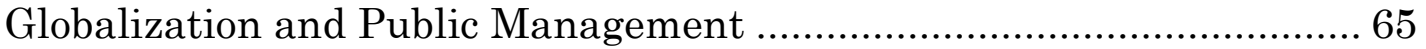

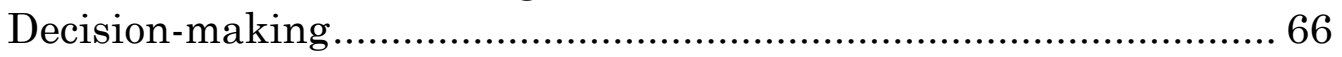

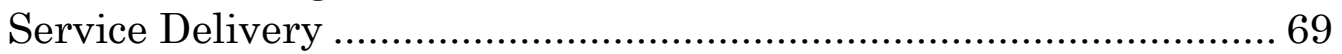

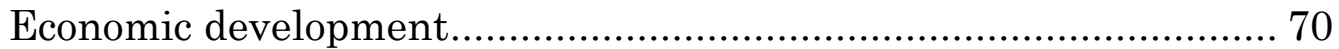

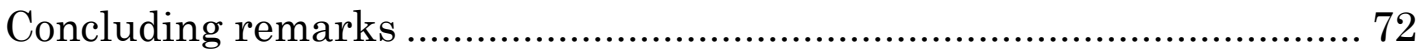


IV. RESEARCH DESIGN AND METHODOLOGY...................................... 74

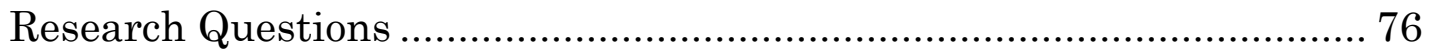

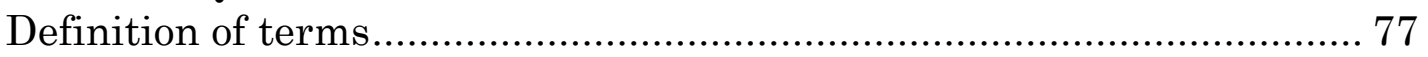

Focus of the study - The State of Florida.............................................. 78

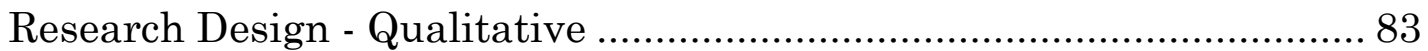

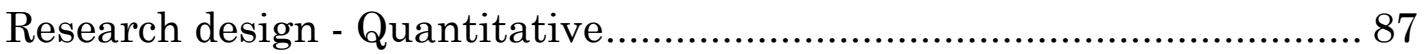

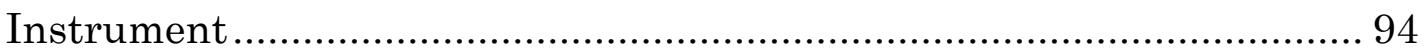

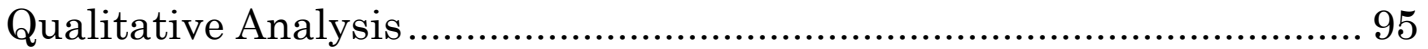

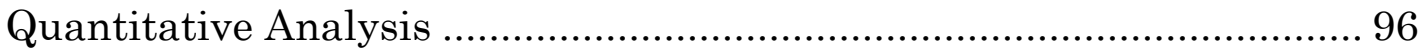

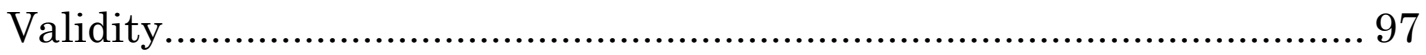

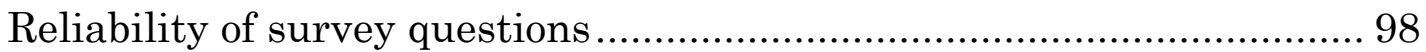

V. MANAGERS' PERCEPTIONS OF GLOBALIZATION …......................... 104

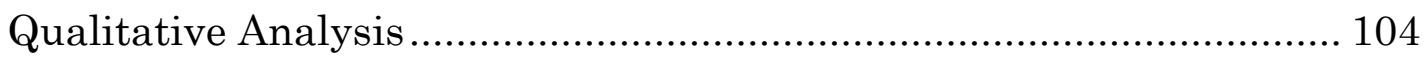

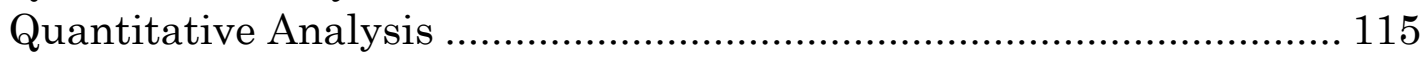

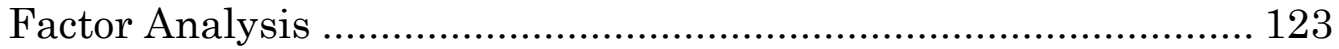

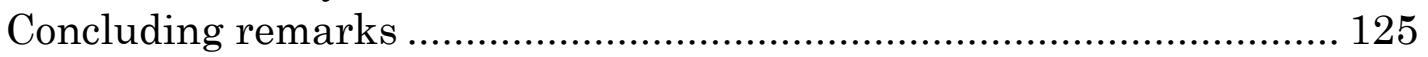

VI. MANAGERS' PERCEPTIONS OF MUNICIPALITIES' GLOBAL

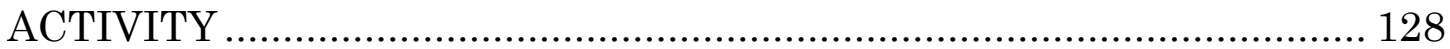

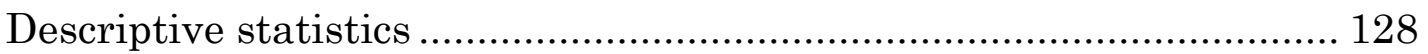

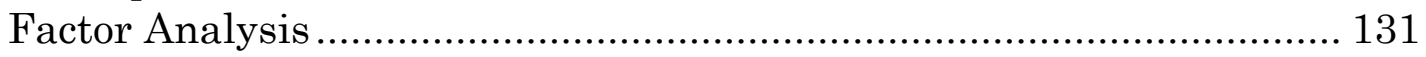

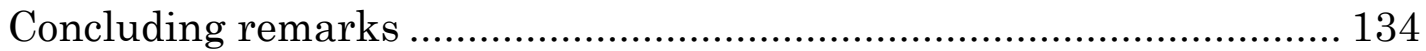

VII. MANAGERS' PERCEPTIONS OF GLOBALIZATION'S IMPACT ON

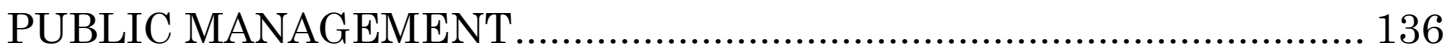

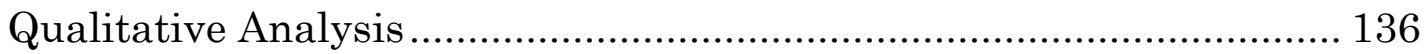

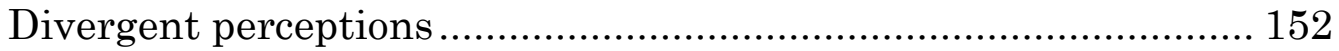

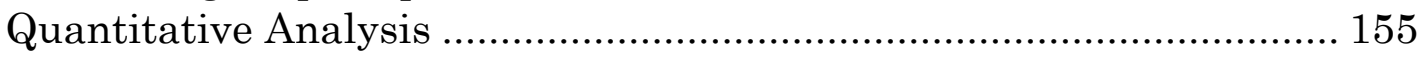

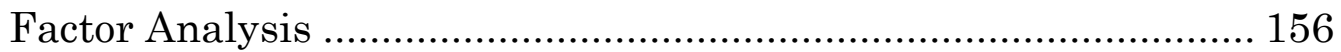

Concluding remarks ....................................................................... 158

VIII. MANAGERS' PERCEPTIONS OF GLOBALIZATION'S IMPACT ON

SPECIFIC PUBLIC MANAGEMENT FUNCTIONS …............................ 165

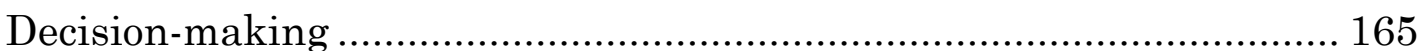

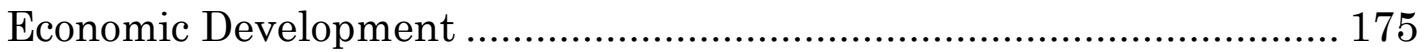

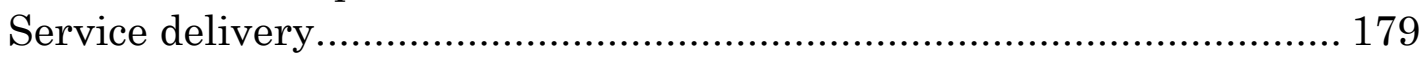

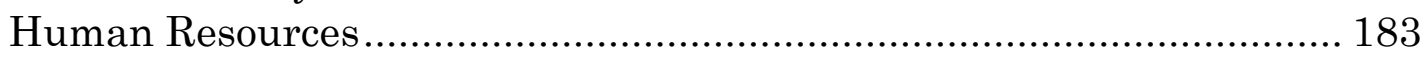

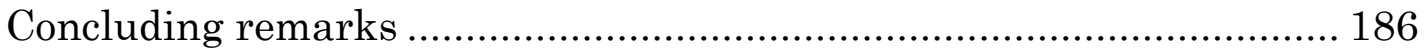

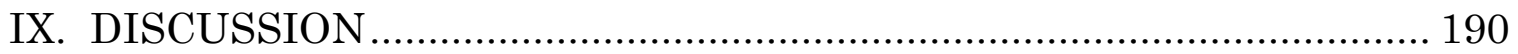

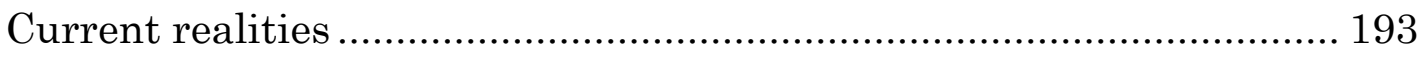

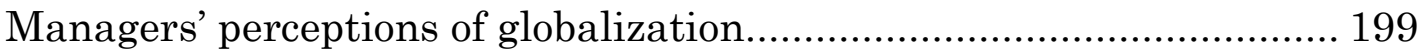

Managers' perceptions of globalization's impact on public

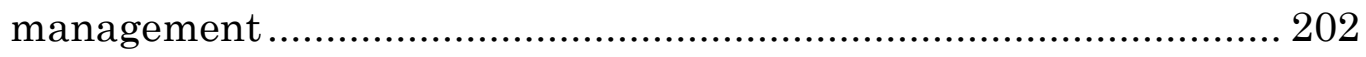


Managers' perceptions of globalization's impact on public

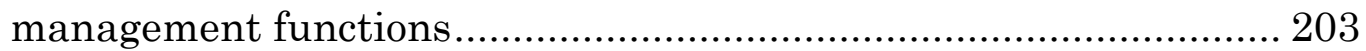

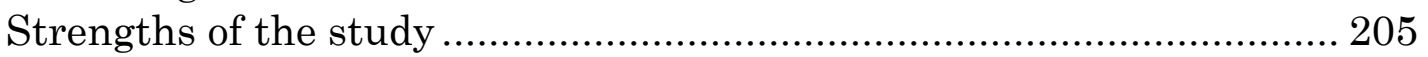

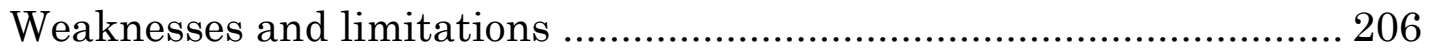

Implications for future study and the field of public management....... 208

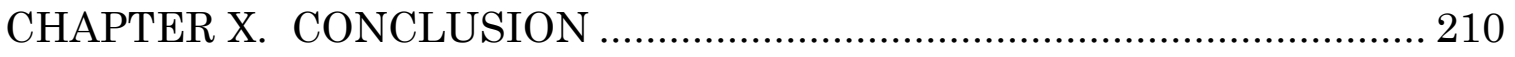

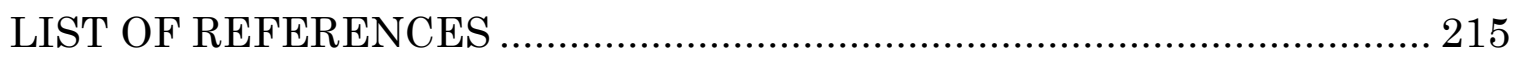

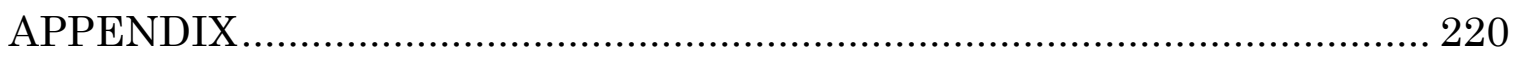

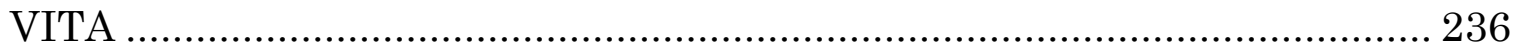




\section{LIST OF TABLES}

TABLE

PAGE

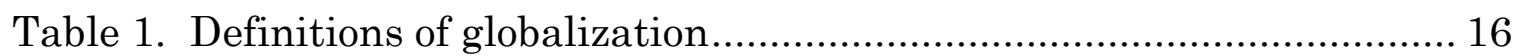

Table 2. Florida metropolitan areas population data..................................... 81

Table 3. Interview participants' and municipalities' data ............................ 85

Table 4. Index of Qualitative Variation for interview sites .......................... 86

Table 5. Distribution of survey respondents by age .................................... 89

Table 6. Distribution of survey respondents by level of education ................ 89

Table 7. Survey respondents' MSA population data ...................................... 91

Table 8. Descriptive statistics for scale measuring municipality's level

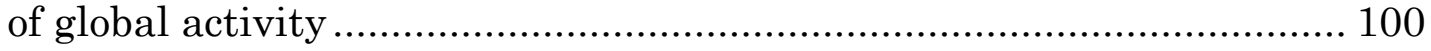

Table 9. Descriptive statistics for scale measuring perceptions of global economy's impact on aspects of municipalities' economy ........................ 101

Table 10. Descriptive statistics for scale measuring managers' assessment of globalization's impact on aspects of municipalities' management.

Table 11. Descriptive statistics for scale measuring perceptions of globalizations impact on aspects of managerial decision-making ......... 102

Table 12. Question 3 - Public managers' perceptions of common

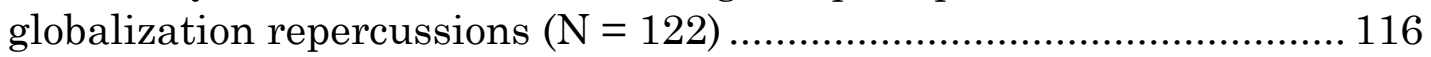

Table 13. Public managers' responses to common perceptions of

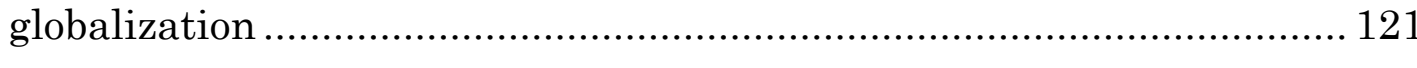

Table 14. KMO and Bartlett's Test for questions 3 and 6......................... 123

Table 15. Rotated Component Matrix for questions 3 and 6 ..................... 124

Table 16. City's global activity on a scale of $1-5 ;(1=$ No activity, $5=$

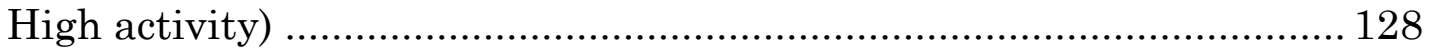


Table 17. Manager's perceptions of global economy's impact on aspects of city's socioeconomic conditions on a scale of $1-5$; $(1=$ low impact, $5=$ high impact

Table 18. Percentage of respondents who indicate that certain strategies have been implemented in their municipality $(\mathrm{n}=116) \ldots \ldots . .130$

Table 19. KMO and Bartlett's Test for questions 1, 7 and 8...................... 131

Table 20. Rotated Component Matrix for questions 1, 7 and 8.................. 133

Table 21. Managers' perceptions of the view that globalization increases job opportunities in my municipality ..................................... 141

Table 22. Measures of association for managers' perceptions of the view that globalization increases job opportunities in my municipality

Table 23. Managers' perceptions of the view that globalization raises wages in their municipality

Table 24. Measure of association for managers' perceptions of the view that globalization raises wages in their municipality

Table 25. Managers' perceptions of the view that globalization improves quality of life standards in their municipality

Table 26. Measures of association for managers' perceptions of the view that globalization improves quality of life standards in my municipality

Table 27. Managers' perceptions of globalization's impact on managerial concerns …….................................................................. 155

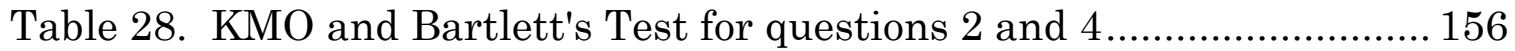

Table 29. Rotated Component Matrix for questions 2 and 4 ..................... 157

Table 30. Classification of public managers' perceptions of globalization's impact on public management...................................... 157

Table 31. Cross-tabulation analysis for the relationship between cities' IQV and managers' perceptions ............................................................ 160

Table 32. Cross-tabulation analysis for the relationship between city size and managers' perceptions 
Table 33. Cross-tabulation analysis for the relationship between metropolitan areas and managers' perceptions...................................... 161

Table 34. Public managers' perceptions of globalization's impact on

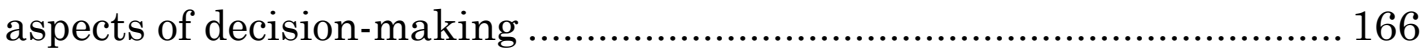

Table 35. Managers' perceptions of the view that increased racial/ethnic diversity in my municipality complicates policymaking

Table 36. Measure of association for managers' perceptions of the view that increased racial/ethnic diversity in my municipality complicates policymaking....

Table 37. Managers' perceptions of the view that access to and participation in the global economy lowers operating costs for my municipality

Table 38. Managers' perceptions of the impact of a more competitive global economy

Table 39. Measures of association for managers' perceptions of the impact of a more competitive global economy

Table 40. Managers' perceptions of the impact of entrepreneurship

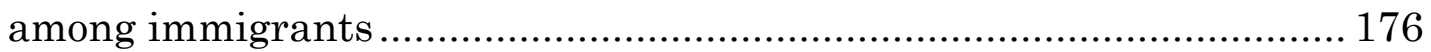

Table 41. Measures of Association for managers' perceptions of the impact of entrepreneurship among immigrants

Table 42. Managers' perceptions of the impact of local establishment of multinational corporations

Table 43. Measure of association for managers' perceptions of the impact of local establishment of multinational corporations 


\section{LIST OF FIGURES}

FIGURE PAGE

Figure 1. Map of Florida showing spatial distribution of small-medium

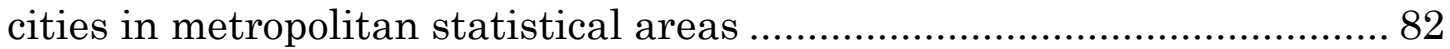

Figure 2. Bar chart showing distribution of survey respondents by

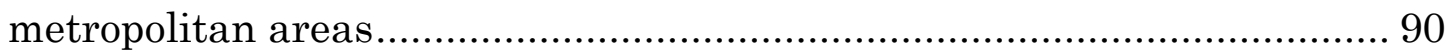

Figure 3. Bar chart showing perceptions of a more competitive global

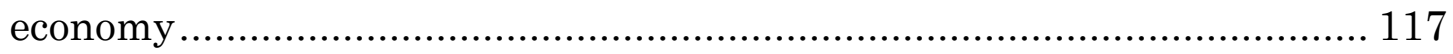

Figure 4. Bar chart showing perceptions of entrepreneurship among

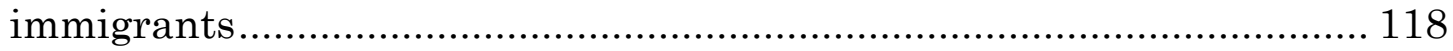

Figure 5. Bar chart showing perceptions of local establishment of

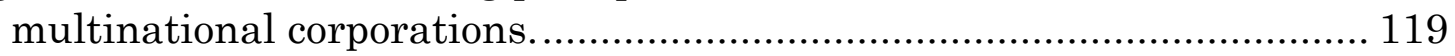

Figure 6. Bar chart showing public managers' responses to common perceptions of globalization.................................................................. 122

Figure 7. Managers' perceptions of globalization ...................................... 127 


\section{CHAPTER I. INTRODUCTION}

The disintegration of the Union of Soviet Socialist Republics and the end of the Cold War has heightened discussion surrounding the shrinking of the globe and the rapid shifting of people, products, and services around the world. This discussion is not new as historians have chronicled the movement of goods and people across geographical and national boundaries since the beginning of time. It has been noted however, that since the early $1990 \mathrm{~s}$, a contemporary version of these movements is being manifested at unprecedented speed and proportion, transcending geographical and time confines. Such movements seem to erode national cultures, identities and economies and have been identified collectively as the phenomenon known as 'globalization'.

The term 'globalization' has become commonplace in interdisciplinary parlance in reference to the simultaneous exchange and interfacing of transnational economic, political, technological and cultural processes. These processes create profound interdependencies among nations and challenges the ways in which localness is experienced all over the world. As information, goods and people traverse the globe, the significance of place is being called into question. Global networks of communication, trade and finance are no longer the domain of metropolises like New York and London. Rather, smaller towns and regions are becoming increasingly active in the global arena and municipal administrations are challenged to innovate to 
remain functional in an increasingly competitive era. My study explores the possibility that globalization has important and far-reaching impacts on the practice of public management in small-medium cities in the State of Florida. The study serves as a conduit for the voice of Florida public managers on how they perceive globalization and its impact in cities smaller than "global" cities.

This work is divided into ten main parts. This first chapter gives an overview of the research. It explains the background and rationale for the research problem, introduces the literature review and theoretical framework and lays out the research design. The chapter ends by stating the methods used to address the research questions and related hypotheses. The second chapter presents a survey of the concept of globalization and its dimensions. Chapter three presents the literature that grounds the study. It draws on work previously carried out by public administration, urban sociology and political science scholars to provide a synthesis of globalization and public management issues as they relate to the research problem.

The fourth chapter describes the methodology employed to answer the research questions. In this chapter, I investigate the reliability and validity of the survey instrument and present a defense for the basis on which the utilized statistical techniques were selected. Public managers' perceptions of the concept of globalization, as gleaned from the interviews and the survey, are treated in Chapter five. Chapters six, seven and eight answer the 
research questions that form the basis of this study. Each of these chapters identifies patterns that emerge from the qualitative and quantitative data and a summary of the results. A full discussion of the analyses' results is executed in Chapter 9 and Chapter 10 closes out the dissertation. In the concluding chapters, I discuss the limitations as well as the strengths of the study and point out implications for future research.

\section{The Research Problem}

Ernest Wilson, in reporting on a foreign policy forum conducted with United States' city mayors in 2006, commented that policymakers need "to listen to what's happening in the states and cities....They have lots to say that we need to hear." That globalization has presented diverse challenges for public administration practitioners is not an absurd assertion in the early days of the twenty-first century. The current study corroborates Wilson (2006) in that the processes related to globalization are actualized and experienced in the places where people live and work. My research argues that ultimately, it is the local public official who has to contend with managing the day-to-day ramifications of these processes in their respective locales.

These contentions vie for prominence among political and administrative leaders as the public sector aims to serve the public interest and continuously negotiate and perform the tasks of managing local activities 
and public policies. Of particular interest in this study is the impact of globalization on the managerial activities of decision-making, economic development and public service delivery in the context of the city. The present study examines how public managers are responding to the forces of globalization in small-medium cities in the State of Florida, while carrying out their responsibilities to provide services in a responsive, efficient and equitable manner.

\section{Rationale/Significance of the study}

Public management is of growing concern in both highly urbanized and rapidly globalizing places around the world. As more of the world's population is concentrated in metropolitan places and the need for competent municipal management becomes more insistent, attention must be given to the highly-constructed social, economic, and political aspects of urban living and development. In reference to the growing important role that local and regional governments around the world play in managing metropolitan areas, urban sociologist Castells (1999) asserts that "the global age is the age of local management" (Susser 2002, p. 379). My study submits that the quality of public management in cities becomes increasingly important as globalization continues to fundamentally affect social existence.

If public management practitioners are to be relevant and responsive to the communities they serve, they have a responsibility to understand the 
complex phenomenon of globalization and their role in it. Subsequently, they must convey this understanding to citizens in a competent and confident manner. This study intends to show a representation of such an understanding, specifically that of managing the complexities of smallmedium urban municipalities in a time of globalization, and the role that such an understanding plays in the advancement of contemporary urban management and policy.

As the interconnectedness among places increase, participation in global activities progressively involve more than a few privileged cities. It means, therefore, that for those who have the responsibility of directing and controlling public affairs in cities, it is crucial that they understand the persistent opportunities and challenges that globalization presents and how to best deal with them. My research considers the perspectives of public managers regarding globalization and its impacts on public management functions in 'small-medium' cities in Florida. The inquiry will bring the small-medium city perspective into the globalization debate which consistently engages primarily the mega-metropolitan centers of the world. Small-medium cities are here defined as incorporated municipalities that have a population size of between 10,000 and 250,000 . Further, the study will serve to fill the existing gap in the wider body of scholarship where the study of the intersection between globalization and public management in smallmedium cities has been largely unexamined. Urban studies and public 
administration scholars alike emphasize that more focused study in this area is necessary (Svara 1990; Sassen 1996; Czarniawaska 2002; Folz and French 2005).

\section{Background to the problem}

As a discipline, public administration is typically understood as the 'the business of government'. As a practice, public administration is what workers in the public sector do. Over the past two decades, challenges to the practice of public administration have manifested in a re-examination of public organizations' management and relevance to citizens. Hughes (2003) points out that since the late 1980s, in many countries "political leaders and the community alike regarded the service they received from the public service as poor, tied up in process and out of touch with reality" (p. 14). This has resulted in greater emphasis on management as opposed to administration and highlighting performance as goal- rather than processoriented. The area of public administration that is concerned with management encompasses a variety of complex concerns and functions as the discipline continuously seeks to maintain a balance between its shared responsibilities of politics and administration.

Today's public managers are challenged with constant changes in the issues they address and the methods in which they are required to address the changes. Changing demographics unquestionably contribute to these 
demands (Katz and Lang, 2003). At the national level, the interface between globalization and governance has been examined and globalization's impact on city management has been examined in large cities (Nye and Donahue, 2000; Czarniawska, 2002). However, this study contends that globalization presents a challenge for public managers in small-medium cities and this scenario deserves attention. Sassen (1996) notes:

the urban level and the community level need to be incorporated in the analysis of economic globalization and the study of new information technologies.... Such a focus decomposes the national economy into a variety of subnational components, some profoundly articulated with the global economy, and others not (para. 2 and 3).

To arrive at a more inclusive and representative understanding of the impact of globalization on the work of a wide cross-section of public managers, researchers must investigate cities other than those considered to be 'global'. As CEOs for Cities informs, "all cities are affected to varying degrees by a formidable set of common problems and challenges, including globalization, technological change, demographic shifts, the global value chain and evolving product life cycles" (p. 4).

Ultimately, the responsibility of serving the public's interest and managing and implementing the political will of the people lies in the purview of public administration. How public managers guide and control their respective jurisdictions while remaining responsible for meeting organizational goals in the face of globalization is of utmost importance. 
Information from this process must be gleaned and understood via deliberate and systematic study.

To this end, the present research is an effort to communicate the experiences of public managers in small-medium cities in Florida, utilizing a constructionist approach to understanding public management practices in places that are typically not studied. This study draws upon literature from political science, urban sociology and public administration while giving voice to practitioners from the State of Florida.

\section{Theoretical framework}

The present research is predicated on the assumption that it will generate usable knowledge for improving the understanding of policies and actions that involve the interactions between globalization and public administration at all levels of practice. It utilizes the constructionist view of public administration, as put forward by Jun (2006), which relies on the interpretive and critical theoretical approaches to understanding. Jun (2006) contends that public administration ought to be viewed as socially constructed as it is concerned with "how people construct and attach certain meanings to their experiences and how these meanings become objectified aspects of public administration, such as rules and regulations, positions, roles, institutions, organizational acronyms, symbols, categories, and specialized tasks" (p. 55). The dissertation advocates, therefore, that the 
construction of public management become fundamental to policy creation in diverse places.

To locate the constructionist perspective in the public administration milieu, Jun (2006) adds that "the social construction of public administration acknowledges that the members of an organization create organizational realities through interaction, dialogue, and discourse" (p. 55). This supports my thesis that public managers' experiences of globalization in large cities do not represent the experiences of public managers in all places. As such, large city experiences should not be used as the universal basis for public management reality. Instead, as the field of public management evolves, it is imperative that the development engages the realities of public management practitioners from varying backgrounds and settings. As Jun (2006) puts it, "when people consider that realities are socially constructed, they accept that there is not one reality or one version of the truth" (p.55).

In the fashion of "paradigm bridging" (Ritzer, 1975), I also employ the sociological structural-functional framework for theorizing public management. Structural functionalism assumes that society is "a system of interdependent parts [that] fulfill different needs or functions of the social system; a basic consensus on values or value system holds society together" (Neuman 2004, p. 40). Such a model presents the city as an organization having interrelated components that must work in harmony for the public good. A structural-functional framework portrays the city as an organization 
that must evolve with changing times in order to respond to the various needs of its citizenry so that it remains relevant and purposeful.

The structural-functional model also lays the foundation for a management/decision-theory approach which regards "the systematic study of public administration as process, and tends to concentrate on core functions of public administration" (Smith and Licari 2006, p. 17). Accordingly, Metcalfe and Richards (1987) define public management as "concerned with the effective functioning of whole systems of organizations...the explicit acknowledgement of the responsibility for dealing with structural problems at the level of the system as a whole" (pp. 73-75).

In view of the structural-functional approach to public management, I consider three functions of city management: decision-making, economic development and service delivery. These three functions are being emphasized on the premise that they are vital to the everyday life and management of a city and provide an important cross-section of potential impacts of globalization on public management. My study submits that the decisions that are made within the constructs of public management ultimately determine whether or not administrative goals are achieved. Service delivery is being acknowledged as the culmination and tangible manifestation of the decisions that are made; and economic development is seen as the chief means by which a city provides for a socially and financially stable living environment (Gianakis and McCue, 1999). An approach to 
understanding the management of a city in terms of its operating constituents, therefore, is crucial to its functionality.

Consistent with a structural-functional approach, the current study posits that, in order for city management to be relevant, its functions must be appropriately responsive to the changes in the environments where they occur. Hence, this research affirms city management as urban public management and defines urban public management as the sociallyconstructed practice of organizing, directing and controlling the various operations of a city necessary to effectively and efficiently meet the needs of its citizens in a responsive and equitable manner. Public managers therefore, together with elected officials assume the responsibility to make cities more equitable, accountable, efficient, and socially-just places. Consistent with this role, the title public manager refers to an individual who has primary responsibility over the operations of a specific municipal department. In an increasingly interdependent world, public managers' perceptions of globalization become an important thread in the fabric of the social construction of public administration. Their perceptions have policy implications for how local governments remain responsive and accountable to their citizenry.

The organization of the research is framed by the intersection of two concepts: globalization and public management. The interaction of both concepts must be studied in context in order to understand the changes in 
managerial functions that arise from their interaction. The constructionist and structural-functional paradigms are the sociological paradigms through which I conduct this inquiry into the nexus of globalization and public management. In sum, the theory being asserted in this study is: The impact of globalization on the socially-constructed practice of public management produces changes in decision-making, economic development and service delivery functions. To critically evaluate this theory, three research questions are posed.

\section{Research Questions}

This study posits that globalization's impact on urban public management produces changes in decision-making, economic development and service delivery functions. I seek to verify this claim by specifically investigating evidence and experiences from public managers in smallmedium municipalities in the State of Florida. The primary research question that drives the study is:

1. How do public managers in Florida's small-medium cities perceive the impacts of globalization on the public management functions of decision-making, economic development and service delivery?

To reasonably arrive at an answer to these questions, two secondary questions are also posed. They are: 
a. How do public managers in Florida's small-medium cities perceive globalization?

b. How do public managers in Florida's small-medium cities perceive globalization's impact on public management?

It is expected that this study will provide an entrée into understanding how public managers are reckoning with the impacts of globalization on public management practices in small-medium cities in Florida's metropolitan areas. By doing so, the study will contribute to closing the gap in the current literature concerning the complexities that public managers in small-medium cities face in handling their respective municipalities in a time of globalization. Further, the study elucidates the opportunities and challenges of globalization as perceived by public managers, specifically in the managerial roles of decision-making, economic development and service delivery.

\section{Methods}

The study utilizes data from those incorporated municipalities in Florida having a population size of between 10,000 and 250,000 according to the 2000 U.S. Census. These municipalities are considered "small-medium" cities. Particular attention is paid to those municipalities that are located within a "metropolitan statistical area" (MSA). The MSA is a statistical unit developed by the U.S. Census to identify "an area containing a recognized 
population nucleus and adjacent communities that have a high degree of integration with the nucleus." ${ }^{1}$ Generally, individual municipalities occupy significant areas of a MSA. A distinction is made here between a suburb and a city. Many suburbs are not self-governing municipalities although many cities are suburbs. For the purpose of this study, cities are defined as geographical entities with municipal charters granting them authority to use powers of local self-government. A public manager refers to an individual who has primary responsibility over the operations of a specific municipal department. My research serves to enrich the scholarly understanding of the management of small-medium cities in the shadow of their larger counterparts, especially in an era of globalization.

The MSA is a logical unit for the study of globalization processes in urban places as it locates a core of economic, political, and cultural activity in a given urban area and represents an important hub for regional and international connections and communications. Whereas it may be assumed that the effects of globalization are most likely to be evident in, and articulated among the practitioners of, the principal city in a MSA, this study will bring to the fore the experiences of public managers in smaller municipalities that are located throughout the metropolitan area. My contribution is that the small-medium cities are undoubtedly being affected by the social, cultural, economic, and political dynamics occurring in the

\footnotetext{
${ }^{1}$ Federal Register / Vol. 65, No. 249 / Wednesday, December 27, 2000 /
} Notices 
principal city by virtue of their proximity to principal cities. Therefore, it is important to learn about the uniqueness of the public management experience in these places and add them to the broader public administration and urban dialogues. 


\section{CHAPTER II. GLOBALIZATION}

\section{Definitions}

Many scholars have written on the subject of globalization and it is widely held that the phenomenon does not address a single condition, but rather a wide range of conceptualizations. This study begins with a review of extant definitions of the term "globalization" as a means of grounding this dissertation.

Table 1. Definitions of globalization

\begin{tabular}{|l|l|}
\hline Robertson (1992) & $\begin{array}{l}\text { "globalization as a concept refers both to the } \\
\text { compression of the world and the intensification of } \\
\text { consciousness of the world as a whole." }\end{array}$ \\
\hline Boxill (1999) & $\begin{array}{l}\text { "a process through which cross-border interactions } \\
\text { intensify and spaces of social action extend well beyond } \\
\text { the nation-state" }\end{array}$ \\
\hline Giddens (2000) & $\begin{array}{l}\text { "political, technological and cultural as well as } \\
\text { economic [process] that is restructuring the ways in } \\
\text { which we live in a very profound manner. [It] } \\
\text { influences everyday life as much as it does everything } \\
\text { happening on a world scale" }\end{array}$ \\
\hline Held et. al. (2000) & $\begin{array}{l}\text { "a process (or set of processes) which embodies a } \\
\text { transformation in the spatial organization of social } \\
\text { relations and transactions - assessed in terms of their } \\
\text { extensity, intensity, velocity and impact - generating } \\
\text { transcontinental or interregional flows and networks of } \\
\text { activity, interaction, and the exercise of power" (p. 55). }\end{array}$ \\
\hline Mittleman (2000) & $\begin{array}{l}\text { "compression of the time and space aspects of social } \\
\text { relations." }\end{array}$ \\
\hline $\begin{array}{l}\text { Czarniawska } \\
\text { (2002) }\end{array}$ & $\begin{array}{l}\text { translocalization: the phenomenon consisting of local } \\
\text { practices, ideas, customs, and technologies that are } \\
\text { spreading to localities beyond their origins - spreading, } \\
\text { in fact, all over the globe" }\end{array}$ \\
\hline
\end{tabular}

Table 1 presents a collection of globalization definitions that emphasize the diversity of thought surrounding the phenomenon. 
Globalization has been compared with other similarly coined terms like 'globalism'. Globalism refers to

a state of the world involving networks of interdependencies at multicontinental distances. These networks can be linked through flows and influences of capital and goods, information and ideas, people and forces, as well as environmentally and biologically relevant substances (such as acid rain or pathogens) (Keohane and Nye Jr., 2000, p. 2).

The comparison between globalism and globalization distinguishes the latter as a course in action - a process, as opposed to a static condition. This study reinforces a relationship and a distinction between globalism and globalization as articulated by Keohane and Nye. They argue that globalization is the thickening of globalism which "involves many relationships that are intensive as well as extensive: long-distance flows that are large and continuous affecting the lives of many people" (Keohane and Nye 2000, p. 7).

As places and individuals spawn new linkages across the world, the process of globalization intensifies globalism via increasingly intricate networks. Globalization, then, is the means by which cross-continental relationships thicken. For the purposes of this study, the perspectives rendered by Giddens (2000) and Czarniawska (2002) seems particularly relevant. Drawing on Giddens (2000), Czarniawska (2002) and Keohane and Nye (2000), I propose that globalization be defined as the process of transnational demographic shifts, rapidly changing technologies and 
heightened inter-continental economic activity that influences and transforms cultures, societies, political and administrative systems. Globalization affects people, places and ideas and, in essence, is about a dynamic influence of the local upon the global and vice versa.

The multiplicity of perspectives and the difficulty of arriving at a single and suitable definition of the term, however, do not imply that there is a lack of coherence among the various definitions that exist. Rather, globalization may be conceptualized as a phenomenon comprised of various elements. Accordingly, Steger (2003) points to four distinct characteristics that lie at the core of globalization. They are the "creation/expansion, multiplication/intensification, acceleration, and awareness" of social exchanges and activities (Steger 2003, p. 9). Therefore, regardless of which dimension of globalization is being considered at any given instance, one can be certain that a combination of stretching and compressing of said dimension is taking place at a certain rate among various stakeholders in the process.

Further, the social, economic, political, technological and cultural exchanges and activities make up a complex web that adds another layer to the understanding of globalization - that of intensity. My study highlights that whereas significant social, technological, economic and political movements have been previously experienced across the globe, the current era of global changes is differentiated by the rapidity and simultaneity of 
these activities. Globalization is not merely synonymous with immigration or international trade. It is a variety of transformative activities happening concurrently and at heightened levels all over the world in many different spheres of life. Whereas qualitatively, global activity of transnational migration, trade and cultural exchanges are not new, the quantitative intensification of globalizing processes since the late 20 $0^{\text {th }}$ Century is unparalleled.

Instead of trying to arrive at a purely descriptive and normative definition of globalization, it may be advantageous to reach an understanding of the phenomenon by looking at its components, all the time recognizing that they coexist in a multi-dimensional matrix and act as one entity. Contrasting with a diagnosed illness, Mittleman (2004) likens globalization unto a syndrome of processes and activities - "a pattern of related characteristics" (p. 5). In terms of the impact of globalization on the management of cities, this author will consider the dimensions of globalization in the following four categories: Social/Cultural, Economic, Institutional/Political, and Technological. The following section addresses each of these dimensions separately. 


\section{Dimensions}

\section{Social/Cultural}

The ease, or lack thereof, with which people physically move across borders in unprecedented volumes and frequencies, is considered to be one of the main reasons that globalization has received so much attention. The United Nations Human Settlements Programme (UN-HABITAT) reported in 2004 that there are approximately 175 million documented international migrants worldwide (The State of the World's Cities 2004/2005). In the United States alone, it has been recorded that 11 percent of the population are foreign-born (U.S. Census Bureau, 2000). Such intense international migration has given rise to the strengthening and expansion of cultural flows across the globe and, immigrants in their chosen places of residence play a significant role in influencing and defining social life. Therefore, to speak of the socio-cultural dimension of globalization, is to consider the construction, expression, and diffusion of such symbolic ideas, practices, and values embodied in music, language, food, dress, and ethnic identity.

Population movements and the development of contacts and flows between different societies and cultures contribute the "human mobility factor" to the equation of globalization and very little of the world remains unaffected by the explosion of the network of socio-cultural interconnections and interdependencies. Owing to the increased use and availability of the Internet and other technologies, images and ideas are more easily and 
rapidly transmitted from one place to another, thereby profoundly impacting the way people across the globe experience their everyday lives (Steger 2003).

One of the main arguments surrounding the socio-cultural dimension of globalization derives from the implication that as the divide between time and space is diminished, Western culture is increasingly dominating the world and the norms and lifestyles of people are becoming more alike than different (Barber, 1996). However, this is not to say that the formation of a uniform global cultural identity is impending. Some argue, on the other hand, that globalization fosters new forms of cultural expression (Robertson, 1992). The rise of nationalism and ethnicity as categories of identification and retreat indicates that as the world seems to be coming together, to some extent it is simultaneously falling apart. Global cultural movements and exchanges often result in the loss of traditional meanings and the creation of new spaces for symbolic expressions, as people inter-relate and co-exist across geographical and cultural borders.

\section{Economic}

The economic facet of globalization is the one most commonly referred to, and globalization is very often used to refer primarily to global capitalism or the application of neo-liberalism and free-market liberalization. Still others associate the economic dimension of globalization with the controversial issue of free trade and the rise of powerful transnational 
corporations. Steger (2003) defines economic globalization as "the intensification and stretching of economic interrelations across the globe" (p. 37). The rapid increase in the amount and rates of moving currency, goods, and services are evidences of the decreasing relevance and necessity of physical spaces for conducting commerce.

As an indicator of increased international trade, the World Trade Organization (WTO) reported that "the year 2006 witnessed robust growth in the world economy and vigorous trade expansion. Global gross domestic production (GDP) growth accelerated to $3.7 \%$, the second best performance since 2000. All major regions recorded GDP growth in excess of population growth" (World Trade Organization, 2006). Transnational investment as reflected in the rapidly growing stock markets in emerging economies and increased investor confidence in emerging markets also increased (World Trade Organization, 2006). The more favorable investment climate was evident in the sharp rise in world foreign direct investment (FDI) flows in 2006. The United Nations Conference on Trade and Development (UNCTAD) reports that World FDI inflows in 2006 were estimated at $\$ 1.23$ trillion, the second highest level ever. In 2000, World FDI flows were reported at $\$ 1.41$ trillion. ${ }^{2}$

In March 2009, financial markets throughout the world experienced a complex and massive catastrophe. The World Bank records that "virtually no

2 UNCTAD Investment Brief, No.1, 2007 
country, developing or high income, has escaped the impact of the widening crisis" in which "credit markets froze; stock markets crashed; and a sequence of insolvencies threatened the international financial system." ${ }^{3}$ These unprecedented events give testimony to the significant linkages within the global economy that has developed over the last three decades. As a result, unemployment rates have skyrocketed in many large economies and much pressure has come to bear on individual and corporate spending. The housing industry in the U.S. which is strongly linked to the banking and financial sectors (by way of mortgages and home equity loans) has come under extreme strain as evidenced by mounting foreclosures - another indicator of a weakened economy. Many foreign financial firms invested in mortgage-backed securities, further reinforcing the global nature of this crisis.

A third component of the economic dimension of globalization is the role that transnational corporations (TNCs) play in the global economy. TNCs, which are companies that conduct production and service-delivery businesses in at least two countries, control much of the world's investment capital, technology, and access to international markets. Examples of TNCs are Wal-Mart, SONY, Toyota, McDonald's, to name a few. In 2005, UNCTAD

\footnotetext{
${ }^{3}$ World Bank, Global Economic Prospects 2009: Outlook summary, December 2008 , http://siteresources.worldbank.org/INTGEP2009/Resources/10363_WebPDF01Chapter1-w47.pdf
} 
reported that there were 68,549 TNCs worldwide; in 2006 that number rose to $75,728.4^{4}$ The increasing number of TNCs with foreign affiliates and subsidiaries in several countries indicates how powerful this sector is in affecting the contemporary global economy. Very large multinationals have budgets that exceed those of many countries. In 2001, Noreen Hertz wrote, "three hundred multinational corporations now account for 25 per cent of the world's assets. The annual values of sales of each of the six largest transnational corporations, varying between $\$ 111$ and $\$ 126$ billion, are now exceeded by the GDPs of only twenty-one nation states" (Hertz, 2001, p. 43).

In addition, it is not only the magnitude of the business of TNCs that is overwhelming but also the implications associated with the strategic geographical positions of their respective parent corporations and subsidiaries. According to UNCTAD, in 2004 the top 100 TNCs, ranked by foreign assets, are headquartered in Europe, Asia, or the United States (World Investment Report 2006). The geographical location of TNCs is of particular importance for two main reasons: "the spread of operations into many countries affects the strategic stance of the company [and] it also affects its ability to develop and spread knowledge and innovation" (World Investment Report 2006, p. 34). Clearly, a place's ability to attract a TNC will strengthen its economy directly and likely improve its position in the global economy.

${ }^{4}$ World Investment Reports 2005 \& 2006, UNCTAD. 
It has become quite evident that the constitution and operation of the international economy has been greatly impacted by the ever-increasing clout of TNCs. These gigantic firms and their global strategies have become significant decision-makers in the execution of trade flows, the location of industries, and other economic activities world-wide. As a consequence, TNCs have become extremely important actors that influence the economic, political, and social welfare of many nations.

\section{Political/Institutional}

International political relations have undergone far-reaching changes in recent decades. The end of the Cold War produced a dramatic change in the climate prevailing among sovereign states and a global political reconfiguration has been taking place giving rise to increasing interconnectedness and interdependence in the international political system (Croucher 2004, p. 141). The heightened political and economic predominance of the United States, European efforts to form a bloc capable of playing a leading role in global economic and political life, the Asian financial meltdown in 1997, and the sudden transition experienced in the former socialist countries may be considered some of the most outstanding features of this period. These political changes have also placed representative democracy and market-based economies in a position of unparalleled 
predominance across the globe making it the preferred and 'recognized' form of governance in world politics.

Globalization is also reflected in the increasing role of international organizations in constraining domestic policies. Despite the gains reflected by per capita income growth, many developing nations continue to be in debt and poverty partly owing to the policies of international financial institutions such as the International Monetary Fund (IMF) and the World Bank, other by-products of contemporary economic globalization (Milanovic, 2003). The establishment of these international economic organizations in the 1970s, along with the World Trade Organization, set in motion the machinery for enforcing the dictates of modern international economic policies. The programs of the international financial institutions have been heavily criticized for years for causing poverty despite their claims that their policies are aimed at reducing social and economic inequalities (Stiglitz, 2002; Milanovic, 2003).

Croucher (2004) attributes the formation of organizations such as the United Nations and World Trade Organization, which she calls "suprastate forms of global governance," to the political restructuring occurring in this era of globalization. These organizations have been formed with the view of enhancing contact and cooperation among sovereign states and purport to ensure that states comply with international rules related to democratization and human rights protection. 
The relationship between the economic and political dimensions of globalization is an intricately entwined one. An adoption of the democratic model of governance generally indicates an embrace of capitalism and often the distinction between the cause and the effect of this relationship is not clear. Nevertheless, globalization is credited as a contributing factor to this reality. As Steger (2003) states, "economic forms of interdependence are set into motion by political decisions, but these decisions are nonetheless made in particular economic contexts" (p. 62). These changes in political arrangements have implied a shift from the power of the nation-state to make sovereign decisions to the capital-rich TNCs and the international financial organizations. The culture of competition fostered by such economic developments as trade liberalization has seen the decline of the nation-state as a sovereign entity in major economic development decisions and an increase in the creation of policy initiatives and diplomatic arrangements among and across municipalities. Consequently, many local governments are forging ahead with making their own foreign policies and becoming active participants in the competitive global market.

\section{Technological}

Globalization is also enabling and being enabled by the rapid movement of technology, especially information technology, resulting in a virtual obsolescence of the significance and distinction between time and 
distance. According to Beynon and Dunkerley (2000), "globalisation operates on the basis of messages, images and symbols that have been freed of spatial constraints" (p. 5). Electronic marvels of the past (such as the television, radio, and the telephone) are constantly being outdone by cell phones, laptop computers, and numerous software applications with unprecedented capacities that enable everyday activities to take place at unusual rates.

Every day thousands of business transactions are conducted on-line, and the preponderance of Internet social networking media, instant messenger services and other means of communication show how community is being re-created and redefined, and how people are being brought closer together despite being separated by geography. The World Bank reports that "technology and knowledge are diffusing at unprecedented speeds across countries [and that] international phone traffic, measured in minutes, increased more than fourfold between 1995 and 2005.”5

The rate at which technology is advancing is central to the entire process of globalization and the effect of the technological changes is evident in, and enabling to, all of the globalization dimensions. Owing to the Internet and the microchip, money, goods, and services are able to move faster around the world thereby spawning worldwide economic growth, ever-emerging transnational communities, and newfangled political ideologies and systems.

${ }^{5}$ World Development Indicators 2007, World Bank. 


\section{Interactions between the global and the local}

The discussion on globalization, heretofore, seems to place it in a somewhat theoretical realm - as a process that is undoubtedly taking place but may not be particularly relevant to the 'man on the street'. However, as Friedman (2006) purports, the "flattening" effects of globalization's social, political, technological and economic processes are affecting society on an increasingly smaller scale. Friedman (2006) distinguishes three phases of contemporary globalization in explaining these flattening effects. In the first two phases, countries globalize then companies, and in the third phase individuals globalize. In other words, the unit of competition and collaboration in the world today is not a nation-state or a corporation; rather, it is a person and a person of any given race or nationality (Friedman 2006, pp. 10-11).

The present research contends that somewhere between the country and the individual in Friedman's phases of globalization is a level worthy of consideration, that of the city; a geographical space occupied by organizations and individuals that influence and shape its social, cultural, political, and economic landscape; a space that is contained by a physical boundary and governed by a select group of officials. The study intends to show how Florida's public managers, as practitioners, construct and understand globalization in their realities of the small-medium city context. 
Spatially, globalization emphasizes the importance of place and the role of cities in understanding how globalization affects and is affected by urban life. Sassen (1996) highlights the importance of locating the processes of globalization in place from three perspectives. From her vantage, place is central to the analysis of globalization as it facilitates one's ability to:

1. see the multiplicity of economies and work cultures in which the global information economy is embedded.

2. recover the concrete, localized processes through which globalization exists and to argue that much of the multiculturalism in large cities is as much part of globalization as international finance.

3. argue that the multiculturalism evident in large cities is as much a part of globalization as is international finance.

Here, Sassen (1996) identifies the multidimensionality of globalization and recognizes the significance of the role that place plays in the analysis of global processes.

Cities tend to be defined, in part, by mobility. In the realm of urban sociology, some argue that the city as "the local" is being threatened by "the global." This dichotomy portrays the city as a static entity that is incapable of responding to external inflictions. My study will show that the city, by virtue of its fluid and resilient nature, is as dynamic as the global forces that act upon it. Hardt and Negri (2000) contend that, as the significance of place 
is contemplated in the globalization discourse, the distinction between the local and the global may not be as discrete and simplistic as commonly perceived. They argue that too often the local is romanticized and presented as pure and original and that the global is presented as threatening, homogenizing and ought to be resisted. Hardt and Negri (2000) reframe the local-global binary as deterritorialization and reterritorialization and proffer that in contemporary reality, the global cannot be easily separated from the local since

in many cases what appears as local identities are not autonomous or self-determining but actually feed into and support the development of the capitalist imperial machine. The globalization or deterritorialization operated by the imperial machine is not in fact opposed to localization or reterritorialization, but rather sets in play mobile and modulating circuits of differentiation and identification (p. 45).

This is what Czarniawska (2002) recognizes as glocalization, an interplay of the global and the local wherein "globalization and localization happens simultaneously and intertwine, becoming the cause and result of one another" (pp. 12-14). As the political, social, economic and cultural interrelationships within a city change, so do the demands and preferences of the people who live and work there. This study asserts, therefore, that the local-global dichotomy is an important acknowledgement in the study of the impacts of globalization on the management of the city. 


\section{Concluding remarks}

To promote an understanding of the effects of globalization on the everyday life of a city and its citizens is of utmost significance to the field of public management. Globalization theorists maintain that the idealized global 'flows' of human and financial capital, technology and information must ultimately come down to the ground where daily lives of ordinary people are impacted in several ways. Ernest Wilson (2006) writing for America Abroad, a division of the public online forum TPM Café states:

Lots of what we call 'international' really gets acted out at the local level, in neighborhoods. At the end of the day, where does 'globalization' really happen? Not someplace called 'the nation'; who lives there? Most of us live someplace in a town or a city - in Mobile or Milwaukee, in Oakland or Chicago. That's where new immigrants come to live and work and settle and become our new neighbors; it's where we lose our jobs to globalization; where we go to the latest Hong Kong action flick; and where people will suffer if there is a terrorist attack.

The impact of globalizing changes that are being experienced at the level of the city is an important issue that ought to be elucidated. Sassen (1996) agrees by positing that "a focus on cities and communities allows for a more concrete analysis of globalization, and in that regard we can think of cities and communities as strategic sites for an examination of global processes and major politicoeconomic processes" (para. 2).

Globalization is a multidimensional phenomenon that gives a contemporary framework for understanding how we live in the world. Cities, 
as conveyors and crucibles of human, social, technological, economic and political interactions, are useful tools for testing the impacts of globalization. The ensuing chapters of this dissertation demonstrate how the impacts of globalization are being perceived through the prism of public management in Florida's small-medium cities. 


\section{CHAPTER III. LITERATURE REVIEW}

This chapter examines the research problem through the lens of urban sociology and public administration scholarship. Given that the research problem locates it in the urban setting, the literature review begins by appraising the identity of "the city". Additionally, since the study is concerned with the city as a distinct self-governing organization, the review distinguishes the traditional view of "the city" as urban space from the typology of "the city" as municipal organization. This chapter also relays the impact of globalization in the contexts of the global city and the metropolitan area. The chapter ends with a discussion of the practice of public management and its intersection with globalization with a particular focus on the management functions of decision-making, economic development and service delivery.

\section{The city as contested space}

Cities are spaces where people and commerce converge. When one speaks of the city, it usually conjures up images of bright lights, congested traffic, high-rise buildings, the hustle and bustle of commercial activity, and large numbers of people walking hurriedly along sidewalks. Urban sociologist, Manuel Castells theorizes the city as network nodes in a "space of flows [that] work across distance through communication flows, processed and transmitted by telecommunications, electronic networks of information 
systems, and transportation networks" (Susser 2002, p. 381). Bridge and Watson (2002) note that the West has traditionally characterized the city as "both dystopia and hell - Sodom, the city of corruption - and utopia or heaven - Athens, the city of enlightenment, democracy, and reason.” The city as a construct has been studied widely by sociologists, historians, political scientists, economists, and geographers alike; and all concede that, fundamentally, the city is a site of complex exchanges.

Cities locate the economic, social and cultural action that resides in time and space, and has evolved through various stages over time (Harvey, 1990; Castells, 1999). Cities worldwide are shaped by a diverse set of processes that give them their unique character and culture. The city of Venice in Italy is known as the "Queen of the Adriatic" or "the City of Bridges," Chicago is called "Windy City," Philadelphia is nicknamed "the City of Brotherly Love" and Los Angeles is colloquially referred to as "the City of Angels." Hall (2006) suggests that the diversity of cities be appreciated by acknowledging that there are different types of cities rather than concluding that their evolution is simple and linear.

Savage, Warde and Ward (2003) proffer that there are four types of cities. They are "developing cities, global cities, older industrial cities, and informational cities" (p. 42). While this classification is by no means comprehensive, it recognizes that urbanization occurs differently in different places all over the world (Savage, Warde and Ward 2003, 42-44). Similarly, 
Tasan-Kok and van Weesep (2006) recognize that, in spite of its ability to "facilitate the hyper-mobility of capital and its accoutrements such as images and values", globalization and its forces do not have an homogenizing effect on cities around the world. They inform that "although the forces moving around the world are the same, they work out differently in individual cities" (p. 4). This perspective aligns with a central basis for my study: that as people, ideas, technology and capital interact across international borders, varying realities are created which may be unique or syncretic, making a constructionist approach to understanding public management justifiable and relevant.

In addition, the city is represented as a public entity - a governmental institution. Frederickson et al (2004) proffer that "cities are collective institutions... organizations and governmental jurisdictions" that have been constructed by people in much the same way that roads and houses are built. In the realm of public administration and throughout this study, a city is understood to be an urban area confined within specific geographical boundaries and governed with a measure of autonomy by a body of elected officials. As a municipal organization, the city is an incorporated entity with vested powers granted by the State in which it is located. In this study, the term "the city" may be interpreted in some instances as an organizational unit of professionals and, in others, as a physical place. My study focuses on cities that exist as parts of a larger metropolitan region but rarely are noted 
as key contributors to studies in public administration and urban affairs on account of their size.

\section{The "global city"}

Within a country, cities are focal points of business, education, politics, and social activities. Major cities are typically homes to the capitals of countries and the main points from which countries connect to the rest of the world. The significance of a country's relationship to the rest of the world, via the city, has been redefined during the latter half of the twentieth century. During this period, the highly industrialized and manufacturing characteristics of cities have diminished. New technological inventions in industry replaced the dependency on manual labor, and major cities subsequently lost jobs and citizens.

Abrahamson (2004) opines that in reacting to this shift, cities have issued a "globalization response" (p. 4). By this he means that in response to globalizing movements, cities have aimed to "recruit transnational corporations and the specialized firms that follow these corporations, and provide cultural attractions for international tourists", as opposed to the country as a whole (Abrahamson, 2004:4). City administrations evidently corralled the viability of their municipalities by becoming a part of the global supply chain. The evidence shows that some cities have been able to make the transition into the global network more successfully than others. Those 
cities that have adapted thoroughly to the "postindustrial" mode and have become leading actors in the global economy and are considered to be global cities.

Sassen (1998) defines the "global city" as a place where "servicing and financing international trade, investment, and headquarter operations [of multinational corporations]" are located. She claims that global cities are "strategic production sites for today's leading economic sectors." The inherent peculiarity of the identification of a "global city," however, suggests that there are some cities that are 'non-global'. The present research advances that the manifold nature of globalization has forced cities of all types to participate in the global economy on some level. Sassen (2006) agrees. A later clarification advises that the label "global city" should not be strictly taken as a description for a certain type of city. Instead, the characterization should be understood as:

an analytic construct that allows one to detect the global as filtered through the specifics of a place, its institutional orders, and its sociospatial fragmentations. The extent, composition, and institutional or social locations of the global will vary across cities, including in leading global cities (para. 4).

Sassen's identification resonates with the general thesis of this study; that globalization is occurring in various places at different rates all across the world and that virtually no city is outside its reach. Castells (1999) suggests another understanding. He states that "the global city is not a city, 
it is a new spatial form, the space of flows, characterizing the Information Age" (Susser 2002, p. 372). In other words, the global city is not fixed but fluid and its identity shows up in a variety of places where social, economic and technological dealings occur. The global city, in a sense, can change its location depending on the level of global activity that it incorporates from time to time. Abrahamson (2004) corroborates this notion by submitting that the global city can be identified along a continuum. Therefore, how global a city is, is a measure of how connected it is to the global network economically, socially, and politically at any given point in time. It is also a measure of how pervasive the global economic, social, and political activities are in the city. The identity of the global city is not relegated to specific metropolises. I concur with Abrahamson (2004) and submit that, on the basis of his acknowledgement, a large number of cities in the U.S. can be considered global cities; whereby, the 'global-ness' of a city is created by its citizens and institutions that participate in its activities.

This opinion dovetails with Marcuse and van Kempen (2000) who posit that cities are "globalizing" in the sense that they are in the process of becoming global. However, Marcuse and van Kempen (2000) also explain that the globalizing process is one "that affects all cities in the world, if to varying degrees and varying ways, not only those at the top of the 'global hierarchy'” (p. xvii). This study challenges the all-inclusive posture of Marcuse and van Kempen and examines the experiences of public managers 
in small-medium cities since, according to the authors, no city is immune to globalization's impact.

\section{The Metropolitan Statistical Area}

The Brookings Institution (2007) advances that the U.S. has evolved into a "Metro Nation" that is strongly dependent on the economic prowess of its metropolitan areas. For this study, the metropolitan area provides the proxy for 'urban' and is the locus of the cities included in the research. The United States Census Bureau divides the entire nation into metropolitan and non-metropolitan areas. Metropolitan areas contain urbanized centers of large populations and diverse activities. A metropolitan statistical area (MSA) is an analytic construct designed by the United States Census to depict a set of geographic areas that share social and economic linkages between urban cores and outlying, integrated areas.

According to the United States Census Bureau, a MSA is defined as an area having "at least one urbanized area of 50,000 population, plus adjacent territory that has a high degree of social and economic integration with the core as measured by commuting ties." ${ }^{6}$ The MSA identifies an aggregation of urban districts that includes areas peripheral to a principal city. The peripheral areas themselves may not necessarily be urban in character but

${ }^{6}$ Office of Management and Budget Bulletin No. 08-01, November 20, 2007, p. 2, http://www.whitehouse.gov/omb/bulletins/fy2008/b08-01.pdf Retrieved December 7, 2007 
are closely bound to the major urban center by flows linked to employment or commerce. There are four analytic dimensions by which the MSA can be understood. These are spatial, social, economic, and institutional (UN State of the World Cities, 2004).

Over the years, metropolitan areas have expanded beyond their municipal borders into surrounding jurisdictions. The outward movements of people and jobs from the centers of MSAs, and the development of multiple centers about a central city contribute to making MSAs more and more regional in scope. Whereas these urban areas once consisted of a dominant central city surrounded by an assemblage of suburbs, MSAs now consist of multiple centers of economic and social activity (Anas, Arnott, and Small, 1998). Suburban "bedroom communities" have been, and are being, transformed into "edge cities," many of which are becoming significant economic entities in their own right (Garreau, 1991).

The International City/County Management Association (ICMA) identifies the 'headquarters city' that is also gaining in importance on the urban scene. By definition, these are cities "where most of the leading global markets for commodities and investment capital, equities, and bonds can be found [and] they are the locations of the national and international headquarters of trade and professional associations" (Aronson \& Schwartz, 2004). The spread of development associated with the MSA bears great significance. References to central cities often mean entire regions that 
include a wide variety of municipalities of varying sizes and complexities. For example, a reference to Miami could mean the city proper or any or all of its neighboring towns, villages or cities. Rusk (2003) notes that, "the real city is the total metropolitan area - city and suburb" (p. 5).

The MSA is also an area of intense economic activity. Typically, the central city in the metropolitan area is home to large firms and industry. However, as MSAs have expanded over time, the economic strength of peripheral communities has also increased. Businesses that cluster on the peripheries of metropolitan areas create the need for a variety of auxiliary services and several employment opportunities gradually emerge in the neighboring places. These changes are evident in the shifting spatial patterns of job and residential locations.

Conversely, urbanization is accompanied by a commingling of unstable levels of income, employment and poverty. As people and jobs spread out across the metropolitan area, income disparities increase within and among neighborhoods and industries. The consequential varying demographics of the metropolitan area have economic ramifications for all municipalities within its reach. With this variety of purposes, metropolitan areas are significant to global processes. Castells (1999) notes that "as core social and economic activities are based in major metropolitan areas there is a concomitant process of global interaction between metropolitan nodes" (Susser 2002, p. 372). Metropolitan areas, as nodes in the global network, 
represent a conglomerate of municipalities which individually contribute in some way to the social and economic valuation of the entire region in which they are located.

As metropolitan areas expand, public needs also expand and demands on local governments intensify. Urban sprawl has increased the need for schools, transportation, roads, water, and the delivery of multiple services to the residents living in the hinterland of the metropolitan center. The resulting growth has resulted in an increasing number of intergovernmental arrangements and "quasi-governmental" organizations with responsibilities for various functions of metropolitan governance. Many jurisdictions have found it necessary to turn to alternative methods of urban service delivery such as contracting-out and public-private partnerships. Furthermore, new municipalities have been incorporated with respective local governments having the responsibility for meeting various community needs. While these activities may not be directly attributable to globalization, their occurrence in a globalizing environment augments the responsibilities of public managers responsible for administering city services.

\section{Globalization and the city}

To the extent that place is understood as an articulation of spatial relations, the processes of globalization undoubtedly shape the character of cities and in-form their identities (Massey, 1994). Some view the city as the 
site of a global-local conflict where community struggles to overcome the alienating and divisive forces of capital (Castells, 1989; Harvey, 1989). For others, the city is an important node in the dynamic global network of human, commercial, financial and technological flows, generating "a geography of power" (Friedman, 2000; Sassen, 2001). Regardless of the theories that are defended concerning the relationship between cities and globalization, scholars agree that an understanding of the social, economic, and political dynamics that are acted out in cities is instructive for the wider body of knowledge that addresses the intersection of global and urban issues. According to the United Nations report of the State of the World's cities,

the interaction between globalization and cities is not unidirectional; it is not just that cities are affected by global forces, but that local economies, cultures and polities also affect global patterns. Global factors become embedded in local culture, practice and institutions (UN-HABITAT, 2004).

\section{Dimensions of globalization in cities}

Globalization, as explained earlier, is a multidimensional phenomenon that has varying impacts on the physical, economic, political and demographic structure of municipalities in metropolitan areas. In drawing on other literature, Marcuse and van Kempen (2000) note that in addition to accounts of the significant changes that have occurred in cities, accounts of the causes of the changes and other changes that are taking place alongside them have also increased: 
Descriptive accounts of these changes have multiplied. So have accounts of changes in the national and international context that parallel and perhaps cause them: a process of globalization, changing forms of production, a declining state provision of welfare, differences in power relationships, developing technologies, all have their influence on urban patters, within cities as well as among them (p. 2).

This study addresses the socio-cultural, economic and political dimensions of globalization in cities.

\section{Socio-cultural}

As people move in and out of cities, they transport their cultural norms and values. People of various backgrounds converge upon the metropolis and their social interactions transform its space into a place where culture is constructed and negotiated. These effects constantly reinvent the city space and give it its particular social, political, and economic identity. The city as a vibrant, social space demystifies the notion that, singularly, the city is the battleground of the global and the local - a rigid, fixed location of commercial and capitalistic deliberations. On the contrary, and of equal importance, is the recognition that the city is a space of social flows - a space "through which social actors move and within which they operate to give meaning to 'place"' (Smith, 2002).

Globalization has had the effect of both diversifying and enriching cultures. As cultures engage each other, they enrich the cosmopolitan culture 
of the city and increase the social awareness of urban residents. In the city, the interplay of these cultures is manifested in the built environment of parks, art museums, restaurants, and shops; and also in the innovations of fine art, music, and fashion. The tendency for immigrants to congregate, socialize, worship, and live with others from their countries of origin also produces the formation of "ethnic spaces" in many metropolitan areas. New York has its Chinatown, Miami its Little Havana, and Chicago, Little Sicily. Immigrant groups indisputably contribute to creating a more diverse urban culture with their infusions of new music and food into the metropolitan milieu.

Advances in technology have enabled worldwide information to be accessed at the click of a button, and through television, film, and print media, city dwellers see images of "others" and compare them with their own. Nonetheless, the continuous flows of immigrants, products and images across urban spaces have the combined effect of standardizing space and engendering fear and polarization (Barber 1996, Ritzer 1993, Appadurai 1996, Robertson 1992). The arguments here are that, as information and values move across geographical borders, people in cities engage in common activities and urban culture worldwide tends to become homogenized. As a result, urban residents' needs become more and more alike. Meanwhile, as attitudes and actions become similar, strands of fear and polarization among some city residents also develop (Rusk 2003; Levy 2009). The scarcity of 
activity in some public places (parks and downtown areas, for example) and the preponderance of gated communities in suburbs bring out this fact. As "strangers" move into cities, city dwellers tend to move out. These movements are particularly apparent when the strangers are of a different race than the dwellers.

Rusk (2003) notes that racial prejudice has shaped growth patterns in urban America. The quality of neighborhoods and schools when described as "good" often implied the absence of Blacks and Hispanics, and suburbanites, in leaving the city and its problems behind, have incorporated their new communities and resisted city annexations (Rusk 2003, p. 24). As metropolitan areas become more and more urbanized, people are moving even farther away - into other states - especially when the possibility of owning a house is more realizable and affordable in surrounding areas.

As noted elsewhere in this research, globalizing effects such as the exodus of industry has been blamed for much of the increased poverty levels and inequalities present in urban areas. As unemployment rates increase as a result of the movement of jobs across borders, cities all over the world experience weakening economies and the urban poor are further marginalized by heightened global competition. Sassen (1994), for one, argues that many major cities have experienced an increase in inequality owing to the growth in service industries and occupational dispersion which has considerably widened the gap between the rich and the poor over recent 
decades. Watson (2005) illustrates that in American metropolitan areas, neighborhood segregation by income grew between the 1970 and 2000 - a period when rapid changes from industrialization to service - and information technology-oriented businesses were on the rise.

Over the past two decades, the 'Sunshine State' of Florida has experienced rapid population growth, largely as a result of international and domestic migration (Eisenhauer et al, 2008)7, job creation and housing (University of Florida, 2009) ${ }^{8}$. However, Eisenhauer et al (2008) opine that while the influx of Hispanics into the state "has been instrumental to Florida's integration into the international economy since the ability to speak English and Spanish is an essential skill for companies wishing to do business with Latin America", it may have contributed to economic inequality in the State (p.21). Eisenhauer et al (2008) support their view by pointing out that the increased presence of low-wage earning immigrants facilitates a "shift in the occupational structure toward low-wage service jobs" thereby widening the income gap in the State (p. 21). Nissen and Zhang (2006) report that between 1990 and 2005, the industries that experienced the most growth in job creation were the lower-paying professional and business services, education and health services, construction and "other services".

7 The growing divide: Income inequality and its effects on Florida's families, http://www.risep-fiu.org/reports/Growing_Divide_2008.pdf Retrieved 5/10/09

8 http://news.ufl.edu/2009/03/23/slow-florida-growth/ University of Florida News: Slow Florida Growth, Retrieved June 23, 2009 
On the other hand, the worst performers for job creation during the 1990-2005 period in Florida were the higher-paying manufacturing and mining industries ${ }^{9}$. The 1990-2005 period coincides with the era of globalization that frames this study. Florida has undoubtedly fallen victim to the income inequality caused by the disproportionate replacement of highpaying manufacturing jobs with lower-paying service jobs that is a characteristic repercussion of globalization during this time. The University of Florida reports that population growth is declining in some Florida counties as residents move to other states in search of more affordable costs of living. ${ }^{10}$

\section{Economic}

Cities may be considered to be the chief locomotives of economic and social change. The economic impact of cities should not be undervalued as it is overwhelmingly significant for their parent countries on a global level. The U.S. Bureau of Economic Analysis reports that, in 2005, metropolitan areas produced 90 percent of the U.S. current-dollar Gross Domestic Product (GDP); the five largest metropolitan areas accounted for 23 percent of the U.S. total GDP. The current-dollar GDP for the nation in 2005 was $\$ 12.4$

${ }^{9}$ State of Working Florida 2006, http://www.risep-fiu.org/wpcontent/uploads/2009/03/state_of_working_florida_2006.pdf, Retrieved $5 / 10 / 09$

10 http://news.ufl.edu/2009/03/23/slow-florida-growth/ University of Florida News: Slow Florida Growth, Retrieved June 23, 2009 
trillion (U.S. Department of Commerce). ${ }^{11}$ Abrahamson (2004) draws attention to the fact that, in contemporary times, "the key nodes in the international system are (global) cities, not nations." Strategies for protecting and sustaining national economies can be learned from understanding the multiple interactions between globalization and urban economies.

Many immigrants relocate from their countries of origin with education, skills and professional experience; but often are only employable in existing vacant positions. Consequently, foreign-born populations make up a considerable proportion of the employment base for middle- and lowwage jobs in metropolitan areas. Immigrants play a significant role in the urban economy as employers hire them to work in positions like customerservice that require bilingual skills. The Foreign Policy Institute reported that, in 2007 , immigrants contributed $\$ 229$ billion to the New York economy, equating to 22.4 percent of the total New York State GDP. ${ }^{12}$ In Florida, "immigrants contributed an average of $\$ 6.5$ billion in federal income taxes annually from 2002 to 2004 , and $\$ 3.98$ billion in FICA taxes, for a total of \$10.49 billion” (Eisenhauer et al. 2007, p. 32).

11 U.S. Department of Commerce Bureau of Economic Analysis News Release, http://www.bea.gov/newsreleases/regional/gdp_metro/2007/pdf/gdp_metro090 7.pdf Retrieved June 19, 2009

12

http://www.fiscalpolicy.org/publications2007/FPI_ImmReport_WorkingforaBe tterLife.pdf, Retrieved December 3, 2007 
Immigrants are also entrepreneurs, opening new businesses and generating new knowledge that gets integrated in the U.S. economy. The Ewing Marion Kauffman Foundation reports that the entrepreneurship rate among immigrants in the U.S. rose dramatically from 0.46 percent (460 out of 100,000 adults) in 2007 to 0.53 percent in $2008 .{ }^{13}$ The organization CEOs for Cities (2008) informs that the evidence of the past few decades indicates that the nation's openness to immigration has been an important contributor to innovation and entrepreneurship: "cities that can navigate the difficult politics of immigration may be well positioned to grow in the decades ahead" (p. 40).

The rapid exchange of information and currency associated with globalization has also changed the nature of economic activity in cities. Opportunities for investment in the financial and information services sector have grown as these industries have become more profitable and dependency on industrialized production has declined (Levy, 2000, pp. 31, 50-51; Milakovich, 2001, p. 482). The heightened liberalization of trade across the globe, enabled by improved transportation networks and advanced technology in industry has increased the significance of competitive materials and labor costs among manufacturers. In turn, companies have moved to

\footnotetext{
${ }^{13}$ Kauffman Index of Entrepreneurial Activity: http://sites.kauffman.org/kauffmanindex/ Retrieved May 9, 2009
} 
locations in search of lower wage and materials costs that ensure higher profits. $^{14}$

Cities evidently have become the victims of this "race to the bottom" as they are forced to compete in attracting industry and investment.

Competitiveness among cities is a by-product of the increasingly complex global economy and cities are compelled to become positioned in global networks in order to improve their competitive advantage (Tasan-Kok and van Weesep, 2007). Concurrently, large segments of the urban workforce shift from one sector to another to meet the demands of the employment market in a competitive environment (Rusk, 2003, p. 42).

\section{Political/Institutional}

The effective power and control of public institutions in cities have become weakened by the vigorous arrival of powerful, decisive, and informed external private sector companies. Companies arriving in cities to explore the possibility of investing in a factory or shopping center often do not feel constrained by local building codes, zoning or environmental regulations. The lure of tax holidays and other regulation waivers by competing and desperate local authorities leave public authorities feeling compromised to attract private investment to create jobs and generate incomes in their cities.

\footnotetext{
${ }^{14}$ UN-Habitat Information Services Section, City Mayors Society, http://www.citymayors.com/society/urban_growth.html, Retrieved July 1, 2007
} 
The availability of such incentives, therefore, may produce an asymmetry in power and negotiations among private and public authorities.

As urban areas grow and local governments are required to provide public goods and services at the highest levels of efficiency, the decision to privatize services has become more attractive (ICMA, 2004, p.81). Investment decisions in cities, employment opportunities and even the management of some public services seem to have been transferred away from local governmental jurisdictions. Consequently, the privatization of public services contributes to shrinking the effective power of government when specific services and functions are "outsourced" and local preferences are not satisfied.

Privatization is only one of several administrative considerations that that impact the political currency in jurisdictions. Other arrangements such as franchises, subsidies and vouchers also affect political legitimacy as local governments are often left with no choice but to negotiate with companies whose primary responsibility is to provide stockholders with the highest gains on their investments. Sassen (1991) cautions that the economic effect of globalization on cities poses a political question: "what happens to accountability when the leading economic sectors are oriented to a world market and to firms rather than to individuals?" (p. 334). In the delivery of public services, private investors tend to favor those services that are more profitable, leaving governments with already poorly performing services. 


\section{City management structure}

Central to the discussion of urban public management is an understanding of the relationship between function and the organizational structure of city government. The connection between a municipality's governmental structure and functions determines how power is allocated, policy is implemented and the various functions of management are carried out in American cities (Svara, 1990; Frederickson et al., 2004). Over the past five decades, local government structure in the U.S. has responded to changing needs and circumstances of the citizenry they are created to serve. The structural changes of local government are indicative of the needs and expectations presented by a changing society (Frederickson et al, 2004). It is appropriate to review the main organizational structures of city government in order to locate the institutional contexts in which contemporary public management is practiced.

In the United States, local government and by extension, city administration is a part of the federalist machinery of government established by the Constitution. The constitutional separation of powers places public administration in a position subject to the executive, legislative, and judicial branches of government. The intergovernmental relations feature of the U.S. constitution significantly affects the practice of public management. In this system, there are three levels of government - federal, state, and local. The particular form of intergovernmental relations in the 
U.S. allows the administrators of states, counties, cities, and towns to carry out their work in their respective locales in ways that they feel are appropriate and beneficial to their citizens. Such a network of intergovernmental relations promotes diversity of leadership and control.

According to Ott and Russell (2001), a system of intergovernmental relations means that municipalities and government agencies "are not forced into a single national model of public provision" (p. 152). Therefore, although the intergovernmental structure in the U.S. often results in a proliferation of governments and public benefit corporations, such a system fosters creativity within jurisdictional borders, and encourages a constructionist and interpretive approach to its understanding.

The U.S. Constitution does not specifically provide for the sovereignty of local governments. Sovereign power is shared only by the federal government and the states. However, through a process of incorporation, the state may grant a municipality legal status to function as a corporate entity with its own governing body. Through incorporation, municipalities are legally established and a local government is formed and validated at the will of the states. Local governments for a state-chartered municipality are under the full authority of the state. Municipalities can carry out only those activities that are specifically authorized by state law. The organization of cities as incorporated municipalities locates public management in a 
distinctive position from which to operate, what some have termed "the fourth branch of government" (Smith and Licari, 2006).

There are three main structures of local government in the U.S.: the council-manager, mayor-council and commission governments (Ruchelman, 2004). In 2003, the National League of Cities reported that the majority of city governments in the United States follow the 'council-manager' structural model and the second popular type of city government follows the 'mayorcouncil' structural model. In the council-manager form of government, the members of the city council are elected officials who are responsible for general administration, policymaking, developing and maintaining the budget, and having overall supervisory authority in the city government. The council carries out the legislative function and hires a city manager or administrator to direct administration and manage the overall implementation of the policies adopted by the council. The council-manager form of government recognizes the manager as a professional with distinct executive responsibilities and the manager serves the council, supervising department heads and overseeing their activities.

In the 'mayor-council' form of government, the mayor has executive powers while the council has legislative powers. Some mayor-council form governments employ chief administrative officers who serve the same function as a city manager. Some perceive this dichotomy as increasingly false. In the council-manager form of government, the mayor's role is 
primarily a ceremonial one as head of the local government and the position is often granted on a rotating basis among the council. As a preferred organizational structure, the council-manager form of government's rise in popularity among municipalities in contemporary times reinforces the acknowledgement of the relevance and necessity of managerialism for directing public organizations.

\section{City management as public management}

Rosenbloom and Kravchuk (2005) posit that the practice of public administration may be viewed from three perspectives: political, legal, and managerial. My study focuses on the managerial role. Rosenbloom and Kravchuk (2005) submit that public administration should function practically and competently in such a way that public organizations "ought to be run according to the same managerial principles and values" as big business (p. 15). In performing their managerial role, public administrators are therefore expected to negotiate and control the public's affairs in a business-like fashion with fairness and efficiency, and with a focus on results. Further, Shafritz and Russell (2000) interpret the managerial perspective of public administration to be the executive function in government that works to "put into practice legislative acts that represent the will of the people" (p.

18). Shafritz and Russell's position acknowledges the management of public 
affairs as a conversion of the citizenry's desires, often expressed through a political process, into programs and services.

Hughes (2003) elaborates on the significance of understanding the difference between public administration and public management for these contemporary times. Hughes (2003) argues that "administration essentially involves following instructions and service, while management involves: first, the achievement of results, and secondly, personal responsibility by the manager for results being achieved" (p. 6). The distinction between administration and management is central to this study as waves of public sector reform have challenged the traditional process and rules-driven approach to the practice of public administration in contemporary times. Hughes' (2003) clarification demonstrates a public management approach that emphasizes relevance through results and responsibility.

A deliberate shift from strictly administrative functions to managerial ones suggests an emphasis on "improving efficiency, productivity, and performance measurement of organizations" and broadening the scope of public administrators' knowledge development to pay attention to issues such as "values, complex realities, hidden cultural and symbolic aspects of organizational life, social equity, the public good, democratic governance, or other value-laden topics" (Jun 2006, p. 41). As globalization intensifies crosscultural exchanges and idea- and information-sharing, the practice of public management must adapt to becoming more accountable and results-oriented. 


\section{Public management functions}

The current research studies the city as a municipal organization that performs various functions to meet the needs of its citizens. The three functions of primary interest to the study are decision-making, service delivery and economic development. I posit that, ultimately, the worth and work of public management rests on the effectiveness of the decisions that are made in respective contexts. The delivery or provision of services may be considered to be the main purpose for which the public sector exists and economic development may be seen as the livelihood by which the public sector exists.

\section{Decision-making}

Milakovich and Gordon (2001) claim that decision-making is "a process in which choices are made to change (or leave unchanged) an existing condition, and to select a course of action most appropriate to achieving a desired objective, while minimizing risk and uncertainty to the extent deemed possible" (p. 198). Decision-making in public management is timely and deliberate. It involves choosing alternatives and options that, in a given context, meet the public's needs and work for the benefit of the citizenry. The administration and politics of urban affairs are greatly impacted by the import of decisions. At the crux of the public decision-making process is the substance of who gets what, why, when, where, and how, along with the 
technical capacities, values and accountability of the decision-makers. Limited time and a measure of risk also attend the making of managerial decisions.

Ultimately, public administrators are charged with choosing from among rival means and ends by which a program, policy or organization will be pursued and employed. Rosenbloom and Kravchuk (2005) advise that regardless of the approach taken to decision-making, certain pitfalls should be avoided. Among these are 1) misplaced priorities as a result of unclear goals, 2) confusion of the public interest with that of a customer, clientele, group or a constituency, 3) overly rigid adherence to rules, 4) oversimplification of reality, 5) over-quantification at the expense of qualitative factors, and 6) reluctance to engage in policy and program evaluation to obtain feedback.

Urban public managers are responsible to the entire city administration (elected and hired) and ultimately, to the residents of the municipality which they manage. The decisions they make are vital to the overall operation of the municipal government and the municipality. The location of a school, introduction of a new bus route, construction of a park, arrival of new businesses into a community are all outcomes of public management decisions. In addition, the longevity and success of an urban manager's career can be determined on the basis of a single decision. 


\section{Service Delivery}

"Decisions are only a prelude to further action by the city government - the development of programs and the delivery of services" (Morgan, England and Pelissero, 2007:186). City administration is essentially responsible for managing the provision of public goods and services to the citizens over whom they have jurisdiction. Public managers have the complete task of directing, organizing, administering and controlling this responsibility. On one hand, certain public goods and services are intended to benefit all members of society and the management of those provisions is handled at the national level. On the other hand, the provision of public goods and services that benefit citizens collectively - at the level of the communities in which they live - are managed by the respective local governments. Some examples of these services are water treatment, garbage disposal, sewer systems maintenance, and fire and police protection.

Public services such as parks and recreation, solid waste management, road works and public safety have traditionally been the responsibility of local governments. As these governments have been forced to do more with less in the face of various budgetary constraints, the goals of efficiency, effectiveness, equity and responsiveness for service delivery have become more pressing. In an effort to respond to citizens' demands on local government for efficiency, effectiveness and equity, administrations have utilized alternative approaches to service delivery. Some of these include 
contracting out, intergovernmental agreements, franchise and subsidy arrangements and vouchers. For example, in a survey carried out by ICMA in Fall 2002-Spring 2003, 39.4\% of respondents from municipalities and counties indicated that residential solid waste collection was being done by a private for-profit firm.

Peterson (1981) advocates that the social, political, and economic construction of cities that drives multiple interests among government and residents determines the programs and policies implemented. He notes that:

Although social roles performed within cities are numerous and conflicting, all are structured by the fact that they take place in a specific spatial location that falls within the jurisdiction of some local government. All members of the city thus come to share an interest in policies that affect the well-being of that territory (p. 21).

In addition, Ammons asserts that "urban services are policy outputs in the urban political system." Therefore, it is concluded that services are the products of policies which originate with the expressed interests of urban residents, community leaders and government. The following diagram illustrates the connection among these concepts:

\section{Community Interests $\rightarrow$ Policies $\rightarrow$ Services}

The literature shows that there is a consensus among authorities on the goals that guide the provision of public services, regardless of the structural model of local government. These are efficiency, effectiveness, responsiveness, and equity. Efficiency involves maximizing output from a given amount of input 
or resources. It refers to the level of resources required to deliver the desired level of services. Effectiveness concerns the extent to which goals are met. It refers to the extent to which public services achieve the desired results set by administrators. Responsiveness refers to how well government is able to meet the preferences and demands of individuals and groups in the community and whether it does so in a timely manner. Equity refers to the distribution of goods and services to individuals and various subgroups of the community. It demands that people are served with equal and nondiscriminatory treatment and that people are treated similarly except when there is justified reason that they should be treated with differentiation. This study points out that the said goals that dictate the delivery of services also constitute key values that motivate the overall performance of public managers.

\section{Economic Development}

The economic development function of public management helps to determine the fiscal health of a city by stimulating opportunities for revenueearning. Local governments are constantly seeking out innovative ways to increase the size of the local tax base or number and quality of local jobs. Morgan, England and Pelissero (2007) define economic development as "a process for achieving and maintaining the economic health of a community through the retention, expansion, and attraction of commerce and industry" 
(p. 135). Within any given metropolitan area and even among states, intercity competition for jobs and economic activity is central to the efforts of economic development. As cities are being forced to manage their own destinies, they must find ways of becoming attractive to businesses, adapt to changing national and international economic trends while competing with each other for limited resources (Morgan, England and Pelissero, 2007, p. 136).

Blakely and Bradshaw (2002) list three goals of local economic development. They are: (1) Build quality jobs for the current population, (2) achieve local economic stability, and (3) build a diverse economic and employment base. Local governments are advised to consider the existing labor supply in their municipalities and respond to the provision of employment according to the types and levels of skills the populations provide. In doing so, jobs are provided for the existing population and the need to import labor is minimized. Further, city governments must demonstrate that they possess the socioeconomic, technical, and political capacities to obtain and retain jobs. Cities must also be able to provide a diverse cross-section of human resources and capital if they are to be successful in economic development. Firms will relocate to places that have the capacity to support their overall corporate goals; not only to where there are attractive tax incentives or cheap raw materials. 
Essentially, the function of economic development in urban management has become synonymous with improving a community's wellbeing by economic means. It should be borne in mind, however, that improved standards of living may be realized at the expense of other conveniences. More and better job opportunities, education, and entertainment, along with increases in wealth and the ability to generate wealth are likely to be traded for increased traffic congestion, pollution, the loss of open space, and even the loss of jobs. The importance of urban managers' ability to make and execute effective, efficient, and equitable decisions is reinforced in their responsibility to devise and actualize sound economic development plans for the community.

\section{Globalization and Public Management}

The challenges posed by globalization affect all areas of city management. Kamarck (2000) postulates that at the beginning of the twenty-first century, four factors converged to spawn administrative reform at the national level in various countries around the world. These factors are: "global economic competition, democratization, the information revolution, and the performance deficit" (Nye and Donahue, 2000, p.232). All of these factors, except the performance deficit, have been shown to be related to the overall processes of globalization. Ott and Russell (2001) also opine 
that information technology and population diversity are two factors that challenge public management in the twenty-first century.

The development and execution of resultant policies from these factors at national and sub-national levels can have far-reaching repercussions in the wider world. As the federal government in the U.S. continues to grapple with global social, economic, political and technological forces, state and local governments have no choice but to look for coping strategies at sub-national levels. The present section considers the challenges that globalization presents for urban policy and management in light of the managerial functions of decision-making, economic development and service delivery being examined in this study.

\section{Decision-making}

As the social and economic diversity of urban populations continue to proliferate, cities have to formulate clear strategies for addressing the anxieties of a diverse population while highlighting and taking advantage of the positive effects of urban multicultural existence. Current realities in urban municipalities call for creative and effective decision-making by administrative and political leaders in order to arrive at feasible and sensible solutions to difficult and often nebulous issues. Mismatch between problems and the capacity to deal with them result in radically different perceptions of politics and social justice across neighborhoods. Timney Bailey (1992) 
recommends that, in a time of interconnectedness as articulated with this research, a "SupraRational" approach to decision-making in public management be taken that focuses "on the achievement of long-term, collective values or benefits [where] costs and benefits are examined in relation to multiversalist effects rather than merely individual gain" (p. 38).

The SupraRational model is purported as appropriate for a globalized world and better than the traditional rational model for public decision-making for the SupraRational model "views problems as global and interconnected; they cannot be addressed piecemeal because of the synergism among the parts" ( $p$. 44). Timney Bailey's suggested SupraRational model challenges the traditional rational model that emphasizes rigid outcome-driven parameters, individual-centered decisions and self-interest.

Public managers must take the lead in fostering and enabling the creation of harmonious multicultural and inclusive cities. In a time of globalization, it is advisable that specific municipal committees be created to address the issues that concern a multicultural community. Innovative and progressive urban management decisions must be made according to thought-provoking and creative discussions and activities carried out by such committees. Local authorities are challenged to be able to identify the types of change that introduce considerable stability into the lives of urban residents within a constantly changing dynamic of people and systems. This requires urban decision-makers to establish a longer decision-making time 
frame to assure the sustainability of the benefits of urban life. Projects such as Buenos Aires 1910: Memoria del Porvenir and New York 2050 are initiatives that exemplify this kind of citizen participation and visioning. They show that citizens are concerned about whether or not their locally elected institutions have the capacity to anticipate a broad range of social, economic, environmental, and political changes. They have also served to unleash strong creative and imaginative energies that pose new questions for urban policy and management beyond the normal daily concerns of municipal authorities. ${ }^{15}$

The ability to recognize and cushion pending external impacts requires that public managers are trained and equipped with the appropriate tools and information necessary to distinguish, interpret and choose among changing trends; particularly economic and technological exchanges, and the new lifestyles and livelihoods that are developing around them. Today's public manager must stay with 'the learning curve' to be able to relate and respond to rapid changes in their cities. In some instances, decisions to invest in training may be more logical than investing in the extension of new infrastructure or other services. This is probably more important in smallmedium cities than in principal cities where there is already information and connectivity. Indeed, if the pace of demographic growth is likely to be faster in smaller and medium-sized urban centers, it would be particularly

${ }^{15}$ http://fm.hunter.cuny.edu/ny2050/ 
important to encourage investing in decision-making capacity at that level than in making marginal additions in larger cities.

\section{Service Delivery}

Service delivery within a municipality is integrally tied to residents' involvement in public decision-making. The changing lifestyle of urban citizens, accompanied by their heightened awareness of information and technology, force urban public managers to be sensitive to such changes and respond with innovative management of scarce resources. The challenge of finding the balance between service delivery and management of public resources becomes even more difficult when the complex mix of urbanization and globalization expands and intensifies the "spillover effect" from service among neighboring jurisdictions in a metropolitan area.

These effects have structural ramifications, especially when some jurisdictions are more financially stable than others. Restrictive strategies such as resistance to annexation and zoning regulations may be employed by city administration to protect the tax base of wealthy towns and price lowerincome people out of the housing market. Richer, more advantaged jurisdictions that are better able to handle the problems related to the interplay of urbanization and globalization tend to jealously guard their own

resources. The financial clout of these jurisdictions empowers them to demand more of the local authorities, thereby placing competitive pressures 
on the provision of local public services. The Tiebout hypothesis (1956) substantiates this.

Essentially, Tieboutism holds that households with higher incomes can and may decide to relocate to municipalities that efficiently deliver services that suit their preferences. In turn, certain public concerns as residential segregation and social polarization within municipalities may arise. Gruber (2005) advises that public managers would be prudent, therefore, to be strategic in considering the strategies that minimize systemic fragmentation in the provision of local public services in an effort to evenly distribute resources and address the adverse effects of fiscal inequalities that may exist in municipalities.

\section{Economic development}

At the end of the twentieth century, Rondinelli et al. (1998) predicted that "the rapid integration of the global economy will be among the most critical factors shaping the viability of urban economies in the U.S." As mentioned earlier, increased competition and activity in the global marketplace among nations, corporations and individuals is forcing cities to eke out a place for their survival. According to Rondinelli et al (1998), economic development administrators are well-advised to consider seven trends that are likely to affect the economic growth of American cities and metropolitan areas in the $21^{\text {st }}$ century. They are listed as follows: 
1. The growing importance of international trade and investment;

2. The increasing global mobility of factors of production;

3. The driving force of technology;

4. The growing importance of knowledge-based industries;

5. The critical role of market size;

6. The need to adopt agile business practices; and

7. The necessity of forging international strategic alliances

It is against this backdrop that the economic development approaches of public management must be prepared to contend with the challenges of globalization. Rondinelli et al (1998) offer urban economic development administrators seven responses if they are deliberate about implementing an internationally competitive economic development strategy. They are:

- Improve and leverage education to increase work-force productivity and attract investment;

- Develop stronger entrepreneurial and technological capacities;

- Improve quality of living conditions;

- Enhance civic leadership and community action;

- Expand and modernize urban infrastructure;

- Create new forms of metropolitan cooperation;

- Develop an "international business promotion program

A wise manager would do well to heed these instructions in order to appropriately plan for economic development in a time of globalization. 


\section{Concluding remarks}

Although social scientists argue that in the postindustrial era modern American life is devoid of people's attachment to place, the literature shows that place still matters in determining how people live (Berube, Katz and Lang, 2006, p. 1). The city as the site of varying human and commercial interactions gives urban life its characteristic energy. The reality of city life undoubtedly contains measures of impersonality and anonymity for some while providing a sense of community and identity for others. As a municipal organization, the city exists to enhance quality of life by offering cultural amenities such as museums, parks, theaters and basic public services like water, garbage disposal and police protection. Globalization, defined as the process by which cultures, societies and political systems are transformed as a result of transnational demographic shifts, rapidly changing technologies and heightened inter-continental economic activity, challenges the practice of public management in cities.

As places globalize, urban life becomes more imbricated socially, economically, technologically and culturally. Public managers accountable for the control and organization of municipalities must do so in ways that are appropriate and responsive to the needs of a changing citizenry. The preceding survey of literature discusses the impacts of globalization on the city and on the critical public management functions of decision-making, economic development and service delivery. The following chapter outlines 
the research design and methodology executed to understand public managers' perceptions of globalization and its impact in small-medium cities in Florida. 


\section{CHAPTER IV. RESEARCH DESIGN AND METHODOLOGY}

This study seeks to understand public managers' perceptions of globalization and its impact on their work in small-medium cities in the State of Florida. This chapter will describe the research design, methodology and techniques utilized to execute the study. The methodology applies data from secondary sources such as the United States Census Bureau along with public managers' opinions of whether or not globalization impacts public management practices in Florida's small-medium cities.

The constructionist perspective of public management suggests methodologies which promote learning from the perspectives of practitioners via interpretive and critical techniques. Such an approach supports the notion that small-city public managers have a contribution to make to the dialogue concerning the intersection of public administration and globalization and that these contributions ought to be noted. The interpretive approach to inquiry allows the researcher to present an understanding of public managers' views about the impact of globalization in their municipality and interpretations of the managers' responses to globalization and their role in it. Neuman (2004) states that "the interpretive theorist attempts to discover the meaning of an event or practice by placing it within a specific social context" (p. 37). By studying small-medium cities in Florida, this study provides a specific contextual perspective of public managers in these places. 
Additionally, Jun (2006) submits that a critical perspective is instructive for a study of this nature as it allows for the examination of cultural and social dimensions of complex social phenomena as well as political, economic, and institutional concerns. Neuman (2004) posits that the critical approach allows the researcher to "strip away the surface layer of illusion or falsehood" that often conceals "real' objective reality" (p. 43). Hence, the commonly-held belief that globalization is ubiquitous and affects all societies likewise calls for critical analysis; one that might allow for "nondiscovery' of global impacts or after-the-fact sense-making. The very multidimensional nature of globalization forces the need to examine the experiences of public managers in small-medium cities through a critical and interpretive lens.

A structural-functionalist perspective of public management allows city management to be understood in terms of its various parts. The city in this study is being examined as an organization having various functions carried out by its departments. This research is concerned with the impact of globalization on the decision-making, economic development and service delivery functions of a city. Face-to-face interviews allow the researcher to directly glean from a sample of public managers their professional experiences and perspectives of globalization, and a questionnaire provides the means by which detailed critical analysis can be carried out on a wider cross-section of data. 
Qualitative and quantitative analytical techniques were employed in this inquiry which was completed in two phases. A mixed-method approach to data collection and analysis provides for a more rounded, complementary and inclusive discussion (Tashakkori and Teddlie, 2009). Triangulated methodology purports that results should converge as a means of bolstering internal validity. The first phase of the study was carried out to hear the perceptions of a selected, broad sample of public managers in the three largest MSAs in the State of Florida. In this phase, I conducted semistructured interviews to gain a general understanding of how public managers perceive globalization and its potential impacts on public management practice.

The second phase of the study executed a questionnaire which gathered data used for statistical analysis. The goal of this phase was to identify the factors that public managers perceive as having significant impact on public management and the functions of decision-making, economic development and service delivery. Interviews and open-ended questions enable the interpretive and critical analysis that the study necessitates. Secondary data from the U.S. Census will also be used to provide background information on the cities being studied.

\section{Research Questions}

The primary question that drives this study is: 
1. How do public managers in Florida's small-medium cities perceive the impacts of globalization on the public management functions of decision-making, economic development and service delivery?

Supplementary to this question are two questions. They are:

a. How do public managers in Florida's small-medium cities perceive globalization?

b. How do public managers in Florida's small-medium cities perceive globalization's impact on public management?

\section{Definition of terms}

The following definitions state the meanings of the key concepts that make up the research questions and were used in interviews and the survey.

1. Globalization - the process by which cultures, societies, political and administrative systems are influenced and transformed as a result of transnational demographic shifts, rapidly changing technologies and heightened inter-continental economic activity.

2. Public management - the socially-constructed practice of organizing, directing and controlling systems of functions to efficiently and effectively fulfill the will of the public in a responsive and equitable manner.

3. City management - the socially-constructed practice of organizing, directing and controlling the various operations of a city necessary 
to effectively and efficiently meet the needs of its citizens in a responsive and equitable manner.

4. Small-medium city - a municipal corporation chartered by its state that is headed by a mayor and has a population of $10,000-250,000$ people.

5. Public manager - an individual who has primary responsibility for managing the operations of one or more city departments; for example, city manager, police chief, department director.

\section{Focus of the study - The State of Florida}

The State of Florida is located in the southeastern region of the contiguous United States of America with a population of $18,328,340$ (U.S. Census Annual Population Data in Florida for 2008) ${ }^{16}$. Florida is considered one of the 'gateway' states that receives thousands of immigrants into the U.S. each year. Approximately 18.7 percent of Florida's population is foreignborn (2005-2007 American Community Survey).17 Net international migration for the state for the period April 1, 2000 to July 1, 2008 was 694,850.18 Net international migration is defined by the U.S. Census as:

\footnotetext{
16 http://fred.labormarketinfo.com US Department of Commerce, Bureau of the Census) Retrieved March 24, 2009.

17 http://factfinder.census.gov/ Retrieved March 24, 2009

18 http://www.census.gov/popest/states/tables/NST-EST2008-04.xls Retrieved May 9, 2009
} 
international migration of both native and foreignborn populations. Specifically, it includes: (a) the net international migration of the foreign born, (b) the net migration between the United States and Puerto Rico, (c) the net migration of natives to and from the United States, and (d) the net movement of the Armed Forces population between the United States and overseas. ${ }^{19}$

Florida has twenty Metropolitan Statistical Areas (MSAs). The spatial distribution of the MSAs across the state is shown in Figure 2. For the purpose of the quantitative analysis, the Miami-Fort Lauderdale-West Palm Beach MSA is being represented in the three separate metropolitan divisions that make up that MSA. A metropolitan division is "a county or group of counties within a Metropolitan Statistical Area that has a population core of at least 2.5 million" (U.S. Census). Florida's metropolitan areas constitute 94 percent of the state's population, 96 percent of the state's jobs, and 97 percent of the state's GDP (Brookings Institute). ${ }^{20}$ Seven of the nation's largest metropolitan areas are located in Florida - Miami, Tampa, Orlando, Jacksonville, Sarasota, Cape Coral, and Palm Bay. These metropolitan areas account for 73 percent of the state's population, 77 percent of the state's jobs,

19 http://www.census.gov/popest/topics/methodology/2008-st-co-meth.html

Retrieved March 30, 2009

${ }^{20}$ Blueprint for American prosperity: MetroNation Profile http://www.brookings.edu/ /media/Files/Projects/blueprint/statesbp/Floridabp .pdf Retrieved March 24, 2009 
and 80 percent of the state's gross domestic product (Brookings Institute). ${ }^{21}$ Table 2 presents the population data for the metropolitan areas in Florida.

There are 263 cities (incorporated municipalities) in Florida. Of this number, 132 (50.2 percent) have populations between 10,000 and 250,000. According to the 2000 Census, only three cities in Florida have populations greater than 250,000. These are Jacksonville (a consolidated city-county), Tampa and Miami. Figure 1 shows the spatial distribution of the smallmedium cities in Florida.

${ }^{21}$ Ibid. 
Table 2. Florida metropolitan areas population data ${ }^{22}$

\begin{tabular}{|l|c|c|c|}
\hline Region & $\begin{array}{c}\text { Total } \\
\text { Population }\end{array}$ & $\begin{array}{c}\text { Net } \\
\text { international } \\
\text { migration }\end{array}$ & $\begin{array}{c}\text { Percent } \\
\text { Foreign- } \\
\text { born* }\end{array}$ \\
\hline $\begin{array}{l}\text { Bradenton/Sarasota/Venice } \\
\text { MSA }\end{array}$ & 687,823 & 1,532 & $12.0 \%$ \\
\hline Cape Coral-Fort Myers MSA & 593,136 & 1,492 & $14.4 \%$ \\
\hline $\begin{array}{l}\text { Deltona-Daytona Beach- } \\
\text { Ormond Beach, MSA }\end{array}$ & 498,036 & 689 & $7.6 \%$ \\
\hline $\begin{array}{l}\text { Ft. Lauderdale Metropolitan } \\
\text { Division }\end{array}$ & $1,751,234$ & 171 & $29.9 \%$ \\
\hline $\begin{array}{l}\text { Ft. Walton Beach-Crestview- } \\
\text { Destin MSA }\end{array}$ & 179,693 & 679 & $5.5 \%$ \\
\hline Gainesville MSA & 258,555 & 1,676 & $9.3 \%$ \\
\hline Jacksonville MSA & $1,313,228$ & 1,043 & $6.9 \%$ \\
\hline Lakeland/Winter Haven MSA & 580,594 & 11,770 & $10.1 \%$ \\
\hline Miami Metropolitan Division & $2,398,245$ & 29,568 & $50.4 \%$ \\
\hline Naples-Marco Island MSA & 315,258 & 5,868 & $23.6 \%$ \\
\hline Ocala MSA & 329,628 & 1,805 & $6.0 \%$ \\
\hline Orlando-Kissimmee MSA & $2,054,574$ & 294 & $15.7 \%$ \\
\hline $\begin{array}{l}\text { Palm Bay/ } \\
\text { Melbourne/Titusville/ MSA }\end{array}$ & 536,521 & 9,190 & $8.2 \%$ \\
\hline Palm Coast MSA & 91,247 & 536 & $12.5 \%$ \\
\hline $\begin{array}{l}\text { Panama City-Lynn Haven } \\
\text { MSA }\end{array}$ & 163,946 & 58 & $5.4 \%$ \\
\hline $\begin{array}{l}\text { Pensacola-Ferry Pass-Brent } \\
\text { MSA }\end{array}$ & 452,992 & 108 & $4.2 \%$ \\
\hline Port St. Lucie MSA & 403,768 & 346 & $14.1 \%$ \\
\hline Punta Gorda MSA & 150,060 & 733 & $9.9 \%$ \\
\hline Sebastian-Vero Beach MSA & 132,315 & 138 & $10.3 \%$ \\
\hline Tallahassee MSA & 357,259 & 218 & $5.0 \%$ \\
\hline $\begin{array}{l}\text { Tampa/St. } \\
\text { Petersburg/Clearwater MSA }\end{array}$ & $2,733,761$ & 462 & $12.0 \%$ \\
\hline $\begin{array}{l}\text { West Palm Beach/Boca Raton } \\
\text { Metropolitan Division }\end{array}$ & $1,265,293$ & 7,050 & $21.2 \%$ \\
\hline $\begin{array}{l}* \\
\text { citizalculated as percent of population by naturalization }\end{array}$ & who are not U.S. citizens or are U.S. \\
\hline
\end{tabular}

22 Source: U.S. Census Bureau, Annual Estimates of the Population of Metropolitan and Micropolitan Statistical Areas, http://www.census.gov/popest/metro/CBSAest2008-annual.html Retrieved March 30, 2009 


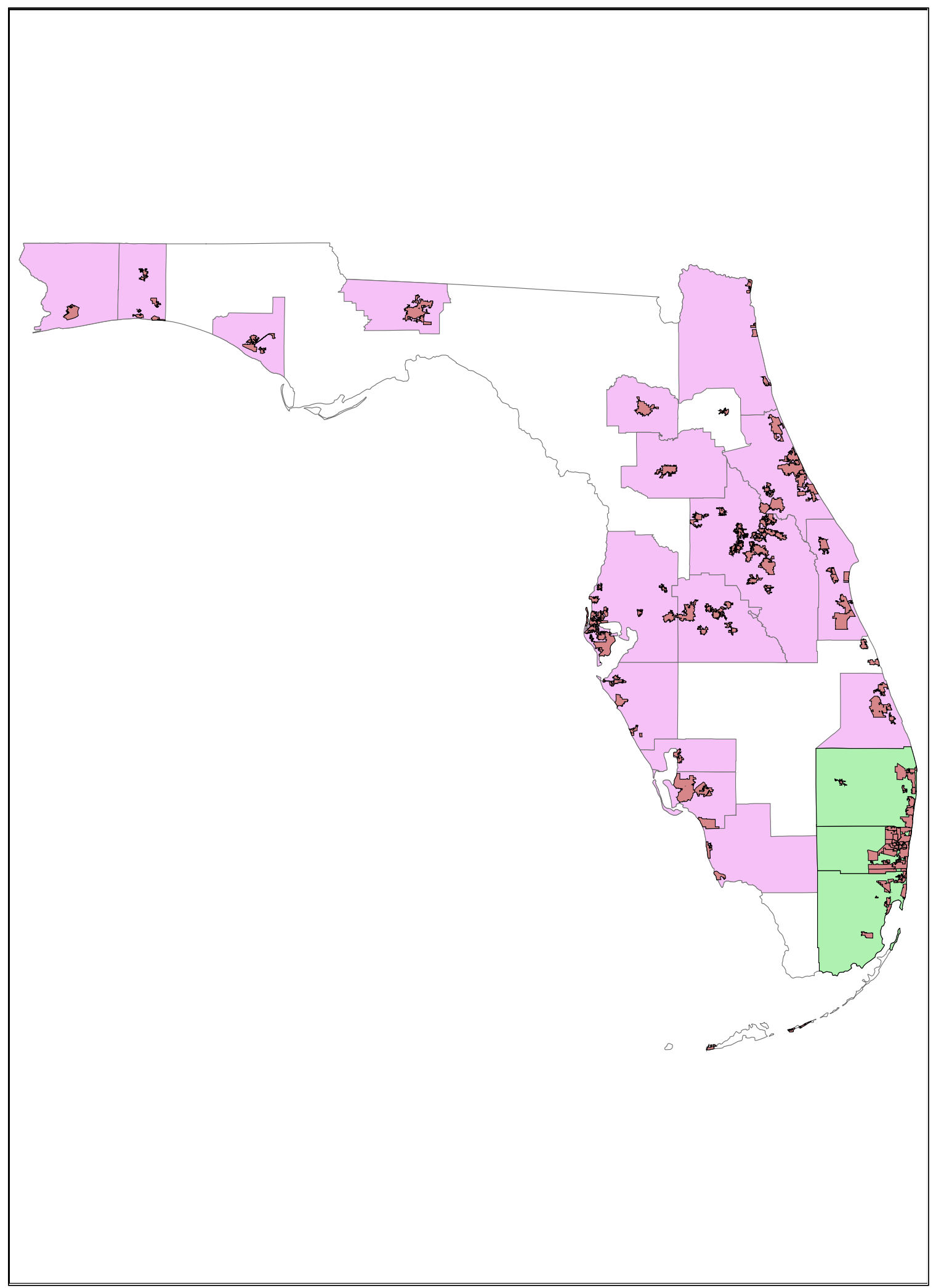

Figure 1. Map of Florida showing spatial distribution of small-medium cities in metropolitan statistical areas 


\section{Research Design - Qualitative}

In order to understand public managers' perceptions of globalization and its impact on public management practices, face-to-face interviews were conducted in March 2008 with directors of various departments in municipalities located within the three largest metropolitan areas in Florida

- Miami/Fort Lauderdale/West Palm Beach, Tampa/St. Petersburg and Orlando. Jun (2006) refers to globalization as

a human construction of a social world in that it is an ongoing process of constructing and reconstructing ways of sharing the meaning of interdependence as well as developing alternatives to improve local as well as global socioeconomic and political conditions (p.67).

This constructionist view of globalization forms part of the theoretical grounding for this study and therefore renders it appropriate that a qualitative approach be taken for its investigation (Babbie, 2008). Accordingly, semi-structured interviews were used to gather data on managers' perceptions of the concept of globalization and adaptations to procedures that they have implemented to respond to changing demographics in their individual municipalities. The interviews gathered information on managers' tenure in public service, their views on globalization's impact on specific urban service areas, and whether or not they felt that globalization presents a challenge or an opportunity for public management officials. The interviews provided a variety of perspectives from across the major metropolitan areas in the State so that the resultant survey included the 
range of factors that public managers perceive as important to the connection between globalization and public management. I collected sufficient information to identify thematic common areas of focus that would help to organize the questionnaire and provide reliable results from the wider crosssection of public managers who would participate in the survey. A total of twenty-five public managers were interviewed. These included four economic development directors, three planning and zoning directors, four police chiefs, five parks and recreation directors and nine city managers. Interviews were recorded upon consent by the participants. One interviewee requested that the interview not be recorded. For this interview, notes were taken by hand.

Table 3 shows demographic characteristics of the interview sites and demonstrates that the cross-section of cities is diverse in terms of income, race/ethnicity and population size. The municipalities selected for carrying out the interviews lie within a radius of 20 miles around a principal city in their respective MSAs. The study advances that cities within this area lend themselves to a significant degree of social, economic, and political activity taking place in their larger counterparts, the principal cities. As a means of pre-testing the interview schedule, preliminary interviews were also carried out among city managers and department directors in Lauderhill, Coral Springs and Homestead, cities located in the Miami and Fort Lauderdale Metropolitan Divisions. 
Table 3. Interview participants' and municipalities' data ${ }^{23}$

\begin{tabular}{|c|c|c|}
\hline Municipality & $\begin{array}{c}\text { Total } \\
\text { population }\end{array}$ & $\begin{array}{l}\text { Median household } \\
\text { income in } 1999\end{array}$ \\
\hline $\begin{array}{l}\text { Clearwater (Tampa MSA) } \\
\text { City Manager } \\
\text { Economic Development Director } \\
\text { Planning and Zoning Director }\end{array}$ & 107,925 & $\$ 36,494$ \\
\hline $\begin{array}{l}\text { Coral Gables (Miami MSA) } \\
\text { City Manager } \\
\text { Planning and Zoning Director } \\
\text { Chief of Police }\end{array}$ & 42,202 & $\$ 66,839$ \\
\hline $\begin{array}{l}\text { Hialeah Gardens (Miami MSA) } \\
\text { Mayor }\end{array}$ & 19,238 & $\$ 38,858$ \\
\hline $\begin{array}{l}\text { Lake Mary (Orlando MSA) } \\
\text { City Manager } \\
\text { Parks and Recreation Director }\end{array}$ & 11,289 & $\$ 69,485$ \\
\hline $\begin{array}{l}\text { Longwood (Orlando MSA) } \\
\text { City Manager } \\
\text { Chief of Police }\end{array}$ & 13,712 & $\$ 51,667$ \\
\hline $\begin{array}{l}\text { Miami Beach (Miami MSA) } \\
\text { Assistant City Manager/Parks and } \\
\text { Recreation Dir. } \\
\text { Economic Development Director }\end{array}$ & 88,061 & $\$ 27,322$ \\
\hline $\begin{array}{l}\text { Oldsmar (Tampa MSA) } \\
\text { City Manager } \\
\text { Planning and Redevelopment Director } \\
\text { Parks and Recreation Director }\end{array}$ & 11,736 & $\$ 50,354$ \\
\hline $\begin{array}{l}\text { Oviedo (Orlando MSA) } \\
\text { Economic Development Director }\end{array}$ & 27,023 & $\$ 64,119$ \\
\hline $\begin{array}{l}\text { Pembroke Pines (Miami MSA) } \\
\text { Assistant City Manager }\end{array}$ & 137,112 & $\$ 52,629$ \\
\hline $\begin{array}{l}\text { Temple Terrace (Tampa MSA) } \\
\text { City Manager } \\
\text { Chief of Police } \\
\text { Parks and Recreation Director }\end{array}$ & 20,871 & $\$ 44,508$ \\
\hline $\begin{array}{l}\text { Winter Garden (Orlando MSA) } \\
\text { City Manager } \\
\text { Parks and Recreation Director }\end{array}$ & 13,999 & $\$ 37,129$ \\
\hline $\begin{array}{l}\text { Winter Springs (Orlando MSA) } \\
\text { City Manager }\end{array}$ & 31,424 & $\$ 53,247$ \\
\hline
\end{tabular}

23 Source: U.S. Census 2000 
To measure the racial/ethnic diversity of each municipality, an Index of Qualitative Variation (IQV) was calculated using U.S. Census 2000 data. The IQV, as a measure of variability, ranges from 0.00 to 1.00 (FrankfortNachmias and Leon-Guerrero, 2009, 138). An IQV of 0 in each place indicates no racial/ethnic diversity while an IQV of 1 indicates maximum racial/ethnic diversity. Table 4 presents the IQV values for the interview sites.

Table 4. Index of Qualitative Variation for interview sites

\begin{tabular}{|l|c|}
\hline Municipality & $\begin{array}{c}\text { IQV (racial/ethnic } \\
\text { diversity) }\end{array}$ \\
\hline Clearwater (Tampa MSA) & 0.33 \\
\hline Coral Gables (Miami MSA) & 0.18 \\
\hline Hialeah Gardens (Miami MSA) & 0.24 \\
\hline Lake Mary (Orlando MSA) & 0.21 \\
\hline Longwood (Orlando MSA) & 0.28 \\
\hline Miami Beach (Miami MSA) & 0.28 \\
\hline Oldsmar (Tampa MSA) & 0.18 \\
\hline Oviedo (Orlando MSA) & 0.33 \\
\hline Pembroke Pines (Miami MSA) & 0.47 \\
\hline Temple Terrace (Tampa MSA) & 0.39 \\
\hline Winter Garden (Orlando MSA) & 0.43 \\
\hline Winter Springs (Orlando MSA) & 0.24 \\
\hline
\end{tabular}

A grounded theory approach was utilized to analyze the interview transcripts. Grounded theory allows the researcher to understand participants' responses by identifying commonalities with reiterative comparisons within and across cases (Babbie, 2008). Consequently, common themes that emerge from the transcripts are organized into categories to generate clarity and structure among the responses. 
The qualitative data from the interviews laid the foundation for critically analyzing public managers' perceptions of globalization and its impacts on globalization. The interview responses proved useful in operationalizing the variables for the second phase of the study.

\section{Research design - Quantitative}

This phase was executed with a 13-question survey comprising multiitem Likert-type questions and Semantic Differential scales. The survey was designed using specific concepts brought out in the interview phase. While the interviews presented mixed perceptions of globalization and its impacts, the purpose of establishing quantitative factors is to introduce objectivity to the understanding of the perceptions. The survey design facilitated the measurement of managers' levels of agreement pertinent to issues raised in the research and subsidiary questions, and municipalities' global activity levels. Some questions were adapted from a survey carried out by the Robert B. and Helen S. Meyner Center for the Study of State and Local Government at Lafayette College in 1996. Respondents were also given the opportunity to record their opinions about globalization issues using open-ended questions. I use descriptive statistics, cross-tabulation calculations and factor analysis techniques to analyze the quantitative survey data.

The responses from the interviews elucidated the significance of globalization's impact on economic development and managerial decision- 
making. Therefore, in the second phase of the research, the survey was sent to city managers, economic development directors and budget/finance directors of all small-medium cities in Florida. Survey instruments were primarily disseminated using the Internet. Regular mail and facsimile transmission (fax) were used to distribute surveys to managers who did not respond by internet and for whom e-mail addresses were not available. A total of 293 surveys were issued. Of the 293,126 were returned, constituting a response rate of $43 \%$. Of the 126 respondents, $64(50.8 \%)$ are city managers, $29(23.0 \%)$ are budget/finance directors, $33(26.2 \%)$ are economic development directors. Thirty-two of the surveys (25\%) were returned by mail or fax.

Table 5 shows that survey respondents fall into different age groups with $36 \%$ belonging to the group aged 50 years and over. These data indicate that most participants may be considered to be in their senior years with likely many years of service already given to the public sector. Table 6 shows that approximately $63 \%$ of the respondents have a Masters' degree and nearly $3 \%$ have a Doctoral degree. These figures demonstrate that the survey respondents overwhelmingly have high levels of educational achievement and imply that the majority of research participants are very well-trained and qualified for their positions.

In sum, the survey respondents comprise mainly city managers aged 55 years or older with advanced degrees. 
Table 5. Distribution of survey respondents by age

\begin{tabular}{|c|c|c|c|c|c|c|c|c|}
\hline \multirow[t]{2}{*}{ Age } & \multicolumn{2}{|c|}{$\begin{array}{c}\text { City } \\
\text { Manager }\end{array}$} & \multicolumn{2}{|c|}{$\begin{array}{l}\text { Budget/Fin. } \\
\text { Dir. }\end{array}$} & \multicolumn{2}{|c|}{$\begin{array}{c}\text { Economic Dev. } \\
\text { Dir. }\end{array}$} & \multicolumn{2}{|c|}{ Total } \\
\hline & $\mathrm{n}$ & $\%$ & $\mathrm{n}$ & $\%$ & $\mathrm{n}$ & $\%$ & $\mathrm{n}$ & $\%$ \\
\hline 25-39 years & 7 & 12.5 & 2 & 7.7 & 3 & 10.3 & 12 & 10.8 \\
\hline 40-54 years & 21 & 37.5 & 18 & 69.2 & 20 & 69.0 & 59 & 53.2 \\
\hline $55+$ years & 28 & 50.0 & 6 & 23.1 & 6 & 20.7 & 40 & 36.0 \\
\hline Total & 56 & 50.5 & 26 & 23.4 & 29 & 26.1 & 111 & 100.0 \\
\hline
\end{tabular}

Table 6. Distribution of survey respondents by level of education

\begin{tabular}{|c|c|c|c|c|c|c|c|c|}
\hline \multirow[t]{2}{*}{ Edn. Level } & \multicolumn{2}{|c|}{$\begin{array}{c}\text { City } \\
\text { Manager }\end{array}$} & \multicolumn{2}{|c|}{$\begin{array}{l}\text { Budget/Fin. } \\
\text { Dir. }\end{array}$} & \multicolumn{2}{|c|}{$\begin{array}{c}\text { Economic Dev. } \\
\text { Dir. }\end{array}$} & \multicolumn{2}{|c|}{ Total } \\
\hline & $\mathrm{n}$ & $\%$ & $\mathrm{n}$ & $\%$ & $\mathrm{n}$ & $\%$ & $\mathrm{n}$ & $\%$ \\
\hline $\begin{array}{l}\text { Some } \\
\text { College }\end{array}$ & 4 & 6.9 & 0 & 0.0 & 1 & 3.3 & 5 & 4.4 \\
\hline Bachelor's & 10 & 17.2 & 13 & 50.0 & 11 & 36.7 & 34 & 29.8 \\
\hline Master's & 42 & 72.4 & 13 & 50.0 & 17 & 56.7 & 72 & 63.2 \\
\hline Doctorate & 2 & 3.4 & 0 & 0.0 & 1 & 3.3 & 3 & 2.6 \\
\hline Total & 58 & 50.9 & 26 & 22.8 & 30 & 26.3 & 114 & 100.0 \\
\hline
\end{tabular}

The distribution of respondents across the metropolitan areas is shown in Figure 2. The Fort Lauderdale metropolitan area provided the most responses to the survey at $26.2 \%$ with Tampa and Orlando metropolitan areas providing $11.1 \%$ and $11.9 \%$ of the responses respectively. There were no participants from the Ocala, Punta Gorda and Tallahassee (seat of the state capital) MSAs. Table 7 displays the IQV for each of the participating cities and the available data indicating the size of the respective foreign-born populations. 


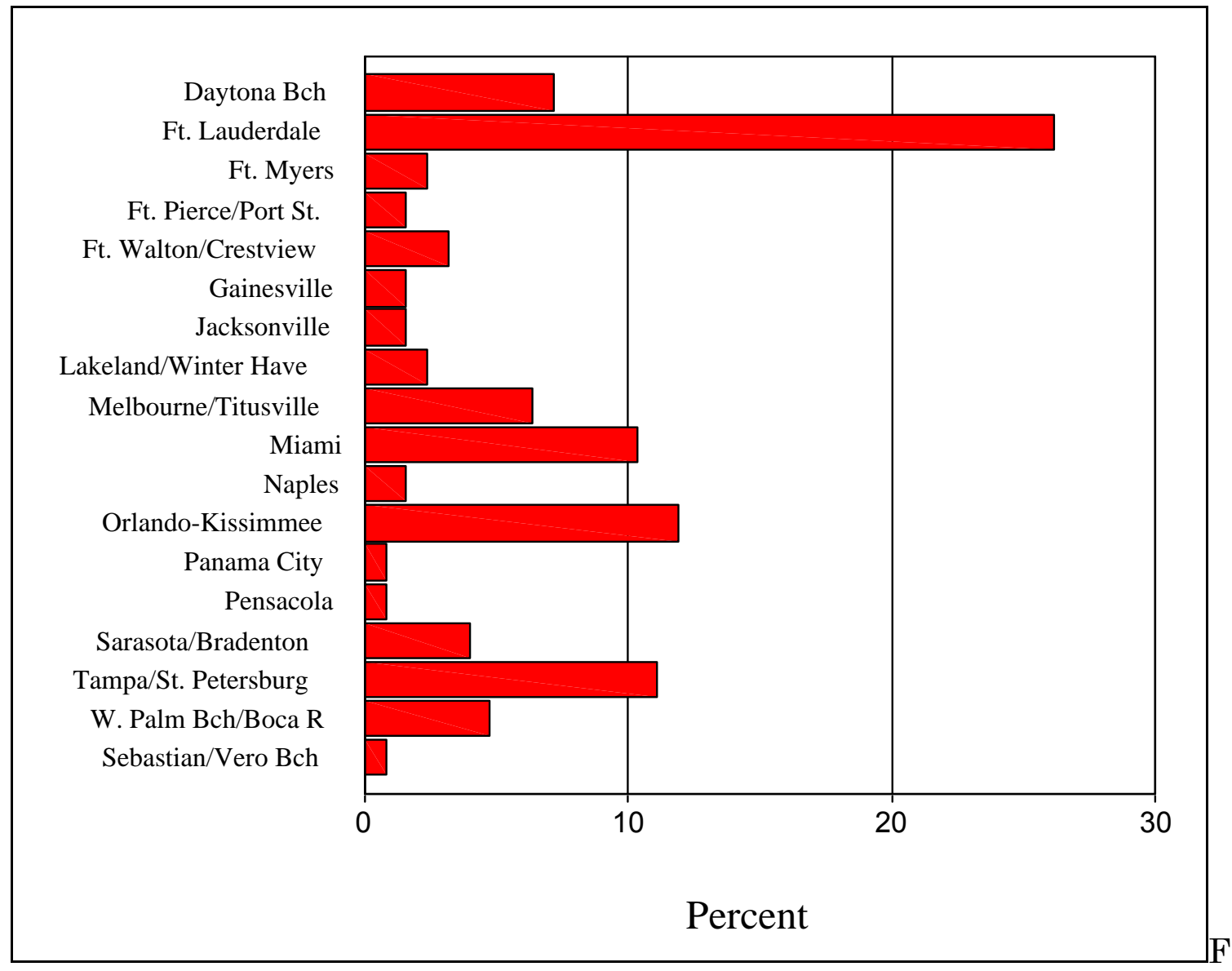

Figure 2. Bar chart showing distribution of survey respondents by metropolitan areas 
Table 7. Survey respondents' MSA population data

\begin{tabular}{|c|c|c|c|}
\hline Municipality & $\begin{array}{c}\text { Total } \\
\text { Population }\end{array}$ & $\begin{array}{l}\text { Foreign born } \\
\text { percent* }\end{array}$ & $\mathrm{IQV}^{* *}$ \\
\hline \multicolumn{4}{|l|}{ Daytona Beach MSA } \\
\hline Deltona & 69,543 & 9.1 & 0.33 \\
\hline Port Orange & 45,823 & 5.7 & 0.10 \\
\hline De Land & 20,904 & 10.2 & 0.47 \\
\hline De Bary & 15,559 & - & 0.12 \\
\hline South Daytona & 13,177 & -- & 0.24 \\
\hline \multicolumn{4}{|c|}{ Fort Lauderdale Metro Division } \\
\hline Fort Lauderdale & 152,397 & 21.3 & 0.58 \\
\hline Hollywood & 139,357 & 31.6 & 0.43 \\
\hline Pembroke Pines & 137,427 & 35.0 & 0.47 \\
\hline Coral Springs & 117,549 & 26.0 & 0.38 \\
\hline Pompano Beach & 78,191 & 27.5 & 0.55 \\
\hline Miramar & 72,739 & 42.4 & 0.72 \\
\hline Deerfield Beach & 64,583 & 30.9 & 0.44 \\
\hline Lauderhill & 57,585 & 34.1 & 0.63 \\
\hline Tamarac & 55,588 & 27.5 & 0.37 \\
\hline Margate & 53,909 & 28.2 & 0.42 \\
\hline Weston & 49,286 & 38.4 & 0.26 \\
\hline Coconut Creek & 43,566 & 24.2 & 0.29 \\
\hline Hallandale & 34,282 & 41.4 & 0.44 \\
\hline Lauderdale Lakes & 31,705 & 45.2 & 0.56 \\
\hline Cooper City & 27,939 & 20.4 & 0.24 \\
\hline Dania Beach & 20,061 & 25.7 & 0.53 \\
\hline Parkland & 13,835 & 16.9 & 0.19 \\
\hline Wilton Manors & 12,697 & -- & 0.41 \\
\hline Lighthouse Point & 10,767 & -- & 0.07 \\
\hline \multicolumn{4}{|l|}{ Fort Myers MSA } \\
\hline Cape Coral & 102,286 & 13.4 & 0.16 \\
\hline Fort Myers & 48,208 & 20.8 & 0.66 \\
\hline Bonita Springs & 32,797 & 19.3 & 0.22 \\
\hline \multicolumn{4}{|c|}{ Fort Pierce/Port St. Lucie MSA } \\
\hline Port St. Lucie & 88,769 & 16.0 & 0.26 \\
\hline Stuart & 14,633 & -- & 0.34 \\
\hline
\end{tabular}




\begin{tabular}{|c|c|c|c|}
\hline Municipality & $\begin{array}{c}\text { Total } \\
\text { Population }\end{array}$ & $\begin{array}{l}\text { Foreign born } \\
\text { percent* }\end{array}$ & $\mathrm{IQV}^{* *}$ \\
\hline \multicolumn{4}{|c|}{ Fort Walton/Crestview/Destin MSA } \\
\hline Fort Walton Beach & 19,973 & -- & 0.42 \\
\hline Niceville & 11,684 & -- & 0.27 \\
\hline Destin & 11,119 & -- & 0.09 \\
\hline \multicolumn{4}{|l|}{ Gainesville MSA } \\
\hline Gainesville & 95,447 & 10.7 & 0.55 \\
\hline \multicolumn{4}{|l|}{ Jacksonville MSA } \\
\hline Atlantic Beach & 13,368 & -- & 0.36 \\
\hline Fernandina Beach & 10,549 & -- & 0.36 \\
\hline \multicolumn{4}{|c|}{ Lakeland/Winter Haven MSA } \\
\hline Auburndale & 11,032 & -- & 0.38 \\
\hline Lake Wales & 10,194 & -- & 0.61 \\
\hline \multicolumn{4}{|c|}{ Melbourne/Titusville/Palm Bay MSA } \\
\hline Palm Bay & 79,413 & 13.9 & 0.37 \\
\hline Titusville & 40,670 & 6.2 & 0.33 \\
\hline Rockledge & 20,170 & 7.7 & 0.37 \\
\hline Cocoa & 16,412 & -- & 0.59 \\
\hline Cocoa Beach & 12,482 & -- & 0.08 \\
\hline \multicolumn{4}{|l|}{ Miami Metro Division } \\
\hline Hialeah & 226,419 & 70.8 & 0.26 \\
\hline Miami Beach & 87,933 & 53.9 & 0.28 \\
\hline North Miami & 59,880 & 48.8 & 0.67 \\
\hline Coral Gables & 42,249 & 35.9 & 0.18 \\
\hline North Miami Beach & 40,786 & 50.0 & 0.73 \\
\hline Key West & 25,478 & 18.7 & 0.31 \\
\hline Opa-locka & 14,951 & -- & 0.54 \\
\hline Sweetwater & 14,226 & -- & 0.27 \\
\hline Miami Springs & 13,712 & -- & 0.20 \\
\hline Marathon & 10,255 & -- & 0.20 \\
\hline
\end{tabular}




\begin{tabular}{|c|c|c|c|}
\hline Municipality & $\begin{array}{c}\text { Total } \\
\text { Population }\end{array}$ & $\begin{array}{l}\text { Foreign born } \\
\text { percent* }\end{array}$ & $\mathrm{IQV}^{* *}$ \\
\hline \multicolumn{4}{|l|}{ Naples MSA } \\
\hline Naples & 20,976 & 10.0 & 0.17 \\
\hline Marco Island & 14,879 & -- & 0.04 \\
\hline \multicolumn{4}{|l|}{ Orlando MSA } \\
\hline Orlando & 185,951 & 18.4 & 0.64 \\
\hline Kissimmee & 47,814 & 29.1 & 0.60 \\
\hline Sanford & 38,291 & 10.3 & 0.63 \\
\hline Oviedo & 26,316 & 8.2 & 0.34 \\
\hline Ocoee & 24,391 & 15.6 & 0.38 \\
\hline Casselberry & 22,629 & 12.0 & 0.31 \\
\hline St. Cloud & 20,074 & 7.8 & 0.21 \\
\hline Leesburg & 15,956 & 8.2 & 0.55 \\
\hline Eustis & 15,106 & -- & 0.43 \\
\hline Winter Garden & 14,351 & 18.4 & 0.46 \\
\hline Longwood & 13,745 & -- & 0.27 \\
\hline Maitland & 12,019 & -- & 0.31 \\
\hline \multicolumn{4}{|l|}{ Panama City MSA } \\
\hline Lynn Haven & 12,451 & -- & 0.29 \\
\hline \multicolumn{4}{|l|}{ Pensacola MSA } \\
\hline Pensacola & 56,255 & 3.1 & 0.57 \\
\hline \multicolumn{4}{|c|}{ Sarasota/Bradenton MSA } \\
\hline Sarasota & 52,715 & 18.3 & 0.44 \\
\hline North Port & 22,797 & 12.8 & 0.16 \\
\hline Venice & 17,764 & 9.2 & 0.04 \\
\hline Palmetto & 12,571 & -- & 0.48 \\
\hline \multicolumn{4}{|c|}{ Tampa/St. Petersburg/Clearwater MSA } \\
\hline St. Petersburg & 248,232 & 10.9 & 0.51 \\
\hline Clearwater & 108,787 & 16.6 & 0.33 \\
\hline Largo & 69,371 & 11.0 & 0.16 \\
\hline Pinellas Park & 45,658 & 12.6 & 0.24 \\
\hline Safety Harbor & 17,203 & -- & 0.17 \\
\hline Gulfport & 12,527 & -- & 0.23 \\
\hline Oldsmar & 11,910 & -- & 0.21 \\
\hline Seminole & 10,890 & -- & 0.08 \\
\hline
\end{tabular}




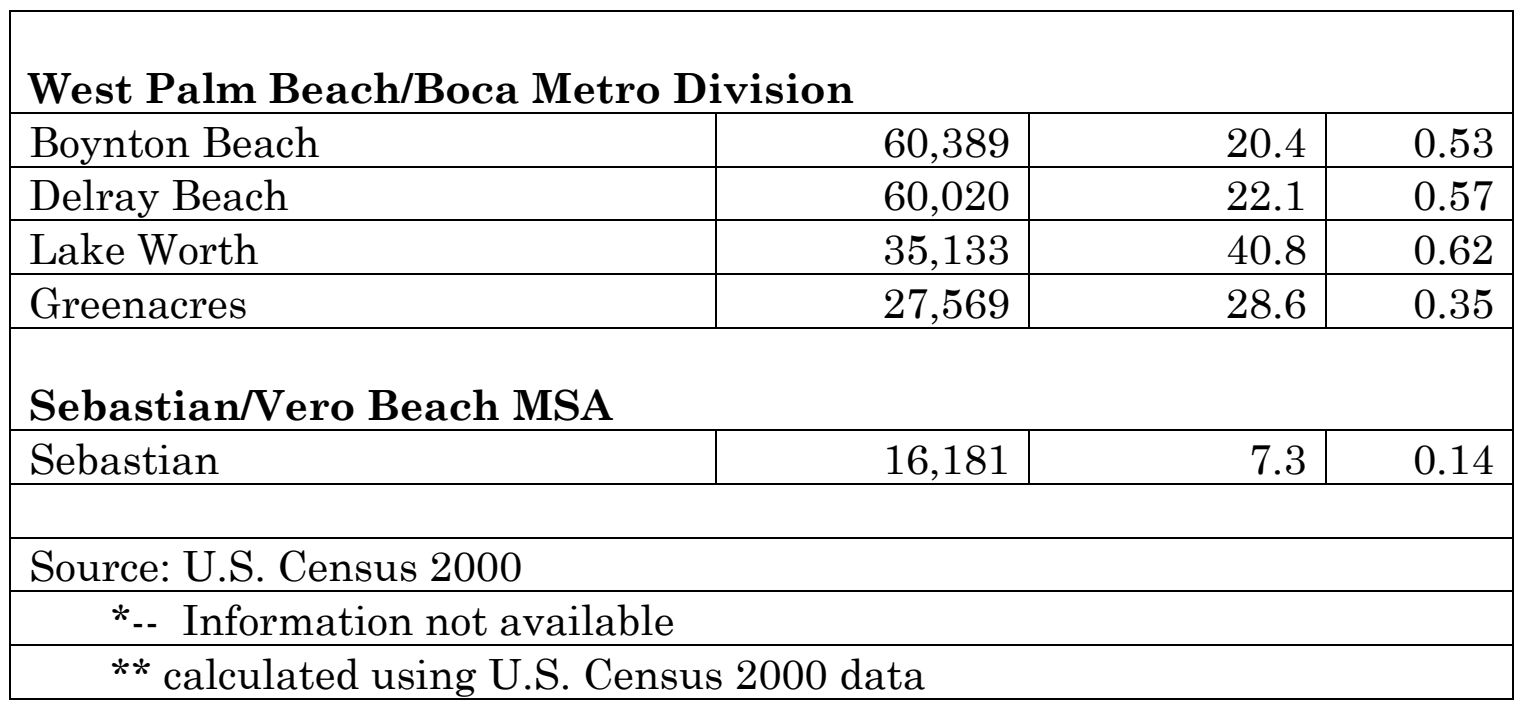

\section{Instrument}

The questionnaire used for the survey was organized into five categories aimed at measuring (1) municipality's level of global activity, (2) globalization's impact on aspects of municipal management and demographic characteristics, (3) managers' perceptions of globalization's impact, (4) administrative responses to perceived impacts and (5) managers' demographic information. The instrument is shown in Appendix D. Space was provided in the survey for participants to write additional comments, allowing for open-ended recording of opinions.

The questionnaire utilized a variety of question items to address the multi-dimensional nature of globalization. The first question regarding municipality's level of global activity invokes commonly used indicators of economic, social and cultural dimensions of globalization. Question two seeks to ascertain the managers' perceptions of the global economy's impact on municipalities' economic characteristics. Question three presents common 
repercussions of globalization and asks respondents to indicate their perceptions on the issues in the context of their municipality.

Questions four and five asks respondents to indicate their perception of globalization's impact on aspects of municipal governance and public management practice. Question six measures participants' level of agreement with statements that capture commonly-held views about globalization. Questions seven and eight provide respondents with likely administrative actions that may be taken in their municipality, as a result of globalization, and asks respondents to indicate the actions that apply in their municipality. Question nine is an open-ended question that asks participants to share any comments that they may have regarding globalization. Questions ten through thirteen obtain information on the participants' age, level of education, place of birth and whether or not they have worked outside the United States of America.

\section{Qualitative Analysis}

A grounded theory approach is used to identify common themes that emerge from the qualitative data collected via the interviews and survey. The interview schedule is presented in Appendix C. According to Neuman (2004), the grounded theory method seeks to "build ideas and theoretical generalizations based on closely examining and creatively thinking about the data" (p. 30). Hence, for this study, responses to open-ended questions from 
the survey and interview transcripts were analyzed through an iterative process of comparison to categorize commonalities within and among them. Excerpts from interview transcripts are provided in this chapter to summarize and support the analysis. Interviews were recorded and transcribed verbatim in order to facilitate the coding that is fundamental to the grounded theory methodology used in the analysis.

\section{Quantitative Analysis}

The quantitative analysis covers the data collected with the survey. The analysis begins with a reliability analysis of the items used in the survey for measuring managers' perceptions of globalization and globalization's impact on municipalities' demographic and socio-economic characteristics. Descriptive statistics carried out to summarize the data are discussed in Chapter five. Results of the summary statistics are represented in graphs and tables.

Cross-tabulation of public managers' demographic data are carried out against managers' perceptions to ascertain if there is any statistically significant relationship between the variables. The Pearson Chi-square statistic is used to determine the statistical significance of relationships between variables used in cross-tabulations. The statistical significance of the relationships is interpreted as a probability less than or equal to 0.1.

This probability measures "the extent to which the observed and expected 
frequencies differ by chance" (Shannon and Davenport, 2001, p. 154). For statistically significant relationships, their respective measures of association are reported. I use the Somers' d measure of association for this research. The Somers' d measure accounts for ties in the responses, thereby ensuring that identical responses will not be ignored (Nerusis, 2004). In this study, where many responses are the same, it is prudent to use the Somer's d measure to make certain that data is not excluded from the analysis.

To further validate and categorically understand public managers' perceptions of globalization and its impact on their work, this study applies factor analysis using the principal components method. Factor analysis is used to parse the conceptualization of public managers' perceptions of globalization; public managers' perceptions of globalization's impact on aspects of public management and municipal governance; and cities' responses to globalization. Factor analysis generates and applies correlations among indicators of a construct to determine if the indicators can be interpreted reliably as measures of the construct (Warner 2008, p. 754).i

\section{Validity}

Validity refers to the credibility of the measurement techniques used to collect data. It establishes the degree to which measurement techniques employed in a study are applicable and appropriate for accurately assessing the critical elements of the study and for providing trustworthy answers to 
the questions being asked. Babbie (2008) defines validity as "the extent to which an empirical measure adequately reflects the real meaning of the concept under consideration" (p. 160). The triangulated approach taken for completing this study bolsters its validity as data were gathered by speaking directly to managers (in the field) as well as with the use of a survey to learn from a wider cross section of practitioners.

For the first phase, interviews were conducted among five categories of managers (city managers, economic development, planning and zoning, parks and recreation directors and chiefs of police). For the second phase, three categories were targeted (city managers, economic development and budget/finance directors). These professionals were selected on the basis that their positions are responsible for making senior-level managerial and economic development decisions as well as having high direct contact with citizens.

\section{Reliability of survey questions}

The reliability of measurement techniques in research is significant to the results reported. Reliability suggests that "the same data would have been collected each time in repeated observations of the same phenomenon" (Babbie, 2008:157) and speaks to the consistency of the techniques used in

developing the survey instrument. Reliability analysis of the survey instrument used for this study was performed using Cronbach's alpha 
coefficient. A Cronbach's alpha coefficient value of 0.7 or higher for the scale indicates good internal consistency of the items used to develop the scale (Shannon and Davenport, 2000:126). Tables six through nine illustrate the correlations for each question item and their respective means and standard deviations.

According to Table 8, all items in the scale measuring municipality's global activity have positive correlations. This indicates that the items are consistent with the concept being measured. Eight of the nine item correlations are greater than 0.5 which signifies that these items are strongly correlated with the concept of municipalities' global activity. The item with a correlation of 0.3554 pertains to the item asking about "investing with international capital markets". This item's low correlation may be explained by the fact that it is highly likely that small-medium municipalities vary greatly in their level of international investment activity given their local economic activity and political and administrative emphases. The low correlation may also signify managers' inability to meaningfully connect the investment dealings of their municipality to global financial and economic activities. The Cronbach's alpha for Question 1 is 0.8787 which is a strong indicator of the overall reliability of the scale used to measure municipalities' global activity.

Table 9 shows that the items comprising the scale for measuring managers' perceptions of the global economy's impact on aspects of their 
municipality's economy is reliable. Each item-total correlation is greater than 0.5 which means that they correlate with each other in a consistently positive manner. The Cronbach's alpha for Question 2 is 0.8440 which is an indication of the overall high reliability of the question.

Table 8. Descriptive statistics for scale measuring municipality's level of global activity

\begin{tabular}{lccc}
\hline $\begin{array}{l}\text { Question } 1 \text { items } \\
(1=\text { no activity; } 5=\text { high activity) }\end{array}$ & Mean & $\begin{array}{c}\text { Standard } \\
\text { Deviation }\end{array}$ & $\begin{array}{c}\text { Item-Total } \\
\text { Correlation }\end{array}$ \\
\hline Attracting foreign direct investment & 1.472 & 0.8384 & 0.6932 \\
$\begin{array}{l}\text { Promoting exports of local products } \\
\text { Investing with international capital }\end{array}$ & 1.464 & 0.8284 & 0.5615 \\
markets & 1.392 & 0.7502 & 0.3554 \\
$\begin{array}{l}\text { Attracting foreign tourists } \\
\text { Conducting trade missions } \\
\text { abroad/overseas }\end{array}$ & 2.080 & 1.2801 & 0.5765 \\
$\begin{array}{l}\text { Exchanging ideas about city government } \\
\text { and management with foreign cities }\end{array}$ & 2.080 & 1.1887 & 0.5691 \\
$\begin{array}{l}\text { Working with the private sector to } \\
\text { improve your position in the global }\end{array}$ & 2.144 & 1.2228 & 0.7865 \\
$\begin{array}{l}\text { economy } \\
\text { Working with neighboring cities to } \\
\text { improve your position in the global } \\
\text { economy }\end{array}$ & 2.008 & 1.1465 & 0.7480 \\
$\begin{array}{l}\text { Working with state officials to improve } \\
\text { your position in the global economy }\end{array}$ & & & \\
& 2.120 & 1.2155 & 0.7026 \\
$\begin{array}{l}\text { N=125 } \\
\text { Cronbach's Alpha = 0.8787 }\end{array}$ & & & \\
\hline
\end{tabular}

Table 10 illustrates that the items used in the scale developed to measure managers' perceptions of the global economy's impact on aspects of municipal management are strongly correlated with each other. Each itemtotal correlation is greater than 0.5. A Cronbach's alpha of 0.8983 demonstrates that the items used in Question 4 of the survey are very 
reliable for measuring managers' assessment of globalization's impact on aspects of municipal management.

Table 9. Descriptive statistics for scale measuring perceptions of global economy's impact on aspects of municipalities' economy

\begin{tabular}{lccc}
\hline $\begin{array}{l}\text { Question 2 items } \\
\text { (1= low impact; 5 = high impact) }\end{array}$ & Mean & $\begin{array}{c}\text { Standard } \\
\text { Deviation }\end{array}$ & $\begin{array}{c}\text { Item-Total } \\
\text { Correlation }\end{array}$ \\
\hline City's unreserved fund balance & 1.5085 & 0.8448 & 0.5312 \\
City's economic competitiveness & 2.1695 & 1.1040 & 0.5859 \\
City residents' income distribution & 2.2458 & 1.1242 & 0.7367 \\
Economic status of the poor & 2.0085 & 1.1285 & 0.7027 \\
City residents' job security & 2.2797 & 1.1464 & 0.7080 \\
& & & \\
N=118 & & & \\
Cronbach's Alpha $=0.8440$ & & & \\
\hline
\end{tabular}

Table 11 demonstrates that the items in the survey used for measuring managers' views concerning globalization's impact on aspects of decisionmaking are reliable. Each item-total correlation exceeds 0.5 and the Cronbach's alpha coefficient reported is 0.8921 . Question 5 has good internal consistency.

Table 10. Descriptive statistics for scale measuring managers' assessment of globalization's impact on aspects of municipalities' management

\begin{tabular}{lccc}
\hline $\begin{array}{l}\text { Question 4 items } \\
(1=\text { low impact; } 5=\text { high impact })\end{array}$ & Mean & $\begin{array}{c}\text { Standard } \\
\text { Deviation }\end{array}$ & $\begin{array}{c}\text { Item-Total } \\
\text { Correlation }\end{array}$ \\
\hline Stability of revenue streams & 1.9912 & 1.1140 & 0.6541 \\
Residents' sense of neighborhood & 1.8850 & 1.2008 & 0.7794 \\
Provision of affordable housing & 1.8584 & 1.1249 & 0.7735 \\
Procurement and purchasing practices & 1.9204 & 1.0619 & 0.7925 \\
Variety of services delivered to specific & 2.0973 & 1.1799 & 0.7490 \\
demographics & & & \\
& & & \\
Cronbach's Alpha $=0.8983$ & & & \\
\hline
\end{tabular}


Table 11. Descriptive statistics for scale measuring perceptions of globalizations impact on aspects of managerial decision-making

\begin{tabular}{lccc}
\hline $\begin{array}{l}\text { Question } 5 \text { items } \\
(1=\text { no change; } 5=\text { more complicated })\end{array}$ & Mean & $\begin{array}{c}\text { Standard } \\
\text { Deviation }\end{array}$ & $\begin{array}{c}\text { Item-Total } \\
\text { Correlation }\end{array}$ \\
\hline $\begin{array}{l}\text { Assessing the technical and "people" } \\
\text { skills of prospective hires }\end{array}$ & 2.0348 & 1.1311 & 0.6391 \\
$\begin{array}{l}\text { Deploying economic development } \\
\text { incentives }\end{array}$ & 2.0261 & 1.1582 & 0.6921 \\
$\begin{array}{l}\text { Branding your community's image } \\
\text { Setting operating budget priorities }\end{array}$ & 2.3304 & 1.3026 & 0.6797 \\
Making capital budget decisions & 1.9043 & 1.0427 & 0.7962 \\
Benchmarking with other municipalities & 1.9304 & 1.0913 & 0.8087 \\
& & & 0.6828 \\
N = 115 & & & \\
Cronbach's Alpha $=0.8921$ & & & \\
\hline
\end{tabular}

The high reliabilities shown in Tables 8 through 11 suggest that respondents answered the questions similarly and the survey consistently measures the constructs it was designed to measure. It is safe to assume that the instrument mitigates against response bias among respondents.

i Endnote: Through stages of extraction and rotation, the principal component method of factor analysis enables the identification of components that make up the construct being measured. Extraction specifies the number of components that the construct may be reduced to by retaining those components whose eigenvalues are greater than one. These components or factors explain a certain percentage of the variance in the data and correlate with the original variables. Rotation makes "the pattern of correlations between variables and factors more interpretable" (Warner 2008, p. 771). 
The tables showing the extractions in this study are located in the Appendix. A rotated matrix of the correlations, obtained through varimax rotation, demonstrate the groups into which the variables may be combined. The number of groups is determined by the number of factors and variables that correlate highly with the factors (correlations greater than or equal to 0.5 ) are placed together.

The results of each principal component analysis are presented in two parts. The first part gives the results of the Bartlett's and the Kaiser-MeyerOlkin (KMO) Tests. These tests verify that factor analysis is appropriate for the indicators selected. The second set of results entail the rotated correlations of the indicators in terms of their extracted components. The correlations are presented in a correlation matrix that facilitates interpretation of the results of the analysis. 


\section{CHAPTER V. MANAGERS' PERCEPTIONS OF GLOBALIZATION}

Garnering public managers' perceptions of globalization is fundamental to this study. As explained earlier, globalization and public management are theoretical and social constructs that are not directly observable. Public managers' ability to articulate their perceptions of these constructs indicates that they are knowledgeable about the basic concepts of the research and satisfies the constructionist approach that is appropriate for understanding these phenomena.

Both the interview and the survey phases of the research directly solicit public managers' perceptions of globalization. Throughout the survey, globalization and its impacts are operationalized using several indicators and the interview transcripts and open-ended survey questions are analyzed in tandem with the quantitative data. This study therefore applies the quantitative technique of factor analysis techniques as well as textual analysis of interviews to clarify the concept of globalization as perceived by public managers in small-medium cities in Florida. This chapter presents the results of the qualitative and quantitative analyses.

\section{Qualitative Analysis}

Four themes emerged from the qualitative analysis to provide a composite description of public managers' perceptions of globalization. The themes emerge out of a grounded theory approach to analyzing the interview 
texts. Fictitious names are used to honor the confidentiality with which the data were collected. The themes are expanded in the subsequent sections.

Theme 1: Globalization is multifaceted

From the qualitative data collected, it is clear that public managers perceive globalization as a multifaceted phenomenon. When asked in the interviews what the word globalization means to them, public managers responded with responses similar to Paul's. Paul is a public manager in the city of Clearwater located in the Tampa metropolitan area on the west coast of Florida. According to the 2000 U.S. census, Clearwater has a population of 108,787 of which $16.6 \%$ are foreign-born. Clearwater is the third largest principal city in the Tampa metropolitan area. At the time of the interview, Paul had been in his position for eight years. Prior to that, Paul served two years as a public manager in another department and over 20 years in the military.

Paul's perception of globalization captures the multifaceted dimension articulated by other public managers interviewed. Paul explains:

"what comes to mind is that a very strong connection between what we're doing in this space to what others are doing all over the world; that there is a stronger connection with the global community, the global village if you will, and that connection is expressed in a variety of ways, in our language, in our normal day to day living whether it is purchasing of goods, whether it's how we spend our leisure time, whether it's our connection with the internet in how we contract business, pleasure, education, ah, and on a cultural basis; there's just a lot of international interaction that's occurring between groups from all over the world coming into your community.... So when I think globalization, I just think of the myriad of ways that this 
community and its individuals is connected to the global community."

Paul's insight into globalization is particularly interesting as he describes globalization in terms of the local. Paul's acknowledgement resonates with Czarniawska's (2000) conceptualization of the global-local juxtaposition. Other public managers identify the multifaceted characteristic of globalization as follows:

"the myriad of ways that this community and its individuals is connected to the global community" (Clearwater, Tampa MSA)

"To me as a police man, what comes to mind is we deal with international internet crime, we deal with international trafficking of human people, we deal with money laundering across countries, so..." (Temple Terrace, Tampa MSA)

"I think it's some influence or impact from another country and there's a lot of components to it... probably a big factor is the actual movement of people" (Oldsmar, Tampa MSA)

"from my perspective, it's more commercial as in trade. It strikes me more as that. We deal with China on a lot if issues, on imports and when I think of that, that's the first thing that comes to my mind. Not necessarily government... when you say globalization I think more of commercial economics than I do politics." (Longwood, Orlando MSA)

The responses indicate that, despite their locations in various small-medium cities, public managers across the State of Florida are cognizant of the concept of globalization and are able to articulate their understanding of globalization in terms of its various dimensions. The facets of globalization are identified by the managers as interconnected human, economic and information dealings. This observation is consistent with the literature on 
globalization which describes globalization as "a multidimensional phenomenon involving diverse domains of activity and interaction, including the economic, political, technological, military, legal, cultural, and environmental" (Held 1998, p. 13 ). Marcuse and van Kempen (2000) describe globalization as "a combination of new technology, increased trade and mobility, increased concentration of economic control, and reduced welfare-oriented regulatory action of nation states" (p.5). From Sweetwater, a city located in the South Florida county of Miami-Dade, with a population of over 14,200 of which more than $93 \%$ are of Hispanic origin, a public manager states:

"Globalization, when defined in terms of migration, has made our City a thriving, multiethnic community. Migration from various nations has brought a taste of practically every Latin American nation into this City through restaurants, money transfer services and clothing. This, in turn, has enriched our community culturally, created employment and fostered economic activity".

The Sweetwater manager understands the globalization process as one of social, cultural and economic dimensions that has been beneficial for his municipality, especially because of immigration. From Temple Terrace in the Tampa MSA, another manager acknowledges globalization as:

"linking all types of things together in the world, whether it's transportation, economics, manufacturing, agriculture"

Theme 2: Globalization is dynamic

Public managers' references to "flow", "movement" and "exchange" in articulating their perceptions of globalization project a notion of globalization 
as being dynamic. Perhaps the best explanation of the dynamic quality of globalization given by a public manager in the study is that of Gill. Gill is the chief of police for a city in the Miami metropolitan area. He was a police major for twelve years prior to his current position which he has been in for four years. Gill's city has a population of over 42,000 and is home to several consulates and corporate headquarters. More than one-third of this city's population is foreign-born. Gill explained his understanding of globalization this way:

"For me, it's international exchange - the exchange of people, the exchange of goods and services, people traveling, goods back and forth..."

Similarly, public managers in Clearwater describe globalization as:

"free flow of information around the world...tied economies and movement of people"

"there's just a lot of international interaction that's occurring between groups from all over the world coming into our community"

Held and McGrew (2000) submit that "globalization denotes the expanding scale, growing magnitude, speeding up and deepening impact of interregional flows and patterns of social interaction" (p. 4). Others like Harvey (1993) and Scholte (2005) refer to globalization's transforming effect on time and space. This dynamic attribute of globalization consequently results in a perceived heightened level of social, economic, political and technological connectivity with the global community. The interviews disclose that managers understand globalization as having at once a 
compressing and expanding effect on human and physical interactions. The following perceptions as stated in the interviews demonstrate public managers' understanding of the dynamism of globalization:

"The world's getting smaller...we're more connected now." (Oviedo, Orlando MSA)

"Bringing everybody in the world closer together" (Temple Terrace, Tampa MSA)

"The world's a much bigger place now" (Winter Garden, Orlando MSA)

"Globalization to me is just the whole world getting smaller, information passing much more quickly and freely around in different ways" (Temple Terrace, Tampa MSA)

"Just the overall shrinking of the world and that we're all more connected now" (Winter Garden, Orlando MSA)

It is interesting to note that one respondent considers the world to be a "bigger place now" in contrast with the more common view of the world becoming smaller. The study recognizes this notice as the manager perceiving globalization as enlarging, having a widening effect and hence opening up possibilities beyond local reaches.

For the most part, however, the quotes reflect the perception of globalization as the agent of compressing time and space and therefore intensifying social interactions in spite of distance. These perceptions echo Keohane and Nye's (2000) conceptualization of globalization as "the shrinkage of distance but on a large scale" (p. 2). Public managers in 
Florida's small-medium cities are clearly aware of the thickening of social, economic and cultural interactions across the globe.

Theme 3: Globalization is engaging

The public managers in this study recognize globalization as synonymous with constantly changing interactions among people, places and things in different parts of the world. Study participants also concede that globalization may be characterized as engaging, as it offers prospects for cultural and information exchange, improved public management and connection to the global economy. Larry, a public manager in Lake Wales, aptly sums up globalization as engaging like this:

"Globalization is both positive and negative. The positive is the opening of the community to new ideas, products, markets with diversification of the economic, social and cultural base.... A negative to being intertwined in a global community is the current financial crisis we are experiencing. This impact is beyond words but it does demonstrate that greed is universal and that all government programming and planning must look to the local economy for what is best and not reach too far where there are no controls and we see that today."

Lake Wales is one of the smallest cities in this study. It is located in the central Florida MSA of Lakeland-Winter Haven and has a population of 10,194 according to the 2000 U.S. Census. Lake Wales has historically been a citrus farming-economy but the city has expanded its industry base to include retail, light manufacturing and construction in recent times. ${ }^{24}$ Larry acknowledges that globalization fosters diversity of thought and business

${ }^{24}$ City of Lake Wales, Economic Development Department, http://www.cityoflakewales.com/edd/ Retrieved October 1, 2009 
within a community but that it may also cause considerable harm locally. Whereas Larry sees globalization as causing some good, the public manager cautions public management against going 'too global'.

Other managers share Larry's view that globalization increases the availability of information, goods and services. The following quotes depict perceptions of globalization as an engaging force:

"It is an expansion of the marketplace that benefits a community positively when there are corresponding impacts... Globalization can cause certain evolutions in a community, but that would occur regardless - less the community stagnates. I see no problems that are not out of the ordinary." (Pompano Beach, Fort Lauderdale Metro Division)

"Information exchange and adapting ideas and concepts is one of the strengths of globalization." (Port Orange, Daytona Beach MSA)

"Money; both money as an opportunity and money as a liability; meaning globalization gives a lot of opportunity to access more capital and make more money. It also has a danger of costing money to various organizations that it impacts - whether its through loss of markets or increased regulation. But it revolves, to me, around money." (Miami Beach, Miami Metro Division)

The study demonstrates that public managers in Florida's small-medium cities are reckoning with the growing significance of cross-continental networks. One manager articulated the engaging nature of globalization in terms of its potential to improve efficiency in public management:

"It presents huge challenges. Now, probably from those challenges maybe will come some productivity factor that allows us to do more with less... we are reacting. We're not creating globalization. I don't think we're slowing it down or speeding it up but we're definitely impacted by it and I think it does 
represent some opportunities, challenges and opportunities to be more efficient." (Winter Springs, Orlando MSA)

Public managers' recognition of the advantages and disadvantages of globalization also characterizes the engaging characteristic of globalization. The qualitative responses bring out the fact that the engaging characteristic of globalization raises the issue of equity against the backdrop of public management. This acknowledgement by Florida's public managers coincides with extant literature that discusses the competing values of globalization which potentially challenges public management practice. The following responses communicate managers' understanding of the dispute:

"Globalization is positive as long as the playing field is level...i.e., wages, benefits, operating expenses... and regulatory equalization could be a level also. There are no negatives as we all inhabit this small planet and working together is the only way that the planet will thrive."(Palm Bay, Melbourne MSA)

"Positives: Culture diversity, More business, higher living standard, more opportunity for learning and teaching others, growth... Negatives: Crime, More People, More cars, burden on infrastructure, growth.” (Port Orange, Daytona Beach MSA)

"International trade can increase jobs and can increase a business' revenues through imports, exports and providing services to other countries. If jobs are outsourced to other countries, the U.S. economy can be negatively impacted." (Hollywood, Fort Lauderdale Metro Division)

Further, public managers commented that the engaging nature of globalization implies economic and cultural benefits but also generates expensive environmental impacts:

"Positive in that it brings a great deal of economic opportunity to the community through trade. It brings companies wishing to be 
located at a gateway to the Caribbean and Latin America. Diversity brings a richer cultural experience to visitors and residents and helps distinguish community from others. Negatives include that other trade partners may be able to offer the same service overseas. The more commodities have to travel to and from destination, the greater the carbon foot print and the more susceptible to price increases due to the price of oil or weaker dollar." (Miramar, Fort Lauderdale Metro Division)

"Purchased products may be less expensive but global warming because of industrialization of third world nations without proper environmental controls has raised energy cost and changed some priorities.” (St. Cloud, Orlando MSA)

Theme 4: Globalization is historical

The responses from the interviews expose public managers' awareness of globalization as a deepening of interrelations between countries over time. Hebron and Stack (2008) describe globalization as a multilayered process that is "driven by the diffusion of science, knowledge, and technological applications and innovations over time" (p. 2). The temporality of globalization is consistently noted among managers in the study as they discuss their perceptions in terms of current events.

Police Chief Gill, quoted earlier, expressed a perspective of the chronological characteristic of globalization:

"types of things in one country may now be done in another country because of globalization where it was foreign to that country before."

Another manager in Oviedo had this to say:

"Whereas things used to occur locally, possibly regionally, where your influence may have been local or regional, now, today, you can have influence worldwide." 
Oviedo is located in the Orlando-Kissimmee MSA and has a population of 26,316 of which $8.2 \%$ are foreign-born. Oviedo's economy is based largely on service industries like banking, education and retail. A major agricultural planter and marketing company is also headquartered in Oviedo. At the time of the interview, the Oviedo manager reported that he had 20 years experience in local government in various administrative positions.

While globalizing activities are not new, managers acknowledge that they occur in contemporary times at unprecedented rates and intensities owing to current technology. The following quotes exemplify this opinion:

"with technology going to a level that surpasses the average, everyday citizen...comprehension almost compounds daily. It is passing us, going so quickly and a lot of things are being more stepped up."(Lake Mary, Orlando MSA)

"communication between all of the countries given technology is just a lot quicker and faster" (Clearwater, Tampa MSA)

"Globalization has stepped up the pace of change. Change used to be very slow so the way you... the method of how you did something over the years, you did that for a long, long time and then change was gradual. Now change can be almost overnight so it require us to be much more forward thinking than ever, ever before."(Coral Gables, Miami Metro Division)

Additionally, the interviews reveal that managers' consistently compared the past with the present, associating globalization with how processes and events have changed over time. A police chief in the Tampa/St. Petersburg metropolitan area, responsible for a municipality with a population of 23,000 commented: 
"Well, there have been a lot of changes over the last 7 or 8 years. Some of the biggest changes... most of them are related to 9/11. Some of them are related to just the growing internet, the ability to change monies and currencies through banks electronically and stuff like that."

The police chief's response indicates his perception of globalization in terms of its effect on commercial activity and the use of the Internet to execute it. The association of globalization processes with the post-9/11 era is supported by analysts and observers who theorize that " $9 / 11$ marked a fundamental rupture in the patterns and flow of world events - a veritable paradigm shift in how people and states think about and exist in the world" (Croucher 2004, p. 2).

To summarize, the analysis of the interview transcripts demonstrates that the ideas of public managers in Florida's small-medium cities do not vary significantly from the conceptual definitions of globalization rendered at the beginning of the study. Public managers have articulated their understanding of the concept of globalization in terms that convey the fundamental characterization found in extant literature.

\section{Quantitative Analysis}

Question three of the survey asked participants to indicate their perceptions of three commonly-held views of globalization in the context of their municipality. The response options were "no effect," "very negative," 
"negative," "positive," and "very positive." Table 12 shows the frequency distribution of the responses.

Table 12. Question 3 - Public managers' perceptions of common globalization repercussions $(\mathrm{N}=122)$

\begin{tabular}{|l|cc|cc|cc|cc|cc|}
\hline \multirow{2}{*}{ Repercussion } & \multicolumn{2}{|c|}{$\begin{array}{c}\text { Very } \\
\text { Negative }\end{array}$} & \multicolumn{2}{|c|}{ Negative } & \multicolumn{2}{|c|}{ Positive } & \multicolumn{2}{|c|}{$\begin{array}{c}\text { Very } \\
\text { Positive }\end{array}$} & \multicolumn{2}{|c|}{ No effect } \\
\cline { 2 - 12 } & $\mathrm{n}$ & $\%$ & $\mathrm{n}$ & $\%$ & $\mathrm{n}$ & $\%$ & $\mathrm{n}$ & $\%$ & $\mathrm{n}$ & $\%$ \\
\hline $\begin{array}{l}\text { A more } \\
\text { competitive global } \\
\text { economy }\end{array}$ & 3 & 2.5 & 14 & 11.5 & 63 & 50.0 & 18 & 14.3 & 24 & 19.0 \\
\hline $\begin{array}{l}\text { Entrepreneurship } \\
\text { among } \\
\text { immigrants }\end{array}$ & 2 & 1.6 & 6 & 4.9 & 66 & 54.1 & 27 & 22.1 & 21 & 17.2 \\
\hline $\begin{array}{l}\text { Local } \\
\text { establishment of } \\
\text { multinational } \\
\text { corporations }\end{array}$ & 1 & 0.8 & 3 & 2.4 & 50 & 41.0 & 36 & 28.6 & 32 & 26.2 \\
\hline
\end{tabular}

Figure 3 shows that a cumulative $64.3 \%$ of respondents $(\mathrm{N}=122)$ perceive a more competitive global economy as having positive repercussions for their municipality. Figure 4 exhibits that a total of $76.2 \%$ of respondents $(\mathrm{N}=122)$ perceive entrepreneurship among immigrants as a positive repercussion of globalization in their municipality. 


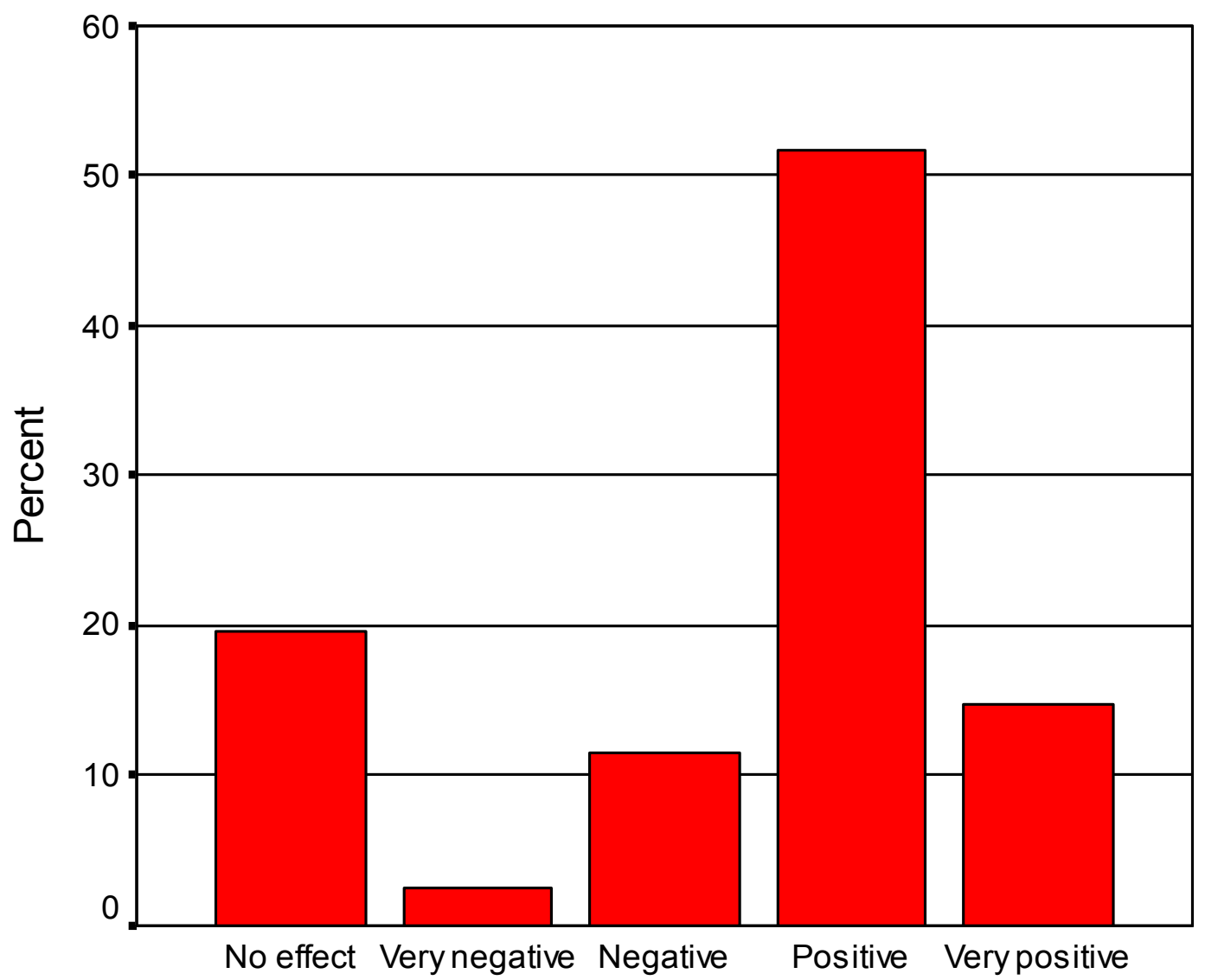

Figure 3. Bar chart showing perceptions of a more competitive global economy.

Figure 5 graphically represents the distribution of responses for managers' perceptions of the local establishment of multinational corporations as a repercussion of globalization. Almost $70 \%(69.6 \%)$ of respondents $(\mathrm{N}=122)$ cumulatively indicate that they perceive local establishment of multinational corporations in their municipality as a positive repercussion of globalization. 


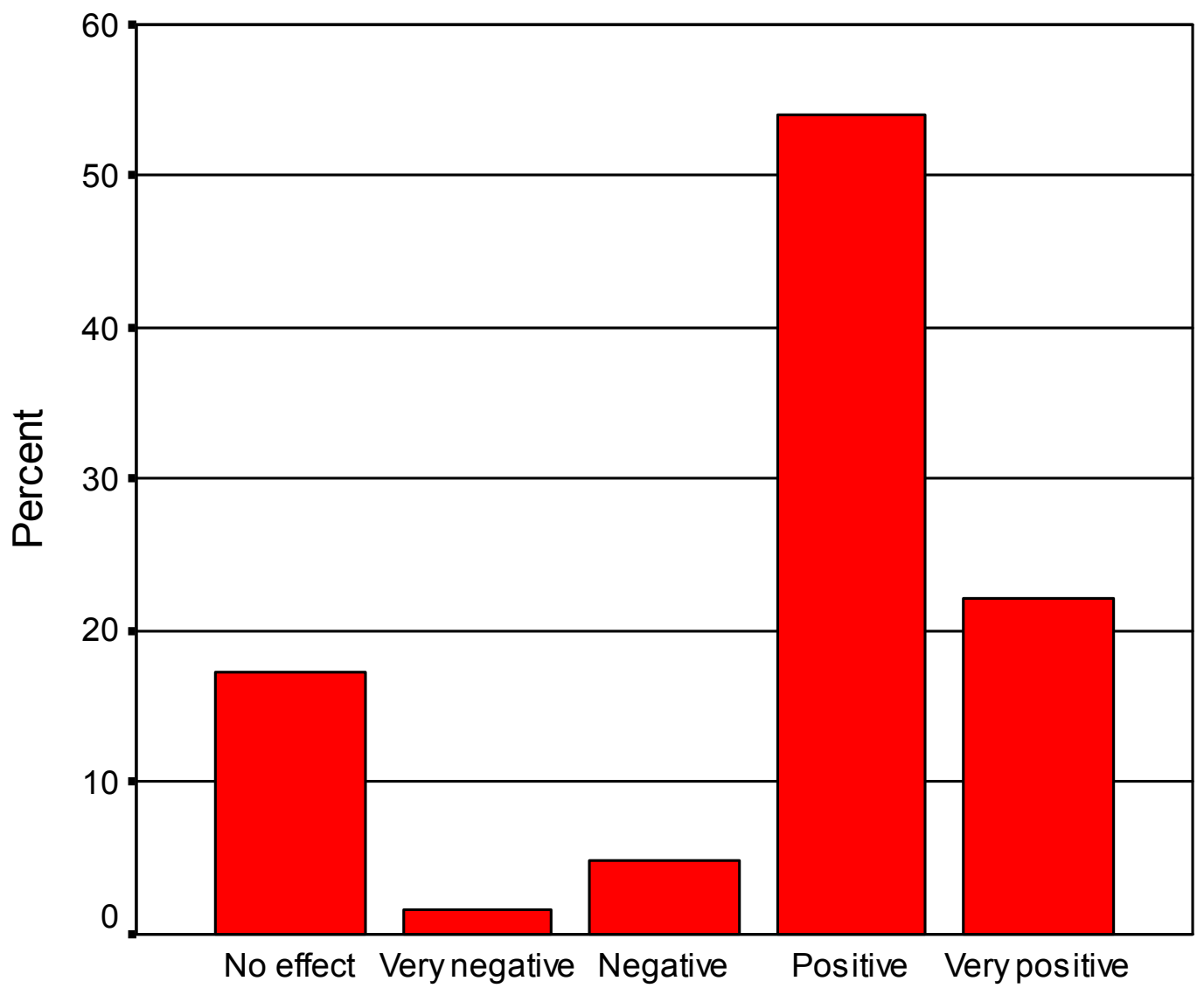

Figure 4. Bar chart showing perceptions of entrepreneurship among immigrants.

These findings infer that, in general, survey respondents have positive impressions about common economic repercussions of globalization. 


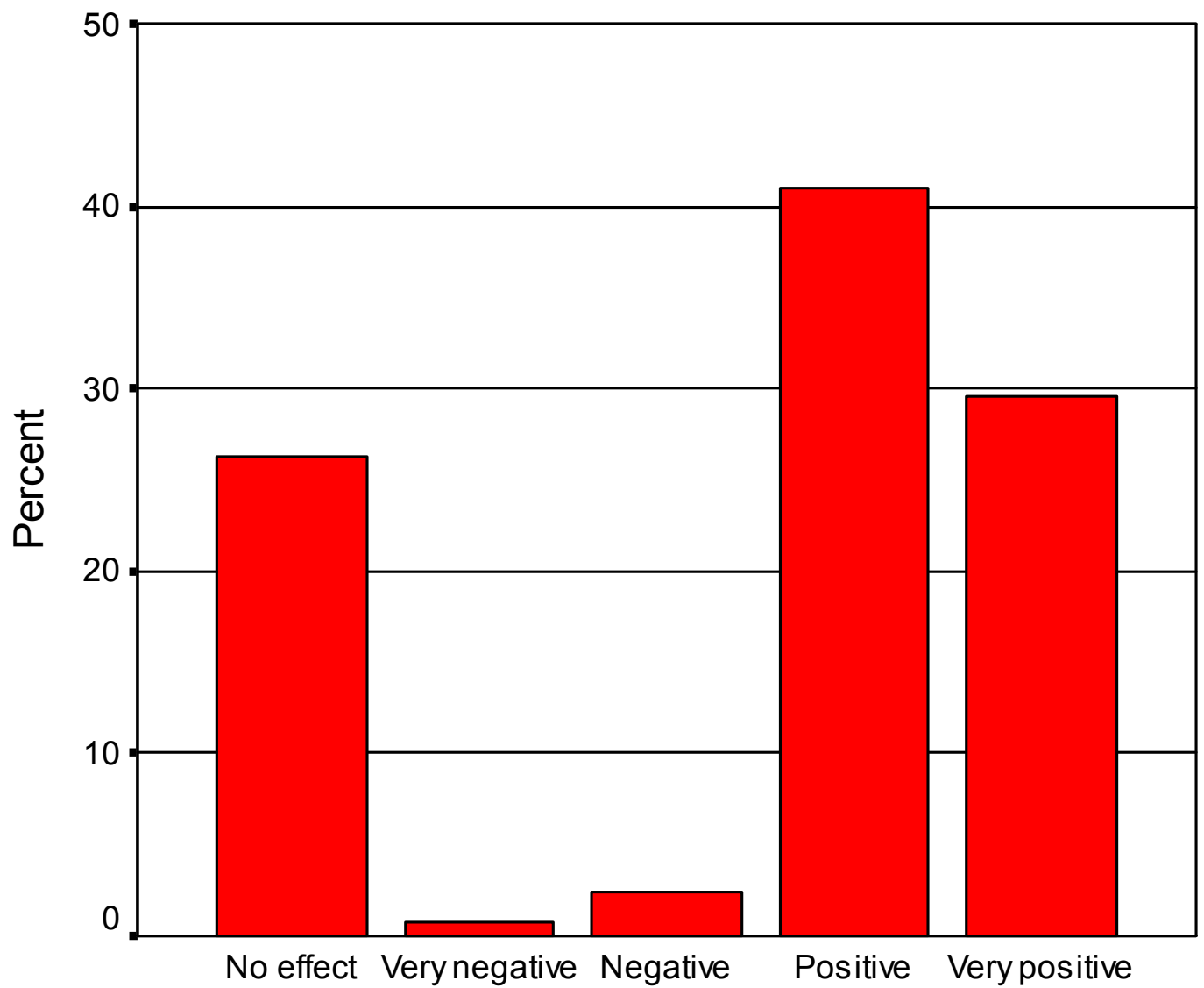

Figure 5. Bar chart showing perceptions of local establishment of multinational corporations.

Question six of the survey asked participants to indicate their perceptions on the basis of five statements that capture ideas commonly associated with globalization. The response options were "no opinion," "strongly disagree," "disagree," "agree," and "strongly agree." Table 17 shows the frequency distribution of the responses and Figure 6 graphically displays the responses among public managers. The results show that whereas $47.4 \%$ of respondents disagree that globalization raises wages in their municipalities, $44.8 \%$ agree that globalization increases job opportunities in 
their municipalities. These results point to a perceived predicament often associated with globalization: the creation of jobs coupled with resultant low wages. The survey responses imply that public managers in Florida's smallmedium cities are cognizant of this dilemma.

Further, for as many respondents who agree that globalization improves quality of life standards (36.2\%), there are as many who have no opinion on the same matter. This is an interesting divide in the perceptions among public managers and may speak to an ambivalence among the professionals in response to globalization. 
Table 13. Public managers' responses to common perceptions of globalization

\begin{tabular}{|c|c|c|c|c|c|c|c|c|c|c|}
\hline \multirow{2}{*}{ Repercussion } & \multicolumn{2}{|c|}{$\begin{array}{l}\text { Strongly } \\
\text { Disagree }\end{array}$} & \multicolumn{2}{|c|}{ Disagree } & \multicolumn{2}{|c|}{ Agree } & \multicolumn{2}{|c|}{$\begin{array}{l}\text { Strongly } \\
\text { Agree }\end{array}$} & \multicolumn{2}{|c|}{ No Opinion } \\
\hline & $\mathrm{n}$ & $\%$ & $\mathrm{n}$ & $\%$ & $\mathrm{n}$ & $\%$ & $\mathrm{n}$ & $\%$ & $\mathrm{n}$ & $\%$ \\
\hline $\begin{array}{l}\text { Access to and participation in the } \\
\text { global economy lowers operating costs } \\
\text { for my municipality }\end{array}$ & 6 & 5.2 & 32 & 27.6 & 34 & 29.3 & 4 & 3.4 & 40 & 34.5 \\
\hline $\begin{array}{l}\text { Increased racial/ethnic diversity in my } \\
\text { municipality complicates } \\
\text { policymaking }\end{array}$ & 14 & 12.1 & 45 & 38.8 & 37 & 31.9 & 6 & 5.2 & 14 & 12.1 \\
\hline $\begin{array}{l}\text { Globalization raises wages in my } \\
\text { municipality }\end{array}$ & 7 & 6.0 & 55 & 47.4 & 21 & 18.1 & 2 & 1.7 & 31 & 26.7 \\
\hline $\begin{array}{l}\text { Globalization increases job } \\
\text { opportunities in my municipality }\end{array}$ & 7 & 6.0 & 31 & 26.7 & 52 & 44.8 & 7 & 6.0 & 19 & 16.4 \\
\hline $\begin{array}{l}\text { Globalization improves quality of life } \\
\text { standards in my municipality } \\
\mathrm{N}=116\end{array}$ & 4 & 3.2 & 22 & 19.0 & 42 & 36.2 & 6 & 5.2 & 42 & 36.2 \\
\hline
\end{tabular}




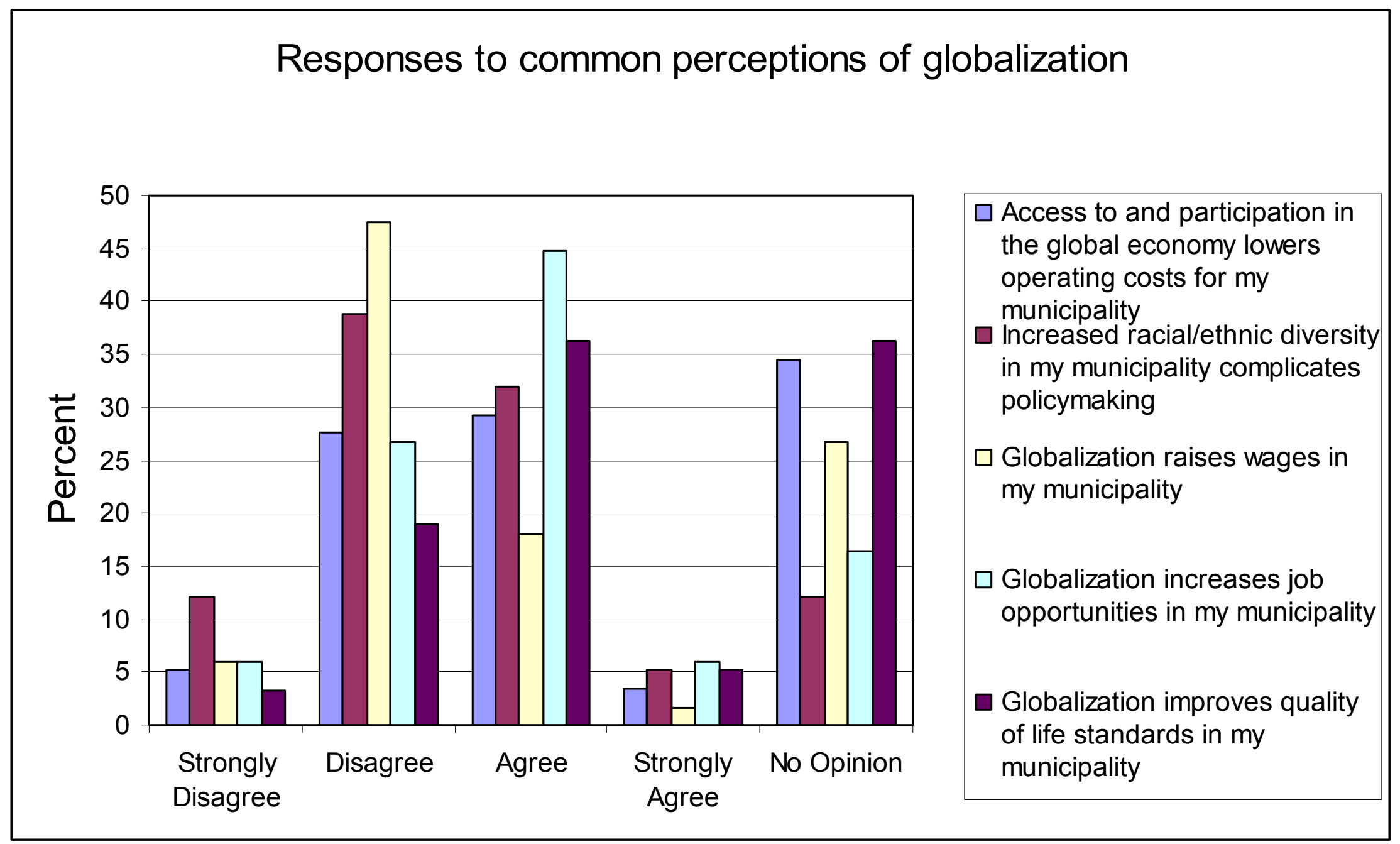

Figure 6. Bar chart showing public managers' responses to common perceptions of globalization. 


\section{Factor Analysis}

Questions three and six of the survey present common repercussions and perceptions of globalization distilled from the literature. Table 14 shows the results of the Bartlett's Test and the KMO measure of sample adequacy for these questions. The method was found to be suitable giving an adequate KMO measure of sample adequacy of 0.745 and Bartlett's test of sphericity as significant at $<0.001$ level. These results ascertain that it is logical to proceed with extraction using the principal component analysis method at this juncture of the analysis. The extraction produces two factors that have eigenvalues greater than 1 . These factors explain $57.5 \%$ of the original variation in the data. Cumulative variances for the two factors are given on Table A1 in the Appendix.

Table 14. KMO and Bartlett's Test for questions 3 and 6

\begin{tabular}{|ll|r|}
\hline Kaiser-Meyer-Olkin Measure of Sampling Adequacy. & .745 \\
& & 266.661 \\
Bartlett's Test of Sphericity $\quad$ Approx. Chi-Square & 28 \\
& df & $<0.001$ \\
\hline
\end{tabular}

Correlations (factor loadings) between the question items and the extracted factors are calculated, rotated via varimax rotation and presented in the component matrix on Table 15. The rotation is done to make the results of the factor analysis more easily understood. Variables 1 to 3 have high loadings on factor 2 whereas variables 4 to 8 have are associated strongly 
with factor one. Based on the rotated component matrix, this study concludes that public managers' perceptions of globalization may be reduced to two factors.

It may be deduced that these factors categorize the managers' perception of globalization as a process of socio-economic actions and effects. In other words, the study reveals that globalization in municipalities is perceived by public managers in terms of globalization's actions and effects upon the socio-economic and cultural elements of a municipality.

Table 15. Rotated Component Matrix for questions 3 and 6

\begin{tabular}{|l|c|c|}
\hline \multirow{2}{*}{ Question responses } & \multicolumn{2}{|c|}{ Component } \\
\cline { 2 - 3 } 1- More competitive global economy & 1 & 2 \\
2- Entrepreneurship among immigrants & 0.160 & $\mathbf{0 . 8 3 5}$ \\
3- Local establishment of multinational corporations & 0.106 & $\mathbf{0 . 8 3 0}$ \\
4- Access \& participation in global economy lowers operating & 0.203 & $\mathbf{0 . 7 8 7}$ \\
costs for my municipality & $\mathbf{0 . 6 2 5}$ & 0.059 \\
5- Increased racial/ethnic diversity in my municipality & $\mathbf{0 . 4 7 2}$ & 0.060 \\
complicates policymaking & $\mathbf{0 . 7 5 2}$ & 0.186 \\
6- Glob raises wages in my municipality & $\mathbf{0 . 7 0 6}$ & 0.276 \\
7- Glob increases job opportunities in my municipality & $\mathbf{0 . 8 3 6}$ & 0.154 \\
8- Glob improves quality of life standards in my & & \\
municipality & &
\end{tabular}

The study proposes that the perceptions described in variables 4 to 8 of Table 15 comprise globalization's actions and the perceptions laid out in variables 1 to 3 make up globalization's effects. Examined more closely, the actions depict public managers' perceptions at a "macro" (big picture) level 
and the effects are understood as public managers' perceptions at a "micro" (detailed) level. The correlation results validate the construction of the questionnaire in that items that were originally placed together in questions three and six show strong relationships, thereby maintaining their related positions even after factor loadings are rotated.

\section{Concluding remarks}

The qualitative analysis exposes public managers' perceptions of globalization as a phenomenon having four primary characteristics. These characteristics are: multi-faceted, historical, dynamic, and engaging. Public managers consistently refer to the rapidity of movement by people, information, goods, and money among countries of the world. Transcripts also reveal public managers' acknowledgement of the noticeable difference in the nature of events taking place now as opposed to in the past, as a result of globalization.

Although public managers reported overall positive impressions with regards to globalization's commonly-held repercussions, on average, the survey responses reveal that public managers seem to be split in their opinions about globalization's impact on job creation and wages in their municipalities. In addition, as many public managers believe that globalization improves quality of life standards in their municipalities as those who have no opinion on said matter. 
In sum, public managers generally perceive globalization in terms of its actions and effects on a municipality's socioeconomic environment. These perceptions may be referred to as macro-level perceptions and micro-level perceptions. Findings in this chapter suggest that public managers' microlevel perceptions of globalization are actions such as lowering operating costs, complicating policy-making, raising wages, increasing job opportunities, and improving quality of life standards. These actions capture the perceived historical and engaging qualities of globalization. The public managers' macro-level perceptions of globalization are its effects, which are viewed as a more competitive global economy, entrepreneurship among immigrants and local establishment of multinational corporations. The effects reflect globalization's multi-faceted and dynamic properties as perceived by public managers in Florida's small-medium cities. Figure 7 demonstrates the synthesis of the managers' perceptions of globalization according to the results discussed in this chapter. 


\section{PERCEPTIONS OF GLOBALIZATION}

\section{Macro/Effects}

- Multi-faceted

- Dynamic

\section{Micro/Actions}

- Historical

- Engaging

Figure 7. Managers' perceptions of globalization 


\section{CHAPTER VI. MANAGERS' PERCEPTIONS OF MUNICIPALITIES' GLOBAL ACTIVITY}

\section{Descriptive statistics}

Question one of the survey aims at discovering the levels of global activity at which municipalities are engaged. Public managers in Florida's small-medium cities most often express that their cities are not actively involved globally. According to the data, attracting foreign tourists is the global activity that is most pursued by small-medium cities in Florida. Table 16 shows the descriptive statistics for each item in Question one.

Table 16. City's global activity on a scale of $1-5 ;(1=$ No activity, $5=$ High activity)

\begin{tabular}{|l|c|c|c|}
\hline Activity & Mode & Mean & $\begin{array}{c}\text { Std. } \\
\text { Deviation }\end{array}$ \\
\hline Attracting foreign direct investment & 1 & 1.47 & 0.84 \\
\hline Promoting exports of local products & 1 & 1.46 & 0.83 \\
\hline $\begin{array}{l}\text { Investing with international capital } \\
\text { markets }\end{array}$ & 1 & 1.39 & 0.75 \\
\hline Attracting foreign tourists & 1 & 2.07 & 1.28 \\
\hline $\begin{array}{l}\text { Conducting trade missions } \\
\text { abroad/overseas }\end{array}$ & 1 & 1.33 & 0.79 \\
\hline $\begin{array}{l}\text { Exchanging ideas about city } \\
\text { government and management with } \\
\text { foreign cities }\end{array}$ & 1 & 2.07 & 1.19 \\
\hline $\begin{array}{l}\text { Working with the private sector to } \\
\text { improve your position in the global } \\
\text { economy }\end{array}$ & 1 & 2.13 & 1.22 \\
\hline $\begin{array}{l}\text { Working with neighboring cities to } \\
\text { improve your position in the global } \\
\text { economy }\end{array}$ & 1 & 2.02 & 1.15 \\
\hline $\begin{array}{l}\text { Working with state officials to improve } \\
\text { your position in the global economy }\end{array}$ & 1 & 2.12 & 1.22 \\
\hline
\end{tabular}


According to Table 16, public managers inform that Florida's smallmedium municipalities have very little to no global activity in terms of trade, information exchange and international investment. The most common response to this question for all options was "no activity".

Question two asked participants to indicate their perception of the global economy's impact on certain municipal socio-economic characteristics, on a scale of 1 to 5 ( $1=$ low impact, $5=$ high impact $)$. Table 17 shows the descriptive statistics of these perceptions.

Table 17. Manager's perceptions of global economy's impact on aspects of city's socioeconomic conditions on a scale of $1-5 ;(1=$ low impact, $5=$ high impact

\begin{tabular}{|l|c|c|c|}
\hline & Mode & Mean & $\begin{array}{c}\text { Std. } \\
\text { Deviation }\end{array}$ \\
\hline City's unreserved fund balance & 1 & 1.53 & 0.87 \\
\hline City's economic competitiveness & 1 & 2.20 & 1.11 \\
\hline City residents' income distribution & 1 & 2.25 & 1.13 \\
\hline Economic status of the poor & 1 & 2.05 & 1.14 \\
\hline City resident's job security & 1 & 2.28 & 1.15 \\
\hline
\end{tabular}

The results shown on Table 17 indicate that public managers in Florida's small-medium municipalities perceive the global economy as having very little impact on their municipalities' socio-economic qualities. Most respondents indicated that the global economy's impact is "low" on the given aspects of a municipality's socio-economic conditions.

Questions seven and eight of the survey presented certain strategic responses that might also indicate municipalities' response to the impacts of 
globalization. Table 18 shows that cultural diversity training and the hiring of bi/multi-lingual individuals are common strategies employed in response to globalization in small-medium cities in Florida. These results speak to the significance of the human resource capacity of public organizations to survive in a time of globalization.

Table 18. Percentage of respondents who indicate that certain strategies have been implemented in their municipality $(n=116)$

\begin{tabular}{|l|c|}
\hline Strategy & $\%$ \\
\hline Teaching cultural competencies to city employees & 34.2 \\
\hline Improving technological competencies of city employees & 32.5 \\
\hline $\begin{array}{l}\text { Hiring individuals who communicate in languages other than } \\
\text { English }\end{array}$ & 59.0 \\
\hline "Marketing" the city internationally & 23.1 \\
\hline Hosting/promoting multicultural community events & 53.8 \\
\hline The city provides foreign language training for its employees & 23.9 \\
\hline $\begin{array}{l}\text { The city requires second-language competencies for certain } \\
\text { employment positions }\end{array}$ & 18.8 \\
\hline The city provides cultural diversity training for its employees & 59.8 \\
\hline $\begin{array}{l}\text { The city uses translation services for non-English speakers at } \\
\text { its public meetings }\end{array}$ & 12.8 \\
\hline $\begin{array}{l}\text { City signage appears in English and at least one language } \\
\text { other than English }\end{array}$ & 6.8 \\
\hline $\begin{array}{l}\text { City publications are presented in English and at least one } \\
\text { language other than English }\end{array}$ & 27.4 \\
\hline
\end{tabular}

Public managers' responses (53.8\%) also demonstrate that municipalities are increasingly involved in the hosting and/or promotion of multicultural community events. Table 18 results imply that public 
management responses to the impacts of globalization in Florida's smallmedium cities have mainly been aimed at the socio-cultural manifestations of globalization.

\section{Factor Analysis}

Questions one, seven and eight of the survey seek to identify activities perceived by public managers as responses to municipalities' globalization's impacts in Florida's small-medium cities. With a view to classifying these variables, factor analysis was carried out on the items that comprise these questions. Table 19 shows the results of the Bartlett's test of sphericity and the KMO measure of sampling adequacy for these questions.

Table 19. KMO and Bartlett's Test for questions 1, 7 and 8

\begin{tabular}{|c|c|c|}
\hline Kaiser-Meyer-Olkin Measur & Adequacy. & .811 \\
\hline Bartlett's Test of Sphericity & $\begin{array}{l}\text { Approx. Chi-Square } \\
\text { df } \\
\text { Sig. }\end{array}$ & $\begin{array}{r}938.434 \\
190 \\
<0.001\end{array}$ \\
\hline
\end{tabular}

The Bartlett's test is significant at the $p<0.001$ level and an estimable KMO measure of 0.811 is obtained. Therefore, it is reasonable to proceed with factor analysis for the variables in questions one, seven and eight. Table 20 shows that the data for questions one, seven and eight can be reduced to five principal factors. These five factors explain $61.46 \%$ of the variation in the data (Table A3 in Appendix). The rotated component matrix 
in Table 20 facilitates the extraction of the variables by presenting correlations in a comprehensible manner.

According to the rotated component matrix given in Table 20, managerial activities engaged in response to globalization fall into five primary categories. These categories may be named as follows: (1) commercial and strategic alliances, (2) organizational communications capacity, (3) community and organizational multiculturalism, international communications and investment capacity, and organizational technological capacity. Closer examination of these categories reveals that the activities may be further grouped into two classes: (a) internal/domestic responses and (b) external/international responses. The five factors are assigned as follows:

Internal/domestic responses

- organizational communications capacity (factor 2)

- organizational technological capacity (factor 5)

- community and organizational multiculturalism (factor 3)

External/international responses

- commercial and strategic alliances (factor 1)

- international communications and investment capacity (factor 4) 
Table 20. Rotated Component Matrix for questions 1, 7 and 8

\begin{tabular}{|c|c|c|c|c|c|}
\hline & \multicolumn{5}{|c|}{ Component } \\
\hline & 1 & 2 & 3 & 4 & 5 \\
\hline Attract foreign direct investments & 0.798 & -0.022 & -0.045 & 0.114 & 0.191 \\
\hline Promote local products' export & 0.665 & -0.111 & -0.014 & 0.124 & 0.277 \\
\hline Attract foreign tourists & 0.663 & -0.034 & 0.257 & -0.054 & -0.025 \\
\hline $\begin{array}{l}\text { Cond } \\
\text { abroa }\end{array}$ & 0.764 & 0.154 & 0.121 & 0.086 & -0.221 \\
\hline $\begin{array}{l}\text { Exchange city mgmt ideas with } \\
\text { foreign cities }\end{array}$ & 0.640 & 0.056 & 0.284 & -0.018 & -0.139 \\
\hline $\begin{array}{l}\text { Work } \\
\text { posit }\end{array}$ & 0.778 & 0.206 & 0.167 & 0.016 & 0.151 \\
\hline $\begin{array}{l}\text { Work with neigl } \\
\text { improve positior } \\
\text { economy }\end{array}$ & 0.774 & 0.303 & 0.016 & 0.051 & 0.085 \\
\hline $\begin{array}{l}\text { Work with state officic } \\
\text { position in the global }\end{array}$ & 0.717 & 0.375 & 0.044 & -0.063 & 0.205 \\
\hline "Market" the city inter & 691 & 108 & 0.198 & 0.207 & 0.128 \\
\hline $\begin{array}{l}\text { The city requires second-lang } \\
\text { competencies for certain emp } \\
\text { positions }\end{array}$ & 0.041 & 0.646 & 0.274 & 0.087 & .052 \\
\hline $\begin{array}{l}\text { The city uses translation services for } \\
\text { non-English speakers at its public } \\
\text { meetings }\end{array}$ & 0.189 & 0.695 & -0.106 & 0.134 & -0.186 \\
\hline $\begin{array}{l}\text { City signage appears in English and } \\
\text { at least one other language } \\
\text { throughout the community }\end{array}$ & 0.048 & 0.735 & -0.121 & 0.118 & 0.281 \\
\hline $\begin{array}{l}\text { City publications are presented in } \\
\text { English and at least one other } \\
\text { language }\end{array}$ & 0.216 & 0.576 & 0.330 & -0.081 & -0.026 \\
\hline $\begin{array}{l}\text { Teach cultural competencies of city } \\
\text { employees }\end{array}$ & 0.106 & -0.019 & 0 & 0 & 0.2 \\
\hline $\begin{array}{l}\text { viduals who communicate in } \\
\text { s other than English }\end{array}$ & -0.016 & 0.328 & 0.559 & 0.096 & -0.123 \\
\hline $\begin{array}{l}\text { Host/promote multicultural } \\
\text { community events }\end{array}$ & 0 & 6 & 36 & -0.028 & 0.025 \\
\hline $\begin{array}{l}\text { The city provides cultural diversity } \\
\text { training for its employees }\end{array}$ & 0 & -0.198 & 0.6 & 0.0 & 0.2 \\
\hline $\begin{array}{l}\text { Invest with international capital } \\
\text { markets }\end{array}$ & 0.317 & 0.326 & 0.005 & 0.683 & 0.206 \\
\hline $\begin{array}{l}\text { The city provides foreign language } \\
\text { training for its employees }\end{array}$ & 0.000 & 0.033 & 1 & 4 & -0.051 \\
\hline $\begin{array}{l}\text { Improve technological competencies } \\
\text { of city employees }\end{array}$ & 0.081 & 0.100 & 0.274 & 0.051 & 0.811 \\
\hline
\end{tabular}




\section{Concluding remarks}

Having analyzed data that presented public managers with various indicators of globalization, the analysis shows that managers perceive their municipalities as minimally active players in the global economy. However, they note that human resources strategies are commonly modified in order to respond to a more diverse citizenry. More than half of the survey respondents inform that employment and training practices have been adapted in their municipalities which may, out of necessity, be because of the impact of globalization.

Further, public managers in Florida's small-medium cities' perceive that public management practices have been responding to globalization's impact in two ways: (1) domestic/internal and (2) international/external. Domestic/internal responses are activities that indicate changing demographics and heightened global economic competition within the municipality. These activities are pursued at the organizational level and may be described as organizational communications capacity, organizational technological capacity, and community and organizational multiculturalism.

International/external responses are seen as activities pursued by municipalities to engage globalizing forces outside their borders. These responses have an outward-looking focus, with a view to collaborating with other agencies and jurisdictions to strengthen the municipality's position in 
the global economy. These responses may be categorized as a municipality's commercial and strategic alliances and its communications and investment capacity.

In keeping with the research questions of the study, the findings reported in the remainder of the dissertation are classified under the following headings: (1) Managers' perceptions of globalization's impact on public management and (2) Managers' perceptions of globalization's impact on the functions of decision-making, economic development and service delivery. Each of these sections is presented separately in the succeeding chapters. 


\section{CHAPTER VII. MANAGERS' PERCEPTIONS OF GLOBALIZATION'S IMPACT ON PUBLIC MANAGEMENT}

Having ascertained that public managers in Florida's small-medium cities are reckoning with the concept of globalization and municipalities' relative position in the global milieu, the second research question of the study seeks to obtain managers' perceptions of globalization's impact on public management practice in their municipalities. Chapter seven presents the findings of the research that directly address this domain. The chapter begins with an examination of interview responses integrated with crosstabulation results to present six conjectures that emerge from the data as common perceptions among the public managers. Subsequently, the factor analysis of questions two and four of the survey is shown. The chapter also brings to the fore some divergent perceptions about globalization articulated by public managers.

\section{Qualitative Analysis}

Throughout the interviews managers were also asked to share their views on globalization's impact on the practice of pubic management and whether or not they considered globalization to be an opportunity or a challenge for public managers. The interpretive analysis of the interview texts identifies five conjectures that underscore public managers' perceptions 
of globalization's impacts on public management practice in Florida's smallmedium cities. The conjectures are explained in the following sections.

\section{$\underline{\text { Conjecture 1: Budget restraints }}$}

Public managers perceive that globalization concurrently presents opportunities as well as challenges for public management in the context of new tax reforms and tightening budgets in Florida. In reflecting on globalization's impact on public management practice, an Oviedo public manager commented:

"I think it's a challenging opportunity.... I really think that what the legislature's doing through its tax reforms is going to make local governments begin to look inward and to not think globally and not think of opportunities, so I really think it's a challenging opportunity because you don't have the means to really go out there and to explore what these opportunities are, especially from an economic development standpoint because an economic development program never pays for itself... So I think that's why I said it's a challenging opportunity because you've got to ask policy makers to think beyond their term and think beyond the day-to-day and really, the situation that the state legislature has put us in is that the day-to-day has to come first."

This manager seems to be saying that, although globalization has opened up opportunities for carrying out innovative public management, financial challenges somewhat inhibit local administrations from being able to take advantage of the opportunities. On the contrary, some public managers see the constraining financial environment as an opportunity for administrations to become innovative and deliberate in carrying out their functions:

"I think the tax cuts are going to force governments to start to look outside the box and be more aggressive. For a large number of years, they've had a comfort level, they didn't have to go 
outside the box. Everything was inside the box. I think the challenge now is going to be to determine what other services the government can provide to the public in a more efficient manner that also would include privatization which is globalized to a certain extent." (Longwood, Orlando MSA)

"It [globalization] widens the perspective or pool of resources you have. It lets you learn how systems work and how economies work. In an era that you see the State representatives cutting back taxes and millage rates for cities, I think we need to find new opportunities and if you can't find them within our local system then you have the opportunity to go abroad and find them somewhere else on an international level. I see it as an opportunity."(Hialeah Gardens, Miami MSA)

The preceding quotes illustrate that although the speakers are located in different parts of the State with distinct demographics, the managers recognize the potential benefit of globalization to help cope with current local financial conditions.

$\underline{\text { Conjecture 2: Economic resourcefulness }}$

Secondly, managers commented that globalization presents the challenge of job loss and industry attrition while offering the opportunity for increased entrepreneurship and economic development. The following quote from Clearwater summarizes this belief:

" $a$ challenge in respect that sometimes (we haven't specifically experienced this but) I think that overall if you have a factory or a key work center that closes because the jobs are going elsewhere, that would definitely affect the community. That would have a very local impact. I think an opportunity is that if you have a community that has a lot of entrepreneurs that you're trying to encourage, that could be a huge opportunity for them and that's something they could take advantage of. So it just depends. It's both challenge and opportunity." 
The public manager is evidently speaking in hypothetical terms and not specifically about activities occurring in his municipality. Nonetheless, the quotation expresses an opinion that speaks to the tentative impacts produced by the economic dimension of globalization. These observations correspond to the employment-related dilemma that globalization presents for public managers. In this vein, globalization is seen as adding jobs and motivating entrepreneurship for some while potentially having the opposite effect of readjusting wage structures that include lower-paying jobs. From the descriptive statistics in the preceding chapter, we learned that approximately half $(51 \%)$ of the survey respondents agree that globalization increases job opportunities in their municipalities while $53 \%$ disagree that globalization raises wages in their municipalities.

Managers consistently commented on the opportunity that globalization presents for their jurisdiction to participate in the global economy. Konvitz (1996) states that

the economic channels of today are no longer hierarchical, passing from one of a small set of world cities (New York, London, Paris, Tokyo) to those on the rung below (Chicago, Manchester, Osaka), and so on down until provincial towns are reached. Cities now require multiple pathways and connections to one another within a region, and to other clusters of cities in other countries. As a result, opportunities to participate in the global economy are more widely accessible to alert entrepreneurs and city leaders (p. 7). 
Globalization has enabled cities to link their local economies with economies that have far more influence than their own and are outside their borders. Public managers in the Miami/Fort Lauderdale metropolitan area particularly share this view. Following are some excerpts from interviews conducted in this region:

\section{"Globalization expands local markets"}

"I think the other thing that's most important for what we do is that what globalization has done from an economic perspective it's increased the importance of cities and it's reduced the importance of states or countries. The economy of Miami Beach has more to do with international markets than it does with even Dade County or the State of Florida. What it's done is, it's linked our city's economy directly to that of Basel, Switzerland; to that of other cities and other cities domestically also."

"Economic development has been impacted as the City competes for U.S. business as well as global business".

These insights reinforce the notion that the nation-state has become less significant, from an economic standpoint, in a globalized world. The insights also show that, despite their size, Florida's small-medium cities are connected to the global economy in particular ways.

Table 21 gives the results of the cross-tabulation of managers' perceptions of globalization's effect with job opportunities in their municipalities from the survey. The results of the analysis show that all explanatory variables are statistically significant in predicting public managers' perceptions. Public managers who are older, native-born U.S citizens are seemingly less-embracing of the notion that globalization 
increases job opportunities in their municipalities. Meanwhile, as the education level of public managers increase, so too does their level of agreement with the view that globalization increases job opportunities in their municipality. Table 22 shows that age and nativity status are negatively related to the perception on job opportunities while education level and overseas work experience are positively related to the perception on job opportunities.

Table 21. Managers' perceptions of the view that globalization increases job opportunities in my municipality

\begin{tabular}{|c|c|c|c|c|c|}
\hline & $\begin{array}{l}\text { Strongly } \\
\text { Disagree }\end{array}$ & Disagree & Agree & $\begin{array}{l}\text { Strongly } \\
\text { Agree }\end{array}$ & $\begin{array}{c}\text { No } \\
\text { Opinion }\end{array}$ \\
\hline \multicolumn{6}{|l|}{$\operatorname{Age}^{* *}(\mathrm{n}=110)$} \\
\hline $25-39$ & 0.0 & 9.1 & 45.5 & 0.0 & 45.5 \\
\hline $40-54$ & 5.1 & 25.4 & 52.5 & 5.1 & 11.9 \\
\hline $55+$ & 10.0 & 32.5 & 30.0 & 10.0 & 17.5 \\
\hline \multicolumn{6}{|c|}{$\begin{array}{l}\text { Education Level } * *(n= \\
113)\end{array}$} \\
\hline Some college & 0.0 & 40.0 & 20.0 & 0.0 & 40.0 \\
\hline Bachelor's & 15.2 & 33.3 & 42.4 & 3.0 & 6.1 \\
\hline Master's & 2.8 & 23.6 & 45.8 & 6.9 & 20.8 \\
\hline Doctoral & 0.0 & 0.0 & 66.7 & 33.3 & 0.0 \\
\hline \multicolumn{6}{|c|}{$\begin{array}{l}\text { Work outside U.S.** } \\
(\mathrm{n}=113)\end{array}$} \\
\hline Yes & 8.7 & 34.8 & 30.4 & 17.4 & 8.7 \\
\hline No & 5.6 & 24.4 & 47.8 & 3.3 & 18.9 \\
\hline \multicolumn{6}{|c|}{$\begin{array}{l}\text { Native-born citizen* }(\mathrm{n} \\
=111)\end{array}$} \\
\hline Yes & 6.9 & 28.7 & 43.6 & 4.0 & 16.8 \\
\hline No & 0.0 & 0.0 & 50.0 & 30.0 & 20.0 \\
\hline
\end{tabular}

*Significant at $\mathrm{p}<0.01 ;{ }^{* *}$ Significant at $\mathrm{p}<0.1$ 
Table 22. Measures of association for managers' perceptions of the view that globalization increases job opportunities in my municipality

\begin{tabular}{|l|c|}
\hline & Somers' d \\
\hline Age X Globalization increases job opportunities & -0.032 \\
\hline Education Level X Globalization increases job opportunities & 0.144 \\
\hline $\begin{array}{l}\text { Worked outside U.S. X Globalization increases job } \\
\text { opportunities }\end{array}$ & 0.094 \\
\hline Native-born citizen X Globalization increases job opportunities & -0.364 \\
\hline
\end{tabular}

Table 23. Managers' perceptions of the view that globalization raises wages in their municipality

\begin{tabular}{|c|c|c|c|c|c|}
\hline & $\begin{array}{l}\text { Strongly } \\
\text { Disagree }\end{array}$ & Disagree & Agree & $\begin{array}{c}\text { Strongly } \\
\text { Agree }\end{array}$ & $\begin{array}{c}\text { No } \\
\text { Opinion } \\
\end{array}$ \\
\hline \multicolumn{6}{|l|}{ Age $(n=110)$} \\
\hline $25-39$ & 0.0 & 36.4 & 27.3 & 0.0 & 36.4 \\
\hline $40-54$ & 5.1 & 49.2 & 18.6 & 1.7 & 25.4 \\
\hline $55+$ & 10.0 & 45.0 & 12.5 & 2.5 & 30.0 \\
\hline \multicolumn{6}{|c|}{$\begin{array}{l}\text { Education Level }(\mathrm{n}= \\
\text { 113) }\end{array}$} \\
\hline Some college & 0.0 & 40.0 & 20.0 & 0.0 & 40.0 \\
\hline Bachelor's & 12.1 & 42.4 & 21.2 & 0.0 & 24.2 \\
\hline Master's & 2.8 & 50.0 & 15.3 & 2.8 & 29.2 \\
\hline Doctoral & 33.3 & 33.3 & 33.3 & 0.0 & 0.0 \\
\hline \multicolumn{6}{|c|}{$\begin{array}{l}\text { Work outside U.S. }(\mathrm{n}= \\
113)\end{array}$} \\
\hline Yes & 13.0 & 39.1 & 21.7 & 4.3 & 21.7 \\
\hline No & 4.4 & 48.9 & 16.7 & 1.1 & 28.9 \\
\hline \multicolumn{6}{|c|}{$\begin{array}{l}\text { Native-born citizen* }{ }^{*} \mathrm{n} \\
=111)\end{array}$} \\
\hline $\begin{array}{l}\text { Yes } \\
\text { No }\end{array}$ & $\begin{array}{c}5.9 \\
10.0\end{array}$ & $\begin{array}{l}50.5 \\
10.0\end{array}$ & $\begin{array}{l}15.8 \\
30.0\end{array}$ & $\begin{array}{c}1.0 \\
10.0\end{array}$ & $\begin{array}{l}26.7 \\
40.0\end{array}$ \\
\hline
\end{tabular}

*Significant at $\mathrm{p}<0.1$

Table 23 displays the relationship between public managers' perceptions of globalization's impact on wages in their municipality. The analysis infers that whether or not a manager is a native-born citizen of the 
U.S. is statistically significant in explaining their perception on the impact of globalization on wages. The relationship is a weak negative one, as demonstrated by the Somers' d value of -0.028 in Table 24 . It is interpreted to mean that a public manager who is a native-born citizen of the U.S. is more likely to think that globalization does not raise wages in their municipality.

Table 24. Measure of association for managers' perceptions of the view that globalization raises wages in their municipality

\begin{tabular}{|l|c|}
\hline & Somers' d \\
\hline Native-born citizen X Globalization raises wages & -0.028 \\
\hline
\end{tabular}

\section{Conjecture 3: Professional favorability}

Third, public managers opine that globalization also presents an opportunity for them to keep learning and growing by forcing them to keep abreast of the demographic changes occurring in their communities. For instance, a public manager in Clearwater states:

"We use the internet a lot for research and information.... When we're looking for demographics, if we're looking at a business, we're looking for statistics, for mapping, for when you're working with businesses, if you're looking at their ratings, like in cities for bonding capacities and credit scores, policies, all that information can now be found on the internet; it's much easier to access so you can use it to understand; if you're looking at performance measures and benchmarking so you can see what other cities are doing - it's a little bit easier to find that out too"

Another manager in Coral Gables stated:

"It [globalization] allows us to learn from other communities because experience is extremely valid, in terms of background, in terms of how you want to move forward." 
This study advances that if public managers are intelligently aware of the changes occurring in their cities, efficiency, effectiveness and responsiveness in the provision of services will improve. Globalization keeps managers both relevant and active as public service practitioners. In light of this, public managers in the Tampa/St. Petersburg MSA verbalize their opinions in the following ways:

"There's some challenges but mostly you're in the business of providing services to the people that are in the community. You adjust to the population and maybe it's because there are more people who came here from another country or maybe your demographics are changing because you have an older population or maybe they're changing because for whatever reason now you're having an influx of families with younger children and so all those things can change the community and then you need to adjust your services to match..."

The public manager acknowledges that a combined effect of shifting demographics and globalization, as pointed out early in the dissertation, presents an opportunity for public managers to rise to the challenge of improving the efficiency and effectiveness of the private sector. He continues:

"so that's an opportunity for urban managers and if you want to continue to do a good job then you have to be aware of what's going on and make those adjustments in the services that you're providing."

Evidently, globalization forces environmental scanning on the part of public managers and insists on responsive and appropriate public management practices. 


\section{Conjecture 4: Global awareness}

Public managers also believe that the challenges and opportunities presented by globalization come in the way of learning and sharing information and adjusting to living among varying cultures. This is expressed in the following quotations from the Miami/Fort Lauderdale and Tampa/St. Petersburg metropolitan areas:

"Having worked for four or five cities, my experience of going through problems of those cities has provided me with the resources, the information for me to make informed decisions on recommendations and then that likewise I can make recommendations to the boards and the commission in terms of hey, this issue was resolved in another community, or these outside forces, ah, they've gone through the good and the bad of a certain situation and we can learn from that so I think it's definitely an opportunity. I don't see it as a challenge at all."

"Globalization makes us more culturally aware of other nations and peoples. Globalization improves foreign relations."

"Globalization is positive because the world is diverse. The city has a chance to experience diversity and understand differences."

\section{$\underline{\text { Conjecture 5: Optimal living standards }}$}

Fifth, the research reveals that public managers are reckoning that globalization gives excellence a magnetic reach, and stimulates and sustains a high quality of life in cities. They recognize that quality of life issues are tied closely to their capacity to improve the economic standing of their city. The following quote from Miramar articulates this acknowledgement:

"We have a very diverse workforce and diverse resident base. The City has determined that the diversity is a strength and has adopted programs, events and policies based on that." 
Miramar is a city in the Fort Lauderdale metropolitan division with a growing population of over 72,000 according to the 2000 U.S. Census. About $42 \%$ of Miramar's population is foreign-born.

In Coral Springs, another city in the Fort Lauderdale metropolitan division, a public manager remarks:

"Cultural diversity is considered one of our strengths"

Coral Springs has a population of nearly 118,000 of which $26 \%$ are foreignborn. A public manager in Kissimmee also stated:

"It [globalization] has increased the cultural diversity of our community, which I see as positive."

Kissimmee is a principal city in the Orlando MSA and has a total population of 47,814 of which approximately $29 \%$ are foreign-born. Thousands of visitors to theme parks in neighboring Orlando pass through Kissimmee every year which conceivably boosts the city's economic status.

For some public managers, globalization presents the opportunity to become involved in the global economy which, though competitive, has the potential to improve the quality of life in their jurisdictions. A manager explains:

globalization obviously raises the stakes for everyone, because it elevates the competition for jobs, business recruitment and the necessity for a greater understanding of diverse values, cultures and the varied means [and styles] of communication among the inhabitants of planet earth. (North Port, Sarasota/Bradenton MSA) 
One city manager in the Orlando metropolitan area explains his understanding of the importance that standards of excellence has in his school district and how it affects the movement of people and business to his municipality. He explains:

"So when you talk globalization, I don't control things like schools, ok? But I certainly contribute to that through helping my schools within my district be the best they can be. The FCAT shows that Seminole County has one of the best school districts in the State of Florida which is very attractive to whoever is considering relocating here, be it businesses who are concerned about their employees; that's just the thing, you know, it's not just a company saying ok, we're moving to Florida, if you want to come, come. They don't do that anymore. That's the difference. They send a scout team that basically evaluates the entire infrastructure. They look at schools, they look at public safety, you know, they look at all those things because they know their employees are the most important asset and they want to bring those core people. They want them to want to come wherever they relocate, whether it's here or Alabama. They want them to go. They want them to look forward to it. They don't want them dragging but they don't want to start over so they look very hard at what we have to offer and from that perspective we become salespeople because we have to show and demonstrate... and they don't just take us at our word, I mean, they want to go out and see it."

This manager points out that although there are certain sectors that are outside a manager's sphere of control, these sectors contribute to quality of life in a municipality. Therefore, a public manager has to be mindful of the reality of 'spillover effects' from neighboring jurisdictions.

Conversely, standards of excellence set in many other spheres of human interaction have local impact and therefore, lifts the standards of excellence socially, economically, politically and otherwise in the small- 
medium city setting. The qualitative analysis shows that the impacts of globalization are perceived by public managers in Florida's small-medium cities as creating "developmental" policies. According to Peterson, "developmental policies enhance the economic position of the city...They strengthen the local economy, enhance the local tax base, and generate additional resources that can be used for the community's welfare" (p. 41).

Chapter five of this dissertation reports that overall, $41.4 \%$ of the survey respondents agree that globalization improves quality of life standards in their municipality. Table 29 presents the relationship between public managers' perceptions and their respective attributes. Table 29 shows that public managers' overseas work experience and place of birth are statistically significant predictors of their perceptions on the view that globalization improves quality of life standards in their community.

An understanding of globalization and its qualities has resulted in city managers gaining an interest in seizing globalization's economic advantages as a means to improve their municipalities' quality of life. Konvitz (1996) notes that, as participants in the global economy, "cities want to draw attention to the high quality of life they can offer, through investment, innovation and the institutions they contain" (p.7). The analysis shows that overseas work experience is positively related to the perceptions and nativity status is negatively related to the perceptions, according to the respective Somers' d values. Both relationships are also weak since the absolute values 
of Somers' $d$ are less than 0.5 . Table 25 shows that the nativity status and overseas work experience of public managers are statistically significant in determining their perceptions of globalization's impact on quality of life in their municipality. The results imply that a public manager who has worked outside the U.S. for at least one year of their professional life as well as one who is a native-born citizen of the U.S. is more likely to believe that globalization improves the quality of life.

Table 25. Managers' perceptions of the view that globalization improves quality of life standards in their municipality

\begin{tabular}{|c|c|c|c|c|c|}
\hline & $\begin{array}{l}\text { Strongly } \\
\text { Disagree }\end{array}$ & Disagree & Agree & $\begin{array}{l}\text { Strongly } \\
\text { Agree }\end{array}$ & $\begin{array}{c}\text { No } \\
\text { Opinion }\end{array}$ \\
\hline \multicolumn{6}{|l|}{ Age $(n=110)$} \\
\hline $25-39$ & 0.0 & 0.0 & 45.5 & 0.0 & 54.5 \\
\hline $40-54$ & 3.4 & 16.9 & 37.3 & 6.8 & 35.6 \\
\hline $55+$ & 5.0 & 25.0 & 32.5 & 2.5 & 35.0 \\
\hline \multicolumn{6}{|c|}{$\begin{array}{l}\text { Education Level }(\mathrm{n}= \\
\text { 113) }\end{array}$} \\
\hline Some college & 0.0 & 20.0 & 20.0 & 0.0 & 60.0 \\
\hline Bachelor's & 9.1 & 21.2 & 30.3 & 3.0 & 36.4 \\
\hline Master's & 1.4 & 18.1 & 38.9 & 5.6 & 36.1 \\
\hline Doctoral & 0.0 & 0.0 & 66.7 & 0.0 & 33.3 \\
\hline \multicolumn{6}{|c|}{$\begin{array}{l}\text { Work outside U.S.* (n } \\
=113)\end{array}$} \\
\hline Yes & 8.7 & 30.4 & 26.1 & 13.0 & 21.7 \\
\hline No & 2.2 & 15.6 & 38.9 & 2.2 & 41.1 \\
\hline \multicolumn{6}{|c|}{$\begin{array}{l}\text { Native-born citizen } * * \\
(\mathrm{n}=111)\end{array}$} \\
\hline Yes & 4.0 & 19.8 & 36.6 & 3.0 & 36.6 \\
\hline No & 0.0 & 0.0 & 40.0 & 20.0 & 40.0 \\
\hline
\end{tabular}

*Significant at $\mathrm{p}<0.05 ;{ }^{* *}$ Significant at $\mathrm{p}<0.1$ 
Table 26 shows that whereas overseas work experience is positively related to the perception, a public managers' native origin is negatively related.

Table 26. Measures of association for managers' perceptions of the view that globalization improves quality of life standards in my municipality

\begin{tabular}{|l|c|}
\hline $\begin{array}{l}\text { Worked outside U.S. X Globalization improves quality of } \\
\text { life standards }\end{array}$ & Somers' d \\
\hline $\begin{array}{l}\text { Native-born citizen X Globalization improves quality of } \\
\text { life standards }\end{array}$ & -0.141 \\
\hline
\end{tabular}

\section{Conjecture 6: Personal reflection}

Public managers offered a philosophical introspection into the challenges and opportunities presented by globalization. Such an introspection propagates positive change among individuals' behavior and outlook, thereby presenting philosophical challenges and opportunities for public managers who serve the communities comprising these reflective individuals. Two public managers assert:

"Our existence by its very nature has been a global existence. We have more recently come to realize that our co-existence is dependent upon a mutual exchange of cooperation and collaboration."(Northport, Sarasota/Bradenton MSA)

"I really don't see how it would present a challenge. I see nothing but opportunities. I am a firm believer in whether it's your across-the-street neighbor or the city next to you or your county or the next country or whatever, the more people know about each other, the more they can understand, the better everything is so I really don't see any challenges." (Clearwater, Tampa/St. Petersburg MSA) 
One public manager in the Tampa/St. Petersburg MSA reflects on the notion that globalization challenges individuals to examine themselves with a wide prism:

"Globalization, I think offers the opportunity for you to achieve your potential, for you to understand and experience the richness of life as it has been given to you and to understand the various ways that we define and understand who we are as human beings. By the same token, that same level of awareness becomes a challenge to overcome in that we often don't always know how to respond to those opportunities, how to respond to that challenge of diversity and embracing the different cultural parts of the community that descend upon us or that we become a part of, or to understand the context of what it means to be numerically as a minority existing in the sea of a majority and you can cut that, slice it all kinds of ways but at the end of the day it's how the individual deals with that internal existence as it interacts with that external existence... and that's where globalization can give you some real challenges, you know, the globalization of technology and all of a sudden you have to adapt to changing standards and it can be overwhelming."

The manager further comments that these challenges are not limited to a single sector of the community but that the challenges are widespread and should not be taken lightly by public administrators. Public managers believe that as individuals increasingly see themselves as belonging to a "global village", these perceptions carry over into residents' demands and preferences that must be met by public managers.

"Certain market changes can introduce changes in your community that you didn't anticipate so now you've got to address those generational differences that often occur because one part of the world latches on to something that is contagious and it spreads to another part of the world then all of a sudden you're caught in the middle of it." 


\section{Divergent perceptions}

The analysis of the qualitative data in this research also revealed perceptions that differed from those identified in the aforementioned conjectures. Some public managers in this study are of the distinct view that globalization does not impact their municipality or their work. Qualitative responses suggest that a number of public managers perceive globalization's impact in their municipality as a function of city size or industry base. Consider the following quotations:

"I work in a community that is a "bedroom" community... Globalization has had little impact on my city." (Atlantic Beach, Jacksonville MSA)

"Globalization does not affect us one way or another because of the size of our community." (Longwood, Orlando MSA)

"This is a small town - no industry. Globalization is not having any measurable effect." (Cocoa Beach, Melbourne MSA)

"We are mostly a residential community. Globalization does not affect service delivery in any measurable way." (Wilton Manors, Fort Lauderdale Metropolitan division)

"I don't believe there's been any impact to the City of Port St. Lucie."

"So far, it has little to no impact on our ability to provide services." (Oviedo, Orlando MSA)

"Have not been exposed to globalization enough to know the impact." (Niceville, Fort Walton MSA)

"No impact."(Seminole, Tampa MSA)

These responses indicate that there are small-medium cities in Florida where globalization impacts are perceived as either non-existent or not evident. It 
is interesting to note that, among these responses, even in metropolitan areas like Orlando and Fort Lauderdale which may be considered more globalized than others, some public managers do not acknowledge that globalization trends are occurring.

Still yet, some qualitative responses from the survey indicate a sense of expectancy with regards to globalization and its impacts. The study shows that there are public managers in Florida's small-medium cities who do not perceive globalization as a current phenomenon in their locale, but as an activity that will occur in the future. These responses give pause and raise the question of whether or not the theoretical claims of globalization as having reached all levels of urban life are substantiated in a real sense. Note the following remarks offered in response to the survey question which asked managers to give their perspectives on globalization.

"At this point globalization has not had an impact on our municipality.” (Largo, Tampa MSA)

"Conceptually it could open up the procurement process to more options for products.” (Lake Wales, Lakeland MSA)

"It has not had a great impact on our city yet. We are beginning to prepare for it..." (Pinellas Park, Tampa MSA)

"Globalization will have a positive impact in the future." (OpaLocka, Miami MSA)

"Minimal effect at the present time in our municipality." (Tamarac, Fort Lauderdale MSA)

"I think in the future it's probably going to present more of an opportunity. I think it's so new right now and it's changing. It's a moving target... I don't think we're going to be impacted 
directly as some of your bigger cities like the New Yorks and even Orlandos although we're going to feel the impacts of it." (Lake Mary, Orlando MSA)

These statements show that the realities of some of the participant public managers are not globalized realities. Rather, although managers are bracing for globalization, they claim to not have experienced globalization in ways purported by theorists. Further, the divergent responses come from public managers in dissimilar metropolitan areas; places with diverse populations, economic bases and amenities. The difference of opinions among these public managers bears out the constructionist view of public administration and further reinforces the contextual nature of perceptions. The responses strongly imply that the size of a city is not a reliable predictor of the experiences of globalization among public managers in Florida's smallmedium cities.

Finally, some public managers acknowledge the occurrence of social and economic changes in their municipalities but do not attribute them to global activity. Instead, they interpret these impacts as regional in origin and scope. For example, the following observation is given by a public manager in the Fort Lauderdale metropolitan region:

"This City has little impact upon and is not impacted to any great degree by globalization that can be a direct correlation. Potentially some job issues may occur, supply issues (availability and Cost) for major construction, but little else. However, from another point of view The County region is impacted a great deal by globalization issues. From that perspective this city is impacted by the activities in the region." (Coconut Creek, FL) 
This acknowledgement brings out the spatial dimension of globalization and highlights the distinction that is made between globalization and other scales of social organization with respect to distance (Held and McGrew, 2000). Keohane and Nye (2000) stress that "for a network of relationships to be considered 'global,' it must include multicontinental distances, not simply regional networks" (p. 2).

\section{Quantitative Analysis}

Question four of the survey asked participants to rate their perceptions of globalization's impact on certain issues that are typically of concern to public managers, on a scale of 1 to 5 ( $1=$ Low impact, $5=$ High impact $)$. Table 15 reports the findings. According to Table 27, public managers' perceive globalization as having very little impact on the stated managerial concerns. The modal response for all concerns is "low impact."

Table 27. Managers' perceptions of globalization's impact on managerial concerns

\begin{tabular}{|l|c|c|c|}
\hline & Mode & Mean & $\begin{array}{c}\text { Std. } \\
\text { Deviation }\end{array}$ \\
\hline Stability of revenue streams & 1 & 1.99 & 1.12 \\
\hline Residents' sense of neighborhood & 1 & 1.88 & 1.20 \\
\hline Provision of affordable housing & 1 & 1.85 & 1.13 \\
\hline Procurement and purchasing practices & 1 & 1.92 & 1.06 \\
\hline $\begin{array}{l}\text { Variety of services delivered to specific } \\
\text { demographics }\end{array}$ & 1 & 2.09 & 1.18 \\
\hline
\end{tabular}




\section{Factor Analysis}

Questions two and four in the survey ask public managers to indicate their opinions of globalization's impacts on various aspects of their municipality's demography and governance. The factors derived from the factor analysis represent dimensions of the public managers' perceptions. Table 29 shows the results of the Bartlett's test of sphericity and the KMO measure of sampling adequacy for questions two and four of the survey. The Bartlett's test is significant at the $\mathrm{p}<0.001$ level and a meritorious KMO measure of 0.870 is obtained. These results support the use of factor analysis for the variables in questions two and four.

Table 28. KMO and Bartlett's Test for questions 2 and 4

\begin{tabular}{|c|c|c|}
\hline \multicolumn{2}{|c|}{ Kaiser-Meyer-Olkin Measure of Sampling Adequacy } & .871 \\
\hline Bartlett's Test of Sphericity & Approx. Chi-Square & 624.717 \\
\hline & $\mathrm{df}$ & 45 \\
\hline & Sig. & $<0.001$ \\
\hline
\end{tabular}

Table 29 demonstrates that public managers' perceptions of globalization's impacts on managerial issues as operationalized in questions two and four can be reduced to two factors. These factors explain $66.3 \%$ of the variation in the data. Table 30 classifies public managers' perceptions of globalization's impact on public management primarily in two ways; in terms of affecting: (1) municipality's socio-economic viability comprised of the items loaded on component 2, and (2) municipality's managerial capacity, which includes the items comprising component one. 
Table 29. Rotated Component Matrix for questions 2 and 4

\begin{tabular}{|c|c|c|}
\hline \multirow[t]{2}{*}{ Question responses } & \multicolumn{2}{|c|}{ Component } \\
\hline & 1 & 2 \\
\hline $\begin{array}{l}\text { 1- Global economy's impact on city's unreserved fund } \\
\text { balance }\end{array}$ & 0.412 & 0.536 \\
\hline $\begin{array}{l}\text { 2- Global economy's impact on city's economic } \\
\text { competitiveness }\end{array}$ & 0.112 & 0.745 \\
\hline $\begin{array}{l}\text { 3- Global economy's impact on city resident's income } \\
\text { distribution }\end{array}$ & 0.336 & 0.767 \\
\hline $\begin{array}{l}\text { 4- Global economy's impact on the economic status of the } \\
\text { poor }\end{array}$ & 0.342 & 0.724 \\
\hline 5- Global economy's impact on city residents' job security & 0.204 & 0.799 \\
\hline 6- Globalization's impact on stability of revenue streams & 0.653 & 0.382 \\
\hline 7- Globalization's impact on residents' sense of neighborhood & 0.777 & 0.346 \\
\hline 8- Globalization's impact on provision of affordable housing & 0.848 & 0.162 \\
\hline $\begin{array}{l}\text { 9- Globalization's impact on procurement and purchasing } \\
\text { practices }\end{array}$ & 0.840 & 0.274 \\
\hline $\begin{array}{l}\text { 10- Globalization's impact on variety of services delivered to } \\
\text { specific demographics }\end{array}$ & 0.842 & 0.219 \\
\hline
\end{tabular}

I hereby submit that the six conjectures identified within the interviews may be categorized under either of the two factors derived from the factor analysis: municipality's socio-economic viability and municipality's managerial capacity.

Table 30. Classification of public managers' perceptions of globalization's impact on public management

\begin{tabular}{|c|c|}
\hline $\begin{array}{c}\text { Municipality's socio-economic } \\
\text { viability }\end{array}$ & $\begin{array}{c}\text { Municipality's managerial } \\
\text { capacity }\end{array}$ \\
\hline \multicolumn{2}{|c|}{ Global awareness } \\
\hline Economic resourcefulness & Budget restraints \\
\hline Optimal living standards & Professional favorability \\
\hline & Personal reflection \\
\hline
\end{tabular}


All variables in questions two and four speak to public managers' global awareness and their ability to evaluate their work in light of this awareness. Based on the results, the impacts of globalization on public management are being perceived as conjectures of economic resourcefulness and optimal living standards which are portrayed by a municipality's socioeconomic viability. Meanwhile, globalization's impacts on public management are also being perceived by managers as reflective of a municipality's managerial capacity which manifest in conjectures such as budget restraints, professional favorability and managers' personal reflection on globalization and their role in it.

\section{Concluding remarks}

The analysis of the survey leads one to conclude that public managers in Florida's small-medium cities perceive globalization as having little to no impact on various aspects of public management in their municipalities. However, the transcripts from the interviews indicate that public managers feel that globalization has positive socio-economic repercussions in their municipality. This chapter demonstrates that public managers' perceptions of globalization's impacts on aspects of public management practice in Florida's small-medium cities are somewhat divided. Some public managers are of the view that globalization's impacts are clear and visible while others believe that globalization is extraneous to their contexts. 
Within Florida's small-medium cities, nuanced perceptions come from municipalities of various sizes, ethnic representations and geographies. The study validates the constructionist view of public management and demonstrates that public managers' perceptions of globalization and its impacts are contextual. The findings suggest that the demography or ethnic diversity of a small-medium city within the State of Florida may be more effective than its population size in understanding public managers' perceptions and experiences of globalization. Take, for example, the cities of Largo and Miramar with populations 69,371 and 72,739 respectively. Largo belongs to the Tampa/St. Petersburg MSA on the southwestern side of the State and Miramar to the Fort Lauderdale Metro Division in the southeast. The sentiments out of Largo assert that globalization is basically a non-event, while in Miramar, globalization is being hailed as a positive experience. Although both cities are close in population size, the perceived experiences of globalization are opposite.

This distinction may be explained by their difference in IQV or geographic location which are dissimilar. The results given in Tables 31 and 32 further illustrate the logic of this hypothesis. The tables present the results of cross-tabulation analysis for the relationships among managers' perceptions, city size and city IQV with their corresponding contingency coefficients and Pearson chi-square significance levels. Table 31 shows that for the statistically significant relationships between perceptions and a city's 
IQV, the associations are fairly strong. The analysis indicates that public managers in more ethnically-diverse cities are more likely to have positive perceptions about generally-accepted impacts of globalization.

Table 31. Cross-tabulation analysis for the relationship between cities' IQV and managers' perceptions

\begin{tabular}{|l|c|c|}
\hline \multicolumn{1}{|c|}{ Perception } & $\begin{array}{c}\text { Contingency } \\
\text { Coefficient }\end{array}$ & Sig. \\
\hline $\begin{array}{l}\text { A more competitive global economy - positive or } \\
\text { negative }\end{array}$ & 0.701 & 0.003 \\
\hline $\begin{array}{l}\text { Entrepreneurship among immigrants - positive or } \\
\text { negative }\end{array}$ & 0.661 & 0.068 \\
\hline $\begin{array}{l}\text { Local establishment of multinational corporations } \\
\text { - positive or negative }\end{array}$ & 0.710 & $<0.001$ \\
\hline $\begin{array}{l}\text { Increased racial/ethnic diversity complicates } \\
\text { policymaking in my municipality }\end{array}$ & 0.684 & 0.055 \\
\hline
\end{tabular}

Table 32. Cross-tabulation analysis for the relationship between city size and managers' perceptions

\begin{tabular}{|l|c|c|}
\hline \multicolumn{1}{|c|}{ Perception } & $\begin{array}{c}\text { Contingency } \\
\text { Coefficient }\end{array}$ & Sig. \\
\hline $\begin{array}{l}\text { A more competitive global economy - positive or } \\
\text { negative }\end{array}$ & 0.872 & 0.256 \\
\hline $\begin{array}{l}\text { Entrepreneurship among immigrants - positive or } \\
\text { negative }\end{array}$ & 0.815 & 0.225 \\
\hline $\begin{array}{l}\text { Local establishment of multinational corporations } \\
\text {-positive or negative }\end{array}$ & 0.850 & 0.221 \\
\hline $\begin{array}{l}\text { Increased racial/ethnic diversity complicates } \\
\text { policymaking in my municipality }\end{array}$ & 0.808 & 0.761 \\
\hline $\begin{array}{l}\text { Access to participation in the global economy } \\
\text { lowers operating costs for my municipality }\end{array}$ & 0.808 & 0.761 \\
\hline $\begin{array}{l}\text { Increased racial/ethnic diversity in my } \\
\text { municipality complicates policymaking }\end{array}$ & 0.830 & 0.198 \\
\hline Globalization raises wages in my municipality & 0.791 & 0.649 \\
\hline $\begin{array}{l}\text { Globalization increases job opportunities in my } \\
\text { municipality }\end{array}$ & 0.826 & 0.917 \\
\hline $\begin{array}{l}\text { Globalization improves quality of life standards in } \\
\text { my municipality }\end{array}$ & 0.830 & 0.691 \\
\hline
\end{tabular}


Table 32 shows that although there are strong associations between a city's size and public managers' perceptions about commonly-held views of globalization, the relationships are not statistically significant. Table 33 further shows that for analysis by metropolitan areas, certain perceptions bear fairly strong associations. These results imply that certain perceptions differ significantly depending on the metropolitan location of the public managers.

Table 33. Cross-tabulation analysis for the relationship between metropolitan areas and managers' perceptions

\begin{tabular}{|l|c|c|}
\hline \multicolumn{1}{|c|}{ Perception } & $\begin{array}{c}\text { Contingency } \\
\text { Coefficient }\end{array}$ & Sig. \\
\hline $\begin{array}{l}\text { Increased racial/ethnic diversity in my } \\
\text { municipality complicates policymaking }\end{array}$ & 0.700 & 0.002 \\
\hline Globalization raises wages in my municipality & 0.673 & 0.031 \\
\hline $\begin{array}{l}\text { Globalization improves quality of life standards in } \\
\text { my municipality }\end{array}$ & 0.673 & 0.032 \\
\hline
\end{tabular}

The importance of public managers' demographic factors such as age, level of education, professional exposure and place of birth was also analyzed. In order to more critically assess the claims gleaned from the interviews, cross-tabulation was carried out using the aforementioned demographic factors to provide compare public managers' perceptions of globalization's impacts in Florida's small-medium cities. The conclusions of the crosstabulation are presented and interpreted in the following statements:

1. Age, education level, overseas work experience and place of birth are all statistically significant in predicting public managers' perceptions of globalization's impact on job opportunities in their municipality. 
a. Older public managers tend to disagree that globalization increases job opportunities in their municipality.

b. Public managers with higher levels of education tend to agree that globalization increases job opportunities in their municipality.

c. Public managers who have worked outside the U.S. for at least one year during their professional life are more likely to agree that globalization increases job opportunities in their municipality.

d. Public managers who are native-born citizens of the U.S. tend to disagree with the notion that globalization increases job opportunities in their municipality.

2. Place of birth is a statistically significant determinant of public managers' perceptions of globalization's impact on wages.

a. A public manager who is a native-born citizen of the U.S. is more likely to disagree with the notion that globalization raises wages in their municipality.

3. Place of birth and overseas work experience are statistically significant variables for predicting public managers' perceptions of globalization's impact on quality of life standards in Florida's smallmedium cities. 
a. Public managers who indicate that they have worked outside the U.S. for at least one year of their professional life are more likely to agree that globalization improves quality of life standards in their municipality.

b. Native-born public managers are more likely to disagree that globalization improves quality of life standards in their municipality.

Interview dialogue and survey responses reveal public managers' ambivalence regarding the economic impacts of globalization. In both phases of the study, the findings show that public managers in Florida's smallmedium cities have mixed feelings about the perceived trade-off between increased job opportunities and wages that may arise from globalization.

Factor analysis results show that public managers' perceptions of globalization's impact on public management can be classified in two ways: (1) municipalities' socio-economic viability and (2) municipalities' managerial capacity. These factors may be used to further organize six thematic conjectures which also emerge from interview transcripts as public managers' perceptions of globalization's impact on public management. Managers' concerns of municipalities' socio-economic viability include issues such as employment opportunities, acceptable standards of living and wage distribution in the municipality. Managerial capacity refers to the municipality's fiscal strength, public managers' professional confidence and 
its ability to effectively and efficiently respond to resident's demands of services.

Finally, some public managers noted that globalization has no impact on public management in their respective locations. Whereas in the interviews some participants were generally positive and articulate about globalization, the survey demonstrates that several other public managers believe that globalization is pending but has not yet occurred in their municipality. However, these public managers indicate that they are mentally prepared for the changes when they come. For some public managers in Florida's small-medium cities, their views of globalization and its impacts on public management appear to be more theoretical than experiential.

This discrepancy between the results of the qualitative and quantitative analyses is noteworthy and prompts explanatory research. It raises a number of questions as to what might explain the divergence between perceptions. Neither the interview nor the survey responses reveal specific explanations but offer generic positive outlooks from public managers on the relationship between globalization and public management practices in Florida's small-medium cities. I submit possible explanations later in the discussion chapter of this dissertation. 


\section{CHAPTER VIII. MANAGERS' PERCEPTIONS OF}

\section{GLOBALIZATION'S IMPACT ON SPECIFIC PUBLIC MANAGEMENT FUNCTIONS}

The research seeks to understand public managers' perceptions of globalization's impact on the functions of decision-making, economic development and service delivery in public management in small-medium cities in Florida. This chapter outlines the findings of the qualitative and quantitative analyses of the data that address these functions.

\section{Decision-making}

Decision-making in public management entails choosing logical and practical options for realizing the multiplicity of citizens' needs within a complex political environment. As such, public managers are interested in making decisions that enhance their city's social, cultural and economic wellbeing. The quantitative and qualitative results of this study again show a difference of importance that public managers ascribe to globalization and its impact on how they carry out decision-making in their jurisdictions.

Question five of the survey specifically asked participants to indicate on a scale of 1 to 5 ( $1=$ low impact, $5=$ high impact $)$ how much they think globalization has affected certain decision-making issues as managers. Table 34 illustrates the findings. The modal response for all aspects given is 1 (low 
impact). For the stated aspects of decision-making, it is evident that public managers perceive globalization as having very little or no impact on the managerial function of decision-making. This finding suggests that decisionmaking among the participant public mangers is occurring with a primarily local focus. Global considerations apparently do not factor greatly in the decisions that are made by public managers in Florida's small-medium cities.

Table 34. Public managers' perceptions of globalization's impact on aspects of decision-making

\begin{tabular}{|l|c|c|c|}
\hline & Mode & Mean & $\begin{array}{c}\text { Std. } \\
\text { Deviation }\end{array}$ \\
\hline $\begin{array}{l}\text { Assessing the technical and people } \\
\text { skills of prospective hires }\end{array}$ & 1 & 2.04 & 1.12 \\
\hline $\begin{array}{l}\text { Deploying economic development } \\
\text { incentives }\end{array}$ & 1 & 2.02 & 1.16 \\
\hline Branding community's image & 1 & 2.32 & 1.30 \\
\hline Setting operating budget priorities & 1 & 1.90 & 1.04 \\
\hline Making capital budget decisions & 1 & 1.85 & 1.09 \\
\hline $\begin{array}{l}\text { Benchmarking with other } \\
\text { municipalities }\end{array}$ & 1 & 1.91 & 1.15 \\
\hline
\end{tabular}

\section{Qualitative analysis}

On the other hand, the qualitative analysis identifies that globalization presents four perceived drivers of decision-making among public managers in Florida's small-medium cities. These drivers are equity, cost, information and competition.

Equity

Public managers convey that globalization processes demand that, in making decisions, consideration be given to the methods used as well as the composition of the citizenry to ensure equitable outcomes. Globalization, as 
discussed earlier in this dissertation, has advantages and disadvantages that arguably challenge issues of social equity in various places. In advancing a "SupraRational Model" that is suited for decision-making in an interconnected world, Timney Bailey (1992) argues that "if a decision is good for the entire society then individual welfare is also maximized" (Timney Bailey and Mayer, 1992, p. 38). Therefore, in today's world, where public managers' decision-making is being impacted by so many different factors like cultural, gender and racial/ethnic diversity, a SupraRational model is quite applicable. The following response from the City of North Miami Beach succinctly invokes an understanding of a SupraRational approach to decisionmaking:

"Globalization affects the type of decisions that a public executive makes in the normal course of business. Immigration factors must be considered as one issue and on another spectrum procurement of goods and materials present other kinds of decision models."

Timney Bailey (1992) purports that "social equity is a key measure of decision effectiveness in the SupraRational model" (p. 50). She further advises that, contrary to the Rational model of decision-making which views reality in absolute terms, the SupraRational approach acknowledges that today's world is

multicolored, diverse, complex, and constantly changing. To make effective policy decisions in this world, we must adopt a multiversalist paradigm in which we accept the truth that answers are situational and temporal, that risks and uncertainties are par for the course, and finally, that the best 
that can be achieved is amelioration of today's problems as we await their new permutations tomorrow (p. 50).

In the survey, public managers were asked their opinion on the notion that increased racial/ethnic diversity complicates policymaking in their respective municipalities. The descriptive statistics in Chapter five show that of those who stated an opinion, $50.9 \%$ disagree with the statement while $37.1 \%$ agree. Table 35 presents the results of the cross-tabulation analysis between demographic factors and managers' perceptions. Table 35 shows that whether or not a manager has worked outside the U.S. for at least one year during their professional life is statistically significant in predicting their opinion on the impact of increased racial/ethnic diversity on policy-making.

The relationship between "worked outside U.S." and managers' perception is a weak negative one. This is determined from the Somers' $d$ value of -0.079 given in Table 36 . It can be deduced from this result that if a public manager has worked outside the U.S. for at least one year of their professional life, they are likely to disagree with the view that increased racial/ethnic diversity complicates policymaking in their municipality. 
Table 35. Managers' perceptions of the view that increased racial/ethnic diversity in my municipality complicates policymaking

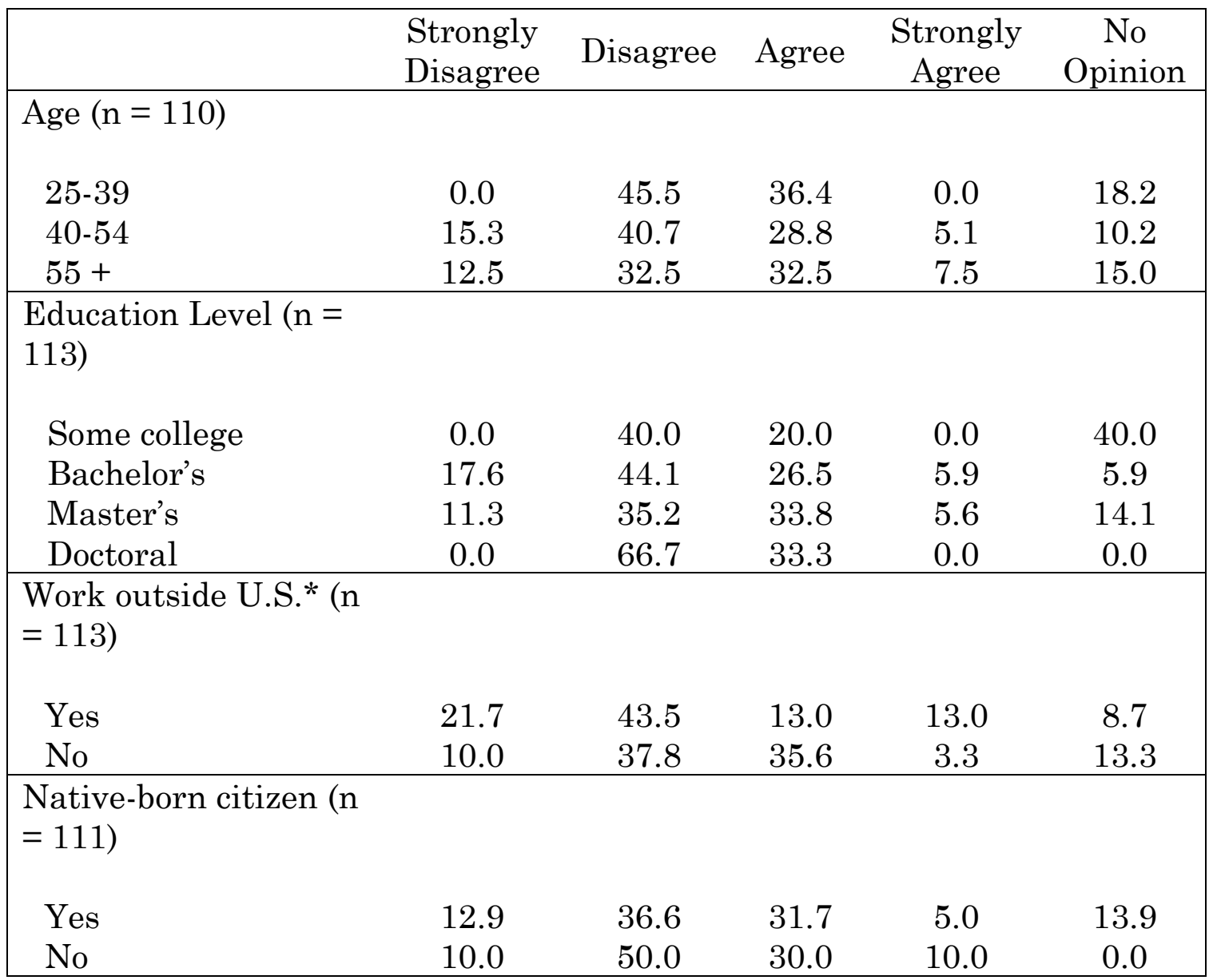

*Significant at $\mathrm{p}<0.1$

Table 36. Measure of association for managers' perceptions of the view that increased racial/ethnic diversity in my municipality complicates policymaking

\begin{tabular}{|l|c|}
\hline & Somers' d \\
\hline $\begin{array}{l}\text { Worked outside U.S. X Increased racial/ethnic diversity } \\
\text { complicates policymaking }\end{array}$ & -0.079 \\
\hline
\end{tabular}

\section{Information}

Managers expressed the view that globalization allows for more access to information and resources in decision-making. Managers consistently 
referred to the facility of the Worldwide Web that literally brings them the world through their fingertips. The managers admit that access to the Worldwide Web facilitates decision-making by making available time- and money saving options and providing informative and useful alternatives for decisions such as benchmarking, planning and purchasing. Consider the following quotes:

"In the way of information, we research for special events and for activities on the internet all kinds of different programs and activities from around the world to see how it's done all around. Now, when we do a search, maybe we are researching a particular problem of a city our size, used to be you called on a phone the areas around Florida that you know. Now you do the internet search and you may be getting replies from Seattle, Washington, from Canada. We've gotten information back from Japan. We've done some stuff and gotten information on how they do stuff in Korea so it just adds a different perspective on to what we're trying to do." (Temple Terrace, Tampa MSA)

"The positive is the opening of the community to new ideas, products, markets with diversification of the economic, social and cultural base. It does force us to view our planning, marketing and service levels differently." (Lake Wales, Lakeland MSA)

Despite the aforementioned expressions disclosed in the interviews, the survey data paint a different picture. When presented with different aspects of decision-making in the survey, the most common response from public managers is that globalization does not affect the complexity of decisionmaking.

$\underline{\text { Cost }}$

Public managers, throughout the interview stage of the research, remarked upon globalization's impact on making decisions that result in 
keeping operating costs low and seeking out cost-effective options for goods and services.

"Cities are not affecting global change. Cities are reacting to global change. Cities exist to provide services. We take in money to provide those services. To the extent that globalization affects the price at which we can buy products and services that we need, to the extent that the economy affects the willingness that people are willing to pay for services are the real impacts...The good things are efficiencies in lower price for things; when that happens is a good thing." (Winter Springs, Orlando MSA)

"It also has a danger of costing money to various organizations that it impacts - whether its through loss of markets or increased regulation.” (Miami Beach, Miami Metro Division)

Table 37. Managers' perceptions of the view that access to and participation in the global economy lowers operating costs for my municipality

\begin{tabular}{|c|c|c|c|c|c|}
\hline & $\begin{array}{l}\text { Strongly } \\
\text { Disagree }\end{array}$ & Disagree & Agree & $\begin{array}{l}\text { Strongly } \\
\text { Agree }\end{array}$ & $\begin{array}{c}\text { No } \\
\text { Opinion }\end{array}$ \\
\hline \multicolumn{6}{|l|}{ Age $(\mathrm{n}=110)$} \\
\hline $25-39$ & 0.0 & 18.2 & 27.3 & 0.0 & 54.5 \\
\hline $40-54$ & 6.8 & 28.8 & 25.4 & 5.1 & 33.9 \\
\hline $55+$ & 2.5 & 27.5 & 37.5 & 2.5 & 30.0 \\
\hline \multicolumn{6}{|c|}{$\begin{array}{l}\text { Education Level }(\mathrm{n}= \\
113)\end{array}$} \\
\hline Some college & 0.0 & 40.0 & 40.0 & 0.0 & 20.0 \\
\hline Bachelor's & 9.1 & 33.3 & 24.2 & 0.0 & 33.3 \\
\hline Master's & 2.8 & 23.6 & 29.2 & 5.6 & 38.9 \\
\hline Doctoral & 0.0 & 0.0 & 33.3 & 66.7 & 0.0 \\
\hline \multicolumn{6}{|c|}{$\begin{array}{l}\text { Work outside U.S. } \\
(\mathrm{n}=113)\end{array}$} \\
\hline Yes & 4.3 & 39.1 & 26.1 & 0.0 & 30.4 \\
\hline No & 4.4 & 24.4 & 30.0 & 4.4 & 36.7 \\
\hline \multicolumn{6}{|c|}{$\begin{array}{l}\text { Native-born citizen ( } \mathrm{n} \\
=111 \text { ) }\end{array}$} \\
\hline Yes & 5.0 & 27.7 & 28.7 & 4.0 & 34.7 \\
\hline No & 0.0 & 30.0 & 40.0 & 0.0 & 30.0 \\
\hline
\end{tabular}

Table 37 shows that none of the predictor variables are statistically significant in explaining public managers' perceptions about the global economy's impact on a municipality's operating costs. This is further borne 
out by the descriptive statistics presented in Chapter five which show that survey respondents' levels of agreement about globalization's impact on operating costs are more or less evenly divided across the categories $-32.8 \%$ disagree/strongly disagree; $32.7 \%$ agree/strongly agree; 34.5 no opinion. These results intimate that globalization's impact on a municipality's operating costs may be difficult to assess and further imply that the perceptions of public managers in Florida's small-medium cities as they pertain to the relationship between globalization and municipality's operating costs are, at best, inconclusive.

\section{Competition}

Public managers also emphasized in the interviews that globalization engenders competition which makes affordable goods and services more accessible. Hence, a competitive market enables optimal decisions. Some quotes that acknowledge this perception are:

"Competition and variety are good... competition generally means better pricing and often better value to the taxpayer....it has caused us to look at competitive markets differently. No longer are we simply competing nationally but we are literally competing internationally.” (Port Orange, Daytona Beach MSA)

"We're an attractor and a major part of our city is urban and most of the income that we derive is from the commercial development of the city which has a global impact because we're in competition with other, not only neighboring municipalities but also with the State of Florida, and nationally, and then internationally because of our proximity, you know, Miami-Dade in general, proximity to South America" (Coral Gables, Miami metro division) 
"More and more of our playground equipment and supplies are coming from manufacturers and distributors outside our city, obviously 'cause Temple Terrace doesn't have any manufacturing, but outside the state, we're getting a lot of our playground equipment manufactured in China, we're getting a lot of our equipment manufactured in Canada, in Mexico, so as that becomes easier to order, it saves time, we get equipment in cheaper, the manufacturers/representatives here in the United States get better products too, so that's just in the materials part..."

On the basis of these results, public managers seem to think that increased global competition is a positive repercussion of globalization. They translate the availability of and access to economical goods into efficient and responsive financial management and service delivery decisions.

The text of question three in the survey presented "A more competitive global economy" as an issue that may be viewed as a positive or negative repercussion of globalization. Public managers were asked to indicate their perceptions of these issues as either "Very negative," "Negative," "Positive," "Very positive," or "No effect." The descriptive statistics show that $64.3 \%$ of the respondents perceive a more competitive global economy as a positive repercussion of globalization.

Table 38 presents the results of a cross-tabulation of these responses with managers' demographics. The table shows that the variables "Age" and "Education Level" are significant when analyzed against managers' perceptions of the impact of a more competitive global economy. Table 39 presents the respective measures of association for these variables. 
Table 38. Managers' perceptions of the impact of a more competitive global economy

\begin{tabular}{|c|c|c|c|c|c|}
\hline & $\begin{array}{c}\text { Very } \\
\text { Negative }\end{array}$ & Negative & Positive & $\begin{array}{c}\text { Very } \\
\text { Positive }\end{array}$ & $\begin{array}{c}\text { No } \\
\text { Effect }\end{array}$ \\
\hline \multicolumn{6}{|l|}{$\operatorname{Age}^{* *}(\mathrm{n}=111)$} \\
\hline $25-39$ & 0.0 & 0.0 & 66.7 & 0.0 & 33.3 \\
\hline $40-54$ & 1.7 & 5.1 & 61.0 & 18.6 & 13.6 \\
\hline $55+$ & 2.5 & 20.0 & 40.0 & 10.0 & 27.5 \\
\hline \multicolumn{6}{|c|}{$\begin{array}{l}\text { Education Level }{ }^{*}(\mathrm{n}= \\
114)\end{array}$} \\
\hline Some college & 0.0 & 40.0 & 60.0 & 0.0 & 0.0 \\
\hline Bachelor's & 0.0 & 11.8 & 52.9 & 8.8 & 26.5 \\
\hline Master's & 1.4 & 6.9 & 52.8 & 18.1 & 20.8 \\
\hline Doctoral & 33.3 & 0.0 & 33.3 & 33.3 & 0.0 \\
\hline \multicolumn{6}{|c|}{$\begin{array}{l}\text { Work outside U.S. (n } \\
=114 \text { ) }\end{array}$} \\
\hline Yes & 0.0 & 8.7 & 47.8 & 21.7 & 21.7 \\
\hline No & 2.2 & 9.9 & 53.8 & 13.2 & 20.9 \\
\hline \multicolumn{6}{|c|}{$\begin{array}{l}\text { Native-born citizen }(\mathrm{n} \\
=112)\end{array}$} \\
\hline Yes & 2.0 & 9.8 & 53.9 & 12.7 & 21.6 \\
\hline No & 0.0 & 10.0 & 50.0 & 30.0 & 10.0 \\
\hline
\end{tabular}

*Significant at $\mathrm{p}<0.005$ $* *$ Significant at $\mathrm{p}<0.1$

Table 39. Measures of association for managers' perceptions of the impact of a more competitive global economy

\begin{tabular}{|l|c|}
\hline & Somers' d \\
\hline Education level X A more competitive global economy & 0.128 \\
\hline Age X A more competitive global economy & -0.145 \\
\hline
\end{tabular}

According to Tables 38 and 39, as education level increases, managers' attitudes towards a more competitive global economy are more likely to be positive. On the other hand, the results show that as the age of a manager increases, attitudes towards a more competitive global economy are more likely to be negative. 


\section{Economic Development}

The economic development function of public management is essentially concerned with ensuring, providing for and maintaining a financially viable environment in a city. The qualitative data exhibit that for several public managers in Florida's small-medium cities, the economic dimension of globalization may be the one of greatest value and interest. Globalization is seen by public managers as a purveyor of opportunities that diversify local business and expand commercial prospects. The following quotes from the surveys demonstrate this:

"Opportunities are expanded, particularly in economic development terms.”(North Port, Sarasota/Bradenton MSA)

"The primary positive is that it opens up greater opportunities for economic development." (Winter Garden, Orlando MSA)

"The positive comments from an economic development perspective include the opportunities for job creation, augmented revenue, multi-faceted points of view which stimulates creativity and shared resources." (Lauderdale Lakes, Fort Lauderdale metro division)

"Globalization diversifies the talent pool available for city jobs and it diversifies the entrepreneurs in the community available to increase the tax base." (Sanford, Orlando MSA)

The descriptive statistics report that a total of $76.2 \%$ of survey respondents believe that entrepreneurship among immigrants is a positive outcome of globalization. Table 40 presents the results of the cross-tabulation for the responses of managers' perceptions of the impact of entrepreneurship among immigrants and demographics. Table 40 also shows that education 
level and nativity status are statistically significant in understanding managers' opinions towards entrepreneurship among immigrants as a repercussion of globalization.

Table 40. Managers' perceptions of the impact of entrepreneurship among immigrants

\begin{tabular}{|c|c|c|c|c|c|}
\hline & $\begin{array}{c}\text { Very } \\
\text { Negative }\end{array}$ & Negative & Positive & $\begin{array}{c}\text { Very } \\
\text { Positive }\end{array}$ & $\begin{array}{c}\text { No } \\
\text { Effect }\end{array}$ \\
\hline \multicolumn{6}{|l|}{ Age $(\mathrm{n}=111)$} \\
\hline $25-39$ & 0.0 & 0.0 & 41.7 & 16.7 & 41.7 \\
\hline $40-54$ & 1.7 & 6.8 & 57.6 & 22.0 & 11.9 \\
\hline $55+$ & 2.5 & 2.5 & 52.5 & 22.5 & 20.0 \\
\hline \multicolumn{6}{|c|}{$\begin{array}{l}\text { Education Level* }(\mathrm{n}= \\
114)\end{array}$} \\
\hline Some college & 0.0 & 20.0 & 40.0 & 40.0 & 0.0 \\
\hline Bachelor's & 0.0 & 5.9 & 58.8 & 11.8 & 23.5 \\
\hline Master's & 1.4 & 2.8 & 52.8 & 25.0 & 18.1 \\
\hline Doctoral & 33.3 & 0.0 & 0.0 & 66.7 & 0.0 \\
\hline \multicolumn{6}{|c|}{$\begin{array}{l}\text { Work outside U.S. }(\mathrm{n}= \\
114)\end{array}$} \\
\hline Yes & 0.0 & 4.3 & 47.8 & 26.1 & 21.7 \\
\hline No & 2.2 & 4.4 & 53.8 & 22.0 & 17.6 \\
\hline \multicolumn{6}{|c|}{$\begin{array}{l}\text { Native-born citizen*** } \\
(\mathrm{n}=112)\end{array}$} \\
\hline Yes & 2.0 & 4.9 & 56.9 & 17.6 & 18.6 \\
\hline No & 0.0 & 0.0 & 20.0 & 70.0 & 10.0 \\
\hline
\end{tabular}

*Significant at $\mathrm{p}<0.005 ;{ }^{* *}$ Significant at $\mathrm{p}<0.01$

Based on the results of this analysis, it may be concluded that in Florida's small-medium cities, a public manager born outside the U.S. is more likely to have a positive impression of entrepreneurship among immigrants than one who was born in the U.S. This observation raises questions about generic perceptions of foreigners among natives even in a professional 
setting. As shown in Table 41, a Somers' d measure of -0.511 implies that there is a fairly strong negative relationship between a public manager's native origin and their perception about entrepreneurship among immigrants in their municipality.

Table 41. Measures of Association for managers' perceptions of the impact of entrepreneurship among immigrants

\begin{tabular}{|l|c|}
\hline & Somers' d \\
\hline Education level X Entrepreneurship among immigrants & 0.111 \\
\hline Native-born X Entrepreneurship among immigrants & -0.511 \\
\hline
\end{tabular}

It is evident from Table 41 that whereas education level and perceptions are positively related, place of birth and perceptions are negatively related. This means that public managers who are not nativeborn citizens of the U.S. and who have higher levels of education are more likely to view entrepreneurship among immigrants as positive.

Further, interview responses more specifically associate globalization with attracting foreign investment and international trade in their municipalities. Public managers, for example, claim:

"I know in economic development, some of the economic development things that we're doing now, particularly here in Seminole County, we're not limiting ourselves to companies that are just in the United States." (Oviedo, Orlando MSA)

"It brings a great deal of economic opportunity to the community through trade." (Miramar, Fort Lauderdale metro division)

"We have people here from all over the world and economic development is one of our big pushes now. We are looking at bringing in some higher tech type business, some would be what they call the creative class type businesses and we're dealing with 
people that bring businesses not only from just America but from anywhere."(Winter Garden, Orlando MSA)

Table 42. Managers' perceptions of the impact of local establishment of multinational corporations

\begin{tabular}{|c|c|c|c|c|c|}
\hline & $\begin{array}{c}\text { Very } \\
\text { Negative }\end{array}$ & Negative & Positive & $\begin{array}{c}\text { Very } \\
\text { Positive }\end{array}$ & $\begin{array}{c}\text { No } \\
\text { Effect }\end{array}$ \\
\hline \multicolumn{6}{|l|}{ Age $(\mathrm{n}=111)$} \\
\hline $25-39$ & 0.0 & 0.0 & 41.7 & 8.3 & 50.0 \\
\hline $40-54$ & 0.0 & 3.4 & 45.8 & 32.2 & 18.6 \\
\hline $55+$ & 2.5 & 2.5 & 35.0 & 27.5 & 32.5 \\
\hline \multicolumn{6}{|c|}{$\begin{array}{l}\text { Education Level }{ }^{*}(\mathrm{n}= \\
114)\end{array}$} \\
\hline Some college & 0.0 & 0.0 & 100.0 & 0.0 & 0.0 \\
\hline Bachelor's & 0.0 & 2.9 & 35.3 & 29.4 & 32.4 \\
\hline Master's & 0.0 & 2.8 & 40.3 & 29.1 & 27.8 \\
\hline Doctoral & 33.3 & 0.0 & 33.3 & 33.3 & 0.0 \\
\hline \multicolumn{6}{|c|}{$\begin{array}{l}\text { Work outside U.S. }(n= \\
114)\end{array}$} \\
\hline Yes & 0.0 & 8.7 & 30.4 & 34.8 & 26.1 \\
\hline No & 1.1 & 1.1 & 44.0 & 26.3 & 27.5 \\
\hline \multicolumn{6}{|c|}{$\begin{array}{l}\text { Native-born citizen (n } \\
=112 \text { ) }\end{array}$} \\
\hline Yes & 1.0 & 2.9 & 40.2 & 26.5 & 29.4 \\
\hline No & 0.0 & 0.0 & 50.0 & 40.0 & 10.0 \\
\hline
\end{tabular}

*Significant at $\mathrm{p}<0.001$

According to Table 42, education level is a significant predictor of public managers' perceptions of the local establishment of multinational corporations in their respective municipality. This relationship, although weak, is a positive one as Table 43 shows.

Table 43. Measure of association for managers' perceptions of the impact of local establishment of multinational corporations 
Education Level X Local establishment of multinational

0.030 corporations

This result implies that public managers with higher levels of education are more likely to perceive local establishment of multinational corporations in their municipality as a positive effect of globalization.

\section{Service delivery}

As presented earlier, this study posits that the delivery of public services is among the chief functions of municipal administration. Whether provided independently, in partnership with other agencies or by third parties, it is the primary responsibility of the local government and its administration to ensure the delivery of municipal services to residents. Data from the interviews show that urban service delivery is being impacted primarily in two ways by globalization: (1) Changes in the types of services offered; and (2) Adjustments to the modes of delivery. General statements from the survey that indicate the impact of globalization on service delivery are:

"Globalization exposes communities to a variety of ideas and service delivery methods.” (Port Orange, Daytona Beach MSA)

"International benchmarks offer examples of service delivery which may be beneficial to our City." (Gainesville, Gainesville MSA)

Public managers express that municipalities' changing demographics brought on by globalization demand relevant and effective service delivery. One 
police chief stated his interpretation of the impact of globalization on service delivery like this:

"Our motto here is "service above self" and you can't do that unless you know the other person, unless you know their needs, their belief systems, and all those things that are associated with them.... you can't really serve them. And that is because of the change in demographics, slowly but surely."

The specifics of how service types and modes of delivery are impacted by globalization are elaborated in the subsequent sections.

$\underline{\text { Types of services }}$

Interviewees noted that as a result of changing demographics among residents and the need to meet their changing demands, consideration has to be given to different types of services that meet these demands.

"Temple Terrace has a very diverse population - a lot of different cultures, a lot of different religions and stuff and we're always trying to gear our facilities and activities to be (let's see, the right word) to be ah... sensitive to some of those cultures."

Confronting issues of rising levels of foreign-born residents in Florida's smallmedium cities, public managers observe that certain services like parks and recreation have been adapted to respond to changing demographics. In particular, the climb in popularity of soccer as a recreation program was noted throughout the interviews. The following quotes from the three largest metropolitan areas in Florida address the presence of soccer in various municipalities:

"I guess, more so from the Spanish-speaking population - soccer is very popular, baseball, football is not very... with soccer there is an explosion and it's not just children it's adults, it's an 
intermix, adult soccer leagues. We have a sports complex at the end of town and we have a huge soccer program so... you just gotta deal with what the future's gonna bring" (Oldsmar, Tampa MSA)

"Change in programs.... There definitely has been an increase in soccer and it's funny you mention cricket. I was thinking that right as you mentioned it. Although we don't have any cricket facilities, I have had a couple requests from citizens in our community that were interested in seeing our cricket started. So we're definitely seeing that in the change in our demographics here in town. I'd say that a lot of traditional activities that parks and recreation has been involved with are still holding on but we are seeing a change in the activities." (Winter Garden, Orlando MSA)

"Soccer is, soccer has always been popular at our place but it has gotten more international that although statistics would say that it's because of the Latin countries or European countries that have come over, soccer was always very big with Americans, believe it or not, youth soccer was because it was looked at as a good way of exercise. They may not play it as professionals but as kids they did. But now what we've seen is that it has swayed. The American children seem to be more into basketball now and soccer is more international so we've had to do some things where the international people who play soccer, they're much more serious about it so we've had to go into more competitive areas where 10 years ago I never sent a team to state or national tournaments, now we have 5 o 7 teams that go to these tournaments because it's become a more serious thing because we have in our state a greater concentration of Latin American and South American teams that are really into soccer so those are the little things that we've done." (Coral Gables, Miami metro division)

"Some of the sports that we offer in our parks department used to be baseball and basketball because that's what the people liked to play. But now we offer soccer, volleyball and sports that are geared more towards other nations that like those other sports and the reason for that is, we have so many more residents now moving into our city that like to play those sports where before it wasn't a need so the fact that our city has become more global and people are finding out about our city impacts even what we do at the parks level." (Hialeah Gardens, Miami metro division) 


\section{$\underline{\text { Modes of delivery }}$}

Interviewees communicated that altering approaches to service delivery has

also had to be considered. The following quote from a public manager in Oviedo gives an example:

"It's all in service provision and being able to find those new techniques or technologies, being able to take advantage of those technologies but also being able to make sure that the service that is provided is provided in a way that is affordable to your residents. From a city standpoint, when you think about customers, if a city is too expensive for someone to live in, they're not going to live here and so you constantly have to be searching and searching for better and newer ways to do things."

This manager is essentially echoing the Tiebout hypothesis to show that residents' preferences influence service delivery and consequently, forces like globalization insist that public managers adapt the ways and means of providing services in order to ensure a viable community. As communities become more diverse, so too do residents' preferences and demands. A global outlook on public management promotes creativity, effectiveness and responsiveness towards citizens.

One of the ways in which managers indicated that service delivery has changed is in the ability of the city to facilitate bilingual residents. Managers mentioned the importance of being able to communicate effectively with immigrant residents in their native tongue where possible.

"I said I've been here a long time so I have experience in one location and one example of that is we encounter more people that speak Spanish or that's their primary language or in some cases it's their only language and you know, that really didn't 
happen 15 years ago, not much 10 years and it's ah, it's not necessarily people that I might see day in and day out but could be someone that is coming in to get their water turned on or someone that's come to the library and they're looking for the same thing anyone else would be looking for - information or books for their children or whatever it might be so the effect in terms of us and service delivery, it's useful if employees can speak Spanish or they're bilingual and we have a few employees that can do that..." (Oldsmar, Tampa MSA)

"One of the big things for us is, and we might have been a little late to the game, is language in terms of providing a lot of our marketing materials in Spanish. Now we're looking at... we've had some instances where we've had to do some interpretation in Creole which we hadn't done previously." (Coral Gables, Miami metro division)

Concurrently, the descriptive statistics show that 59\% of the survey respondents report that hiring bilingual individuals has been undertaken in their municipality.

\section{Human Resources}

Managers also commented on another aspect of management that has been impacted by globalization - the recruitment of a diverse staff and the consideration of employees' cultural competencies. Among the references made to the connection between human resources and globalization was the following from Hialeah Gardens in the Miami Metro Division:

"Where before everyone that had some money to invest were very familiar with the economy, they knew where things were, they knew what cities were good, what cities were not. Now you have to take a more proactive approach and let folks know that your city is just as good as city of Miami or city of Hialeah or city of Miami Beach, it's just a little bit smaller. So it directly affects the way you manage your city and it directly affects the way you 
do the employment for your city. You have to hire people that are bilingual to a certain extent, hire people that have some knowledge in global issues to be able to deal with those demands"

The Hialeah Gardens manager further elaborated:

"we now have a segment of our employment base that are now bilingual and actually, some of them speak three languages. The reason for that is we see over the last few years a lot of our residents have become a broader base of speaking languages. Where before we had primarily English and Spanish, we're getting a lot more now of people that are Brazilians who speak Portuguese so we have to gear our departments towards that... So now if we hire a dispatcher for our police department, for example, if we have two equally qualified and one of them speak Portuguese, we try to hire that person, where before that wasn't even an issue. And even the developers that are coming to our city now and are dealing with us, more times they have to bring a translator to have someone who speaks their language so we offer now our employees the opportunity to go back to school and learn a third language, you know, we incorporate that and that's happened over the last, say, 3 or 4 years so it's very recent."

Throughout the interviews, it was observed that police chiefs, in particular, emphasized the role of cultural competencies among officers:

"For example, our officers have been trained on cultural and human diversity. For Hispanic-Latinos, the touch, their distance away, you know, that's an accepted communication and in ours, it's not. Middle Eastern folks, the communication distance is 1 foot. Stand 1 foot away from a North American person and there is definitely a communication problem there. Making eye contact as we're doing now, for some cultures, it's very offensive. Being aware of those values, and you have to remember too we do see those folks. We have an international airport within a stone's throw away. When those people leave that airport from all over the world, they drive down Lake Mary Blvd. through our city to get to I-4 to get to where their destination might be. So we are impacted.... We really have tried to diversify our agency as well as train those individuals on the cultural values of different folks, understanding how to communicate with people" (Lake Mary, Orlando MSA) 
"We're staffed with a pretty good diverse department. It's been one of my goals since I got here to try and become more diverse and with that it brings a natural understanding that also we study other peoples so we can respond to them." (Temple Terrace, Tampa MSA)

You know, you think of police you think of cops and robbers types of crimes. Now you have internet crime that is very, very big including international internet crimes...We see it in the multicultural societies that we have now that demands that we have a multicultural workforce to be able to deal with the different cultures so I think it is important for city officials to be globally-minded. (Coral Gables, Miami MSA)

Public managers' recognition that human resources management has been impacted by globalization significantly is consistent with other findings in the study. Although not pursued as one of the management functions to be studied in the original question, human resources management has clearly been lifted out by public managers in this study as a dimension of public management that merits a closer look against the backdrop of globalization. The commentary on the human resources function and globalization further reiterates the contextual nature of public managers' perceptions and validates the application of the social constructionist approach to studying public management. Public managers who claim that globalization has little to no impact on their work or jurisdiction are not expected to articulate changes in human resources management in their organizations; insofar as community characteristics may dictate best practice in some but not all jurisdictions. 


\section{Concluding remarks}

Interview transcripts disclose public managers' perceptions of globalization's impact on the areas of decision-making, economic development, service delivery, and human resources management. Crosstabulation analysis further describes the relationships between demographic characteristics of public managers and their perceptions. In response to questions about globalization's impact on the decision-making and other aspects of public management and municipal governance, public managers most frequently reported that globalization has a low impact. While $44.8 \%$ of the respondents agree that globalization increases job opportunities in their municipality, nearly half (47.4\%) of the respondents disagree that globalization raises wages. As many as those who agree that globalization improves quality of life in their municipality, are those who have no opinion. A striking observation is that about one-third (34.5\%) of the respondents have no opinion on whether or not access to and participation in the global economy lowers operating costs for their municipality.

For both decision-making and service delivery functions, public managers in Florida's small-medium cities express that globalization fosters competition and offers the opportunity to seek out low-cost, time-efficient alternatives for goods and services by giving them access to information outside their jurisdictions. Such access is not only available from their immediate metropolitan region but also internationally. Age and education 
level are statistically significant in predicting public managers' perceptions of the impact of a more competitive global economy. Older public managers in Florida's small-medium cities tend to feel that a more competitive global economy is negative for their municipality. Public managers with higher levels of education tend to think that a more competitive global economy is positive for their municipality.

None of the variables used in the cross-tabulations shows up as statistically significant in explaining public managers' perceptions on the effect of access to and participation in the global economy on municipality's operating costs. This finding corroborates the relatively high percentage of survey respondents who indicate that they have no opinion on this dimension.

Public managers were also asked to share their views on the relationship between increased racial/ethnic diversity in their municipality and policy-making. The results show that whether or not a public manager has worked outside the U.S. for at least one year of their professional life is statistically significant in predicting their perception of the impact of increased racial/ethnic diversity on policy-making. In Florida's smallmedium cities, public managers who have worked outside the U.S. for at least one year during their professional life tend to disagree that increased racial/ethnic diversity in their municipality complicates policy- making. 
The thought that globalization is very beneficial for improving economic development and, by extension the quality of life, in Florida's smallmedium municipalities is a common theme that arises from the responses in the interviews. Public managers note that globalization provides the opportunity for their municipality to participate in the global economy by attracting industry and foreign investment and encouraging entrepreneurship.

Education level is a statistically significant predictor of public managers' perceptions of the local establishment of multinational corporations. Public managers with higher levels of education tend to perceive the local establishment of multinational corporations in their municipality as positive. Education level and place of birth are statistically significant predictors of public managers' perceptions of entrepreneurship among immigrants in small-medium municipalities in Florida. Public managers with higher levels of education tend to perceive entrepreneurship among immigrants as positive. Native-born citizens tend to perceive entrepreneurship among immigrants as negative.

Public managers also explain that globalization impacts the provision of services in terms of the types and modes of service delivery being carried out by small-medium municipalities in Florida. Interviewees explain that types of services and the modes through which they are delivered are being adapted and varied to cater to the changing demographics and diverse 
populations now present in their municipalities. According to public managers, these changes have further resulted in the need for city administrators to enable effective communication with residents. Efforts to hire bilingual individuals and train employees in various cultural competencies are given as evidence of this development. 


\section{CHAPTER IX. DISCUSSION}

This study uses responses from face-to-face interviews and a questionnaire among public managers in Florida's small-medium cities to critically ascertain if globalization impacts public management by probing public managers' perceptions of globalization and its impact on their work. This chapter discusses the results of the study which substantiate that globalization impacts public management practice in Florida's small-medium cities, albeit in perceived minimal ways.

Qualitative research and analysis were carried out in the first phase of the study for two reasons. First, results from the interviews provided insight on issues that could be elaborated in the survey. Second, the interviews recorded how a cross-section of public managers are making sense of globalization and its impacts on their work in small-medium cities in Florida. The interviews served to collect data on managers' constructions of globalization and present the social reality aspect of the study as promised with an interpretive and critical approach to inquiry. Subsequent statistical analyses provide a detailed description of the data and illuminate a number of relationships and factors among the variables used for measuring globalization and its impacts.

The study is grounded in a dual theoretical framework. It applies a structural-functional approach as well as a constructionist approach. Although these approaches may appear to be contradicting, this study has 
shown that both approaches may be used in tandem to understand the management of public organizations. The pairing of theoretical models represents best practice in executing triangulation for research.

The bureaucratic arrangement that is traditionally associated with public organizations has long been blamed for its inefficiency and ineffectiveness but does not negate opportunities for understanding social reality. The ability to understand an organization in terms of its constituents or functions facilitates in-depth study on how the parts relate to each other and how individuals working together in various roles enable effective operation of the organization. This research promotes that the impact of globalization on public management practice can be understood by studying the perceptions of those who practice public management. The structural/functional and constructionist paradigms together provide a means of understanding the relationship between structure and activity within an organization.

As applied in this study, the constructionist perspective illustrates that public managers in Florida's small-medium cities have their own formulations of globalization and its impacts on certain aspects of their work. The results of the analyses show that some public managers recognize strategies that are appropriate to respond to changing times and that these strategies are being implemented. Meanwhile, other public managers believe 
that globalization impacts are not at all relevant in their jurisdictions and professional environments.

True to the social constructionist theory, the study highlights that perceptions are contextual. Attitudes towards globalization's impact on public management are not shaped solely by demographic factors such as age or level of education. On the contrary, public managers' perceptions may also be founded on factors such as a municipality's geography and industry base. The following quote adequately summarizes this point:

"I think it's important that the broader field of public administration understand how local government is being impacted by the "outside world" but some of that is also just my own personal philosophy and outlook and Oldsmar is involved, either currently or has been involved in some international projects through ICMA as well so because we have an interest or perspective of what's going on in other places and like I said, some of that is just my own personal interest or I guess, opinions or I don't know if it's philosophy or not, but what you're interested in."

The structural-functional approach facilitates the understanding of the intersection between globalization and public management in light of three key functions of public management: decision-making, economic development and service delivery. The study demonstrates that public managers perceive globalization impacting these functions to some degree. Here again, the research shows that experiences and evidence of globalization's impact on public management functions vary among small-medium cities in Florida. The variation of perception could possibly be explained by a city's or public manager's demographics. Public managers in ethnically-diverse cities 
apparently perceive globalization as having more impact than those in more homogenous cities. Additionally, public managers with higher levels of education generally perceive globalization more positively.

\section{Current realities}

Census data show that small-medium cities in Florida are not immune to such globalizing activities as immigration and economic restructuring across geographical borders. However, the results of the quantitative analysis show that, for some public managers in Florida's small-medium cities, the concept of globalization may be perceived as having little impact in their communities and is yet to be understood in practical terms. Whereas public managers tend to identify with the theoretical definition of globalization, the study shows that there is a "disconnect" between the conceptual understanding of globalization and its real-life implications for the practice of urban public management. This points to a mismatch between public managers' perceptions and experiences; and shows that public managers can have opinions about globalization without necessarily being affected by it.

This paradox is obvious from the high frequency of responses in the survey that echo the opinion that globalization has little or no impact on managerial concerns such as operating costs, decision-making and aspects of 
a city's socio-economic conditions. Nevertheless, qualitative responses such as the following are noted:

"The economic situation of the country is what impacts our budget and capital projects. Housing foreclosures, reduced sales tax revenue, the passage of Amendment One, and a depleted stock market are what impacts this city's finances. The problem is not global issues that impact us but the mess created by Washington, D.C., The New York Stock Market, and a nationwide credit card problem are the real culprits. We still provide the same services to our citizens as last year but next year will be a much more difficult time." (Largo, Tampa MSA)

"Impacts to our budget have to do with legislature's property tax roll backs and "toxic" mortgages. We are a small city with Hispanics (Puerto Ricans, Cuban \& others), African-American, "white" population. We hire bilingual-Spanish - police officers where possible. We do not market nationally or internationally. The Rotary presents an International Folk Festival. We accommodate our residents and customers as best as possible." (Casselberry, Orlando MSA)

Largo and Casselberry are considered 'bedroom communities' in their respective metropolitan areas. Although both managers speak of generally accepted globalization effects such as the economic recession and housing industry which are inextricably tied to each other and the world economy, they do not seem to associate globalization with what they perceive to be pressing issues in their municipalities. As far as these public managers are concerned, their reality is constructed out of a national dynamic rather than a global one.

I hereby argue that, given these findings, the claims of globalization theorists such as Marcuse and van Kempen are simply not borne out on the ground, at least not in medium-sized cities in Florida. Although some public 
managers in this study are bracing for globalization, they have not yet experienced it.

Alternatively, the study may be affirming that these sentiments and others like it are demonstrative of how in-tune some public managers are with the interconnectedness of today's world. Public managers are able to identify dimensions of globalization yet do not recognize how they fit into the "big picture" of public management. The study shows that a significant number of public management practitioners tend to interpret global issues in light of their ability to meet pending intra-organizational needs and less on the mutual effect of the local-global interplay.

The fact that about one-third of the respondents in the survey indicate that they have no sense of whether or not access to the global economy and participation in it lowers operating costs for their municipality reinforces that public managers in small-medium cities in Florida are not readily cognizant of the realities of globalization's impact on the nuts-and-bolts of their work. A possible rationalization for this attitude may be that managers have to deal with change all the time and regardless of the nature of the changes, public managers are accustomed to adapting. They, therefore, do not give much attention or credence to globalization as a significant source of evolving practice. Alternatively, I hypothesize that public managers in small-medium cities in Florida may be in denial about the reality of globalization and its impacts because, as public service workers, they have inflation-adjusted 
salaries and pensions that are tied to cost of living standards as opposed to fluctuating international capital markets. Their jobs, by nature and execution, are relatively sheltered from wider-scale global financial activities compared with jobs in the private sector.

This finding is nonetheless disturbing in a time of globalization; and reinforces what others have already noted - that the field of public administration in theory and practice fails to acknowledge the significance of effectively relating public management and policy to macro-economic and finance issues (Frank et al, 2009). The failure of public managers to relate local concerns to global events ought to give public administration scholars and practitioners pause, especially at a time when Brookings Institute reports that six of Florida's twenty MSAs are among the weakest performing metropolitan areas in the country. ${ }^{25}$ Globalization, described in this dissertation as a contemporary, objective process in motion, insists that new tools be sought and developed to adequately respond to and serve a changing world. This study underscores that public management, as a discipline that seeks to understand and practice the best applications for serving the public interest, must promote global awareness as part of its preparation for being proactive in responding to citizens everywhere.

\footnotetext{
25 MetroMonitor, June 2009: Tracking Economic Recession and Recovery in America's 100 Largest Metropolitan Areas http://www.brookings.edu/ /media/Files/rc/reports/2009/06_metro_monitor/06 metromonitor.pdf Retrieved June 19, 2009
} 
It is not surprising that, among small-medium cities in Florida, attracting foreign tourists is a common activity that connects them to global marketplaces. Florida, the home of Mickey Mouse, miles and miles of sundrenched beaches and year-round tropical weather is famous for its buoyant tourism sector. Meanwhile, according to the mean values calculated for responses to the question on globalizing activities, public managers in the study report that municipalities are working towards improving their position in the global economy via alliances with private and public agencies. This finding shows that small-medium cities in Florida are globalizing as efforts are being made to connect small-medium cities to the global economy.

This study emphasizes that, in a time of globalization, size does not matter as far as it relates to the attitudes of those who manage cities. Short (2006) posits that "globalization is a pervasive force that affects all cities in the urban hierarchy”. The findings of this research show that, even among small-medium cities, public managers' perceptions of globalization vary and the assortment of globalization experiences may result from factors such as a city's economic base, its ethnic diversity, or its management's demographic composition.

Globalizing times require that public managers come to terms with the assets of their respective municipalities and promote them, regardless of size. Such an understanding has implications for municipalities' viability as conjectured by CEOs for Cities (2008): 
when the economy experiences a major change, as with the advent of information technology or from the emergence of new competitors through globalization or rising energy prices or the falling value of the U.S. dollar, this may fundamentally change the factors determining urban success ( $p$. $5)$.

According to CEOs for Cities (2008), against the backdrop of the aforementioned changes, a city can optimize its economic success if urban leaders consider their respective municipalities using three theories: theories of firms, theories of people and theories of place.

The theories of firms "centers on the economics of firms [and] focuses on the decisions of firms and the ways in which corporate organization and changes in technology and globalization affect a city's economic development"; the theories of people "deals with the human element of cities and the ways in which the demographic composition, skills and attitudes of a city's residents influence its economic opportunity"; and the theories of place "revolves around the built urban environment and the way it encourages or supports economic activity” (pp. 11, 35, 49).

Based on this framework, CEOs for Cities (2008) further identify city types derived from each of the three theories. For example, a "human capital city" is one founded on theories of people (CEOs for Cities 2008, p. 36). A human capital city is so identified on the basis that it succeeds because of its ability to "attract talented workers and further develop the talent of their labor force" (p. 36). Similarly, an "entrepreneurial city" is derived from the 
theories of firms and is one "that gives rise to new firms and new work" ( $p$. 31). My study affirms that the CEOs for Cities' model is compatible with the results of this study. The CEOs for Cities' framework bolsters this study and offers ways in which small-medium cities in Florida can take advantage of globalization and its impacts. Globalization presents small-medium cities with an opportunity to develop themselves according to their identified strengths and uniqueness, thereby eking out a space in the global arena. Small-medium cities in Florida like Coral Gables, Miami Beach, and Orlando are examples of highly active global players that have undoubtedly harnessed their particular strengths to enhance their economic prosperity and position in the global economy.

\section{Managers' perceptions of globalization}

To ground the theoretical framework of the study, a select group of public managers in Florida's small-medium cities were asked in interviews to articulate their perceptions of the concept of globalization. After a reiterative process of comparing the contents of the interview transcripts, the study concludes that public managers conceptualize globalization in multidimensional terms consistent with existing literature. Public managers convey that globalization is a multi-faceted, dynamic, engaging and historical process that is changing economic development, decision-making and service delivery functions of city management. In terms of managing a city, 
globalization is here understood as a multifaceted process of transnational demographic shifts, rapidly changing technologies, and municipalities' heightened involvement in the global economy that alters the various functions of public management.

For this study, age, education level, place of birth, and overseas work experience were considered as predictors of a public manager's perceptions of globalization and its impact on their work. The relationships between the managers' perceptions and demographic data were analyzed for statistical significance. The study finds that for those relationships that are statistically significant, public managers who are younger, have higher levels of education and have worked outside the U.S. for at least one year have more positive outlooks on globalization and its impacts. Older public managers who are native-born citizens of the U.S. tend to perceive globalization more negatively.

These findings are noteworthy as the theory and practice of public administration is being reinvented with an emphasis on public management. The results suggest that the profession of public management would be welladvised to broaden the scope of prospective practitioners' demographics for inclusion in its applications. Charih et al (2007) note that the demographics of the public service in the U.S. are critical to public administration reform. They observe that over the last two decades, the public sector has neglected 
to recruit and retain "the most talented candidates" and that the public sector

is less attractive to young Americans... and has not been able to adapt itself to meet the expectations of new generations with regard to work, whether it be in relation to salary or other aspects of work such as the variety of challenges (p. 27).

The negative outlook of older public managers on the concept of globalization and its impacts, as brought out by this study, implies that some Florida public managers in small-medium cities may suffer from what Ascher (1978) calls "assumption drag - the continued use of assumptions long after their validity has been contradicted by the data" (p. 53). Assumption drag among Florida's public managers is evident in those responses that seem to rely upon outdated interpretations of global events and their repercussions, and responses that claim that globalization is not of the present but pending.

The study points out the importance of considering a range of demographic characteristics to ascertain public managers' competencies to respond to the multidimensional nature of globalization that is a current reality. Leuenberger and Kluver (2006) submit that "in the face of a number of cultural, political and environmental changes, public sector organizations need to encourage public managers to attract and develop persons capable of and energized for solving the problems we now face." The fact that "community and organizational multiculturalism" emerges from the quantitative analysis as one of the domestic/internal managerial responses to 
globalization further implies that public managers in Florida's small-medium cities have recognized its salience for the city as a place of employment as well as a place of residence in contemporary times. Comments noted among the open-ended questions of the survey and in the interviews corroborate this finding:

"Globalization diversifies the talent pool available for city jobs."

"Well, we recognize that we benefit tremendously from globalization here. We have a large immigrant population of recent immigrants who are, if not the majority, a large percentage of our small business owners and we do have significant exports coming out of [our city]."

\section{Managers' perceptions of globalization's impact on public}

\section{management}

My research demonstrates that managers' perceptions about globalization and its impacts in Florida's small-medium cities do not differ from reality, theoretically. However, although public managers in Florida's small-medium cities tend to concur that globalization is now integrally tied to the technical expertise required to run a public organization like the city, the results of the study present a subtle consensus among participants concerning the impacts of globalization on public management practices. These results reveal an asymmetry between interview responses and survey responses. For instance, the measures given in question one of the survey are indicators of typical globalizing activities but respondents most frequently point out that their municipality is not involved in these activities. 
Similar opinions were also shared in the open-ended questions. On the other hand, further condensation of the survey responses with factor analysis reveal that managerial activities are being undertaken among the cities, in response to globalization. These responses are classified as internal/domestic and external/international. Public managers in Florida's small-medium cities apparently cognate globalization in a logical manner but may not see its impacts as significant. Nevertheless, the recognition of these responses by public managers reinforces the inclusive nature of public management being practiced in Florida's small-medium cities while disclosing the nuanced perceptions of public managers concerning globalization.

\section{Managers' perceptions of globalization's impact on public management functions}

The findings of this study bear out the notion that public management in Florida's small-medium cities is not immune to globalization and its impacts. In the minds of some of the participant public managers, globalization presents a strong imperative to redefine public management practice. Public managers in Florida's small-medium cities communicate that public management practice can no longer be seen through a solely domestic prism. For many in this study, globalization makes available a wide variety of options, from anywhere in the world, for enhancing public management functions; in particular, those of decision-making, service 
delivery and economic development. In a sense, the study notes that the practice of public management itself is being globalized, resulting in an international exchange of public management methods and ideas among municipalities.

The study shows, conclusively, that public managers in small-medium cities of Florida find opportunities and challenges for public management among the social, cultural, technological and economic dimensions of globalization. The results suggest that managers agree that practicing public management in these times must include more than U.S. concepts and products to stay viable and competitive. Globalization has elucidated the importance of considering city management broader than U.S. personnel, U.S. intelligence and U.S. technology. In addition, Florida's public managers in small-medium cities note how global changes including the advancement of technology and increased immigration have led to the need for adopting contemporary approaches to providing public services such as the increased inclusion of soccer programs in the case of recreation and Internet crimefighting and prevention in public safety.

There is a growing understanding among public managers in Florida's small-medium cities that clinging to notions of the exclusivity of U.S. products, U.S. markets and U.S. personnel renders the city as a public service organization far less competitive. In a time of increasing economic constraints and budget cutbacks, public managers are ever more cognizant of 
the reality that to look outside their immediate geographical borders is the professionally- and practically-wise decision to make. A public manager in the Daytona Beach MSA proffers;

"When you think about the pricing structure of virtually every item a City acquires is impacted by the global economy. No longer are products and services simply available from U.S. vendors or companies."

\section{Strengths of the study}

The research takes an interdisciplinary approach and engages literature from political science, public administration and sociology to emphasize the multi-dimensional nature of globalization and public management. The collaboration of quantitative and qualitative methodological approaches underscores the analytical strength of the study to produce compelling, reliable and relevant results. The generation of components by the factor analysis method especially validates the study as appropriate for use with a structural-functional framework. In analyzing management activities as responses to globalization, the classifications exhibited hark back to Allison's (1982) framework of management which refers to the functions of management as "strategy, managing internal components, and managing external components" (p. 17).

Further, the quantitative results illuminate opportunities for deeper examination of the public managers' perceptions shown up by the qualitative results. The divergence of the qualitative and quantitative results in parts of 
the study ought to be interpreted as a contingency for further critical analysis. The mixed-method approach has also reinforced the discrepancy that is typically ascribed to the field of public administration: that its theory and practice are seemingly at odds with each other.

The research design guards against committing reductionism or an ecological fallacy in arriving at conclusions. Ecological fallacies and reductionism are research errors that occur when there is a mismatch between inferences and units of analysis employed (Neuman, 2004, pp. 9596). The results of this study consistently show that public managers' perceptions are contextual and cannot be used to generalize about globalization effects and experiences in all small-medium cities in Florida. Nevertheless, the responses suggest that at least some participants view their operations through a more global perspective.

\section{Weaknesses and limitations}

Globalization, by nature, is multidimensional, dynamic and not easily operationalized. This study submits a definition of globalization in the context of public management that allows for measurable understanding of its dimensions. However, a few conditions limit this study. First, the collection of data carried out by Internet proved to be more counterproductive than anticipated. E-mail communication with public organizations is not the most reliable as security devices may have oftentimes prevented the survey 
message from being transmitted to its intended recipient. As a result, the representativeness of respondents may be somewhat lacking.

Second, financial constraints inhibited the inclusion of more face-toface interviews as well as the likely offer of incentives to boost the response rate and to enhance the validity of public manager's experiences. Third, respondents report that they lack the information required to answer certain survey questions. Although the survey questions ask for perceptions, participants express a reluctance to offer opinions unsubstantiated with objective data.

Fourth, the study does not consider the concept of place as a determinant of public managers' perceptions. The results of the study shows that a city's amenities and its built environment are important in determining how public managers view globalization and its impacts. For example, a public manager in a city that is located close to the principal city of a MSA or near an international airport is likely to view globalization more broadly than a manager in location less contiguous to a principal city and its amenities.

Fifth, whereas the study's findings may be generalizable to smallmedium cities in other states, this study believes that threats to the external validity of Florida's of public managers' perceptions may exist by virtue of Florida's over-reliance on the tourism and construction sectors, and relative insulation from wide-scale international competition. 


\section{Implications for future study and the field of public management}

The study asserts that the function of human resources management is significantly affected by globalization. While the results of the study points to the area of hiring individuals who are bilingual as one of the main human resources considerations arising from the impacts of globalization, it identifies an opportunity for understanding deeper the ways in which other areas of staffing and interpersonal relationships such as cultural competencies may affect the performance of public organizations. Rice (2007) advises that "the teaching and practice of public administration must focus on cultural competency in a contemporary, multicultural era". As the field of public administration seeks to reinvent itself with an emphasis on management, this study endorses the invitation for the discipline to consider a cultural competency model and globally-aware approach. Future research can explore the in-roads that small-medium cities have made in terms of cultural competency training for its employees.

Additionally, the study points to further research in assessing the contextual effects of place on the intersection between globalization and public management in small-medium cities. Public managers' perceptions of globalization's impact should be studied against the relationship between small-medium cities' global activity and characteristics of the cities' locations, to rationally ascertain if managers' perceptions resemble the reality of globalization playing out in these places. An inquiry into public programs, 
services and their respective clients may be carried out to better understand the reality.

The study notes that participants tend to emphasize the positive repercussions of globalization and while ignoring the theorized negative effects. This observation questions whether or not public managers in Florida's small-medium cities understand the downside of globalization, especially in economic terms. As pointed out earlier, globalization may be beneficial in enhancing the socio-cultural life of a city and may result in higher gross domestic product of cities but may potentially contribute to increased reliance on low-paying jobs and, therefore, lower overall per capita income. Further study can offer a clearer understanding of how public managers' perceive the negative aspects of globalization and its impacts in their municipalities.

The discrepancy in perceptions among public managers may represent the reality of a tipping point that warrants further interpretation. The study seems to pose the following questions: Is there a point at which public managers' perceptions shift from not acknowledging globalization and its impacts in municipalities? and what might cause that shift? 


\section{CHAPTER X. CONCLUSION}

My study has been an attempt to expose the insights of public managers' perceptions of globalization and its impact on their work in order to provide the answer to the question: "Does globalization affect public management practices in small-medium cities in the State of Florida"? It has pursued the goals set forth at the beginning of the study by employing a combination of qualitative and quantitative techniques through interviews and statistical analysis with a combined constructionist and structuralfunctionalist framework. This study shows that examining public management through constructionist and structural-functionalist lens is instructive for understanding the practice in globalizing times. Paradigm bridging, as demonstrated in this study, is useful for critical inquiry into the practice and theory of public administration. Triangulated methodology serves to improve the quality of research and the reputation of the discipline.

The rationale for this study is bolstered by the fact that the impact of globalization in small-medium cities is understudied and that, in general, the intersection of globalization and public management in these contexts requires illumination. The research has shown that public managers in Florida's small-medium cities perceive globalization and its impacts from a variety of perspectives. Whereas some public managers in small-medium cities acknowledge globalization in real terms, others express that globalization has no bearing on their work or jurisdiction. This observation 
reflects a local-cosmopolitan distinction among the participant public managers in this study (Gouldner, 1957). According to Gouldner's theory, the locals in this study may be typified as organization-centered professionals who may not want to identify with global issues and their local impacts. On the other hand, the cosmopolitan public managers may be identified as those who view reality with a wide lens and perceive global activities as an integral part of their everyday activities.

In response to the main research question of "does globalization affect public management practices in small-medium municipalities in the State of Florida?" public managers' answer is "Yes, to a particular extent." After speaking with twenty-five public managers across the state and analyzing 126 surveys, the response to the primary research question is a nuanced one. Whereas the data from the interviews reveal that public managers in Florida's small-medium cities understand globalization as a multi-faceted, historical, engaging and dynamic process that is altering public management functions in their municipalities, the survey results present a more halting perspective.

Public managers of small-medium cities in Florida share common perceptions of the concept of globalization; however, their view of globalization's impact on their work differs slightly. In light of the managerial functions of economic development, service delivery and decisionmaking, most public managers convey that globalization presents 
opportunities and challenges for adapting to transformations in local economies, technology and population demographics but others believe globalization has no impact at all, at least "not yet".

My study reinforces the importance of contemplating and understanding the intersection of two activities that affect how individuals live: globalization and public management. Public managers play a very significant role in the quality of life that is experienced within municipalities. Public managers, if they are to be relevant and responsible in carrying out their duties of public service, must represent a group that is current, aware and responsive.

Davis (2007) notes that how the public sector rises to meet the challenges of this era of globalization is paramount to government renegotiating its role, purpose and reinventing itself for the 21st century. He suggests that the public sector stands to gain from adopting some private sector techniques such as "better transparency, improved performance management, better alignment of incentives, stronger accountability, better incorporation of technology, and, crucially, better attraction, deployment, and development of talent" (p. 5). Certainly, this advice is applicable and appropriate for public management practitioners in Florida's small-medium cities as they ponder their role in globalizing times in an effort to provide efficient and effective service in a responsive and equitable manner. 
The research also discloses that while public managers in Florida's small-medium cities express perceptions of globalization as multifaceted, they do not seem to perceive the impacts of globalization with a broad interdisciplinary gauge. Instead, public managers tend to appreciate globalization in theory as its social dimension, and practically, for its economic development advantages. The responses from the survey suggest that the nature of public managers' work may be the cause of this expressed perception; that is, an emphasis on day-to-day activities that primarily seek to satisfy residents' demands and preferences with the provision of services and promotion of local economic development. The economic dimension of globalization seemingly promises more benefits to public managers that translate into improved quality of life in municipalities.

While there is general agreement among public managers in Florida's small-medium cities that globalization trends are occurring, there is far less agreement about how these trends impact public management practice and play out politically, socially, culturally and economically in respective locales. This research confirms the reality of globalization as a complex and ofteninterpreted vacuous phenomenon in the minds of public managers. In as much as academics have a difficult time understanding globalization and its impacts, so too do public managers in Florida's small-medium cities.

It has been nine years since Giddens (2000) declared that "globalization is not incidental to our lives today. It is a shift in our very life 
circumstances. It is the way we now live" (p. 37). From this study, it appears that for some public managers in Florida's small-medium cities, globalization is not so global after all. 


\section{LIST OF REFERENCES}

Abrahamson, M. (2004). Global cities. New York: Oxford University Press.

Allison, G. (1982). Public and private management: Are they fundamentally alike in all unimportant respects? In F. S. Lane (Ed.), Current issues in public administration. New York: St. Martin's Press.

Amen, M. M., Archer, K., \& Bosman, M. M. (2006). Relocating global cities : From the center to the margins. Lanham, Md.: Rowman \& Littlefield.

Aronson, J. R., ICMA Training Institute, \& Schwartz, E. (2004). In Aronson J. R., Schwartz E. (Eds.), Management policies in local government finance (3rd ed.). Washington, D.C.: Published for the ICMA Training Institute by the International City Management Association.

Berube, A., Katz, B., Lang, R. (2006). Redefining urban and suburban America Volume 3 : Evidence from Census 2000. Washington, D.C.: Brookings Institution.

Beynon, J., \& Dunkerley, D. (2000). Globalization : The reader. London: Athlone.

Bickman, L., \& Rog, D. J. (2009). The SAGE handbook of applied social research methods (2nd ed.). Los Angeles: SAGE.

Boxill, I. (1999). Sovereignty, globalization and Caribbean integration. Social and Economic Studies, 48, 4.

Castells, M. (1989). The informational city: Information technology, economic restructuring, and the urban-regional process. Oxford, UK ; New York, NY, USA: B. Blackwell.

CEOs for Cities. (2008). City success: Theories of urban prosperity. Chicago, IL: Joseph Cortright, Impresa Consulting.

Charih, M., Bourgault, J., Maltais, D., \& Rouillard, L. The management competencies of senior managers: A look at some OECD countries. 7 th Global Forum on Reinventing Government: Building Trust in Government, Vienna, Austria.

Croucher, S. L. (2004). Globalization and belonging: The politics of identity in a changing world. Lanham: Rowman and Littlefield Publishers, Inc.

Czarniawska Joerges, B. (2002). A tale of three cities : Or the glocalization of city management. Oxford: Oxford University Press. 
Davis, I. (2007). Government as a business. The McKinsey Quarterly, (October), 2.

Donahue, J. D., \& Nye, J. S. (2000). Governance in a globalizing world. Cambridge, Mass.; Washington, D.C.: Visions of Governance for the 21st Century; Brookings Institution Press.

Folz, D. H., \& French, P. E. (2005). Managing America's small communities : People, politics, and performance. Lanham, Md.: Rowman \& Littlefield Publishers.

Frank, H. A. (2008). The deeper structure of the fiscal crisis and its implications for the public administration research agenda. Annual Conference of the American Society for Public Administration, Miami, FL.

Friedman, T. L. (2006). The world is flat: A brief history of the twenty-first century (1st updated and expanded ed.). New York: Farrar, Straus and Giroux.

Garreau, J. (1991). Edge city : Life on the new frontier (1st ed.). New York: Doubleday.

Gianakis, G. A., \& McCue, C. P. (1999). Local government budgeting : A managerial approach. Westport, Conn.: Quorum.

Giddens, A. (2000). Runaway world: How globalization is reshaping our lives. New York: Routledge.

Gordon, G. J., \& Milakovich, M. E. (2001). Public administration in America (7th ed.). New York: St. Martin's Press.

Gouldner, A. W. (1957). Cosmopolitans and locals: Toward an analysis of latent social roles. Administrative Science Quarterly. 2(3). 281.

Hall, T. (2006). Urban geography (3rd ed.). London ; New York: Routledge.

Hardt, M., \& Negri, A. (2000). Empire. Cambridge, Mass.: Harvard University Press.

Hebron, L., \& Stack, J. F. (2008). Globalization: Debunking the myths. Upper Saddle River, N.J.: Pearson Prentice Hall.

Held, D. (1998). Democracy and globalization. In D. Archibugi, D. Held \& M. Kohler (Eds.), Re-imagining political community (pp. 11-27). Stanford, CA: Stanford University Press. 
Held, D., \& McGrew, A. G. (Eds.). (2000). The global transformations reader: An introduction to the globalization debate. Malden, Massachussetts: Polity Press.

Hertz, N. (2001). The silent takeover : Global capitalism and the death of democracy. New York: Free Press.

Hughes, O. E. (2003). Public management and administration : An introduction (3rd ed.). New York: Palgrave.

Jun, J. S. (2006). The social construction of public administration: Interpretive and critical perspectives. Albany: State University of New York Press.

Keohane, R. O., \& Nye Jr., J. S. (2000). Introduction. In J. S. Nye, \& J. D. Donahue (Eds.), Governance in a globalizing world (pp. 1). Washington, D.C.: Brookings Institution Press.

Konvitz, J.W. (1995/1996). Cities and the global economy. The OECD Observer, 197, 6.

Leuenberger, D. Z., \& Kluver, J. D. (2005/2006). Changing culture: Generational collision and creativity. Public Manager, 34(4), 16.

Massey, D. B. (1994). Space, place, and gender. Minneapolis: University of Minnesota Press.

Milakovich, M. E. (2006). Improving service quality in the global economy: Achieving high performance in public and private sectors (2nd ed.). Boca Raton, FL: Auerbach Publications.

Milanovic, B. (2003). The two faces of globalization: Against globalization as we know it. World Development, 31(4), 667.

Mittelman, J. H. (2004). Whither globalization? : The vortex of knowledge and ideology. London ; New York: Routledge.

Morgan, D. R., England, R. E., \& Pelissero, J. P. (2007). Managing urban America (6th ed.). Washington, DC: CQ Press.

Neuman, W. L. (2004). Basics of social research: Qualitative and quantitative approaches (4th ed.). Boston: Pearson Education, Inc.

Norusis, M.J. (2004). SPSS 12.0 Guide to data analysis. New Jersey: Prentice Hall. 
Rice, M. F. (2007). A post-modern cultural competency framework for public administration and public service delivery. The International Journal of Public Sector Management, 20(7), 622.

Ritzer, G. (1875). Sociology: A multiple paradigm science. Boston: Allyn and Bacon.

Rosenbloom, D. H., \& Kravchuk, R. S. (2005). Public administration : Understanding management, politics, and law in the public sector (6th ed.). New York: McGraw-Hill.

Rusk, D. (2003). Cities without suburbs : A census 2000 update (3rd ed.). Washington, D.C.; Baltimore, Md.: Woodrow Wilson Center Press; Distributed by Johns Hopkins University Press.

Sassen, S. (2005). Local actors in global politics. Women in Action, , 31.

Sassen, S. Emergent global classes and what they mean for immigration politics. Retrieved 12/20, 2007, from http://www.migrationinformation.org/Feature/print.cfm?ID=490

Sassen, S. (1996). Cities and communities in the global economy: Rethinking our concepts. The American Behavioral Scientist, 39(5), 629.

Shannon, D.M., Davenport, M.A. (2001). Using SPSS to solve statistical problems: A self-instruction guide. Upper Saddle River, NJ: Merrill Prentice Hall.

Smith, K. B., \& Licari, M. J. (2006). Public administration: Power and politics in the fourth branch of government. Los Angeles, California: Roxbury Publishing Company.

Steger, M. B. (2003). Globalization: A very short introduction. Oxford: Oxford University Press.

Stiglitz, J. E. (2002). Globalization and its discontents (1st ed.). New York: W.W. Norton.

Svara, J. H. (1990). Official leadership in the city: Patterns of conflict and cooperation. New York: Oxford University Press.

Tasan-Kok, T., \& van Weesep, J. (2007). Global-local interaction and its impact on cities. Journal of Housing and the Built Environment, 22, 1.

Taylor, P. J. (2006). Cities in globalization: Practices, policies and theories. New York, NY: Routledge. 
Timney Bailey, M. (1992). Beyond rationality: Decisionmaking in an interconnected world. In Timney Bailey, M. \& Mayer, R.T. (Eds.). Public management in an interconnected world: Essays in the Minnowbrook tradition. Westport, CT: Greenwood Press.

van Kempen, R., \& Marcuse, P. (2000). Globalizing cities: A new spatial order?. Oxford ; Malden, Mass: Blackwell publishers.

Warner, R. M. (2008). Applied statistics: From bivariate through multivariate techniques. Los Angeles: SAGE Publications.

Wilson, Ernest. 2006. Globalizing cities and their foreign policies. http://www.tpmcafe.com/node/28748, Retrieved June 12, 2006. 


\section{APPENDIX}

\section{A. SUMMARY OF SURVEY QUESTIONS' RESULTS}

1. For each of the following activities, please indicate the level of activity carried out on behalf of your city by municipal administration/government.

a. Attracting foreign direct investment No activity $70.6 \%$ Little activity $16.7 \%$

Medium activity $7.9 \%$ Medium-high activity $4.8 \%$ High activity $0.0 \%$

b. Promoting exports of local products

No activity $69.8 \%$

Little activity $19.0 \%$

Medium activity

$7.1 \%$

Medium-high activity

$3.2 \%$

High activity

$0.8 \%$

c. Investing with international capital markets

No activity

Little activity

Medium activity

Medium-high activity

High activity

d. Attracting foreign tourists

No activity

Little activity

Medium activity

Medium-high activity

High activity
$73.0 \%$

$18.3 \%$

$6.3 \%$

$1.6 \%$

$0.8 \%$

e. Conducting trade missions abroad/overseas

No activity $46.0 \%$ $25.4 \%$

$11.1 \%$ $10.3 \%$

$7.1 \%$

Little activity $80.2 \%$

Medium activity

$11.9 \%$

Medium-high activity

$3.2 \%$

High activity

$4.0 \%$

$0.8 \%$ 
f. Exchanging ideas about city government and management with foreign cities

No activity

$43.7 \%$

Little activity

$23.8 \%$

Medium activity

$19.0 \%$

Medium-high activity

$8.7 \%$

High activity

$4.8 \%$

g. Working with the private sector to improve your position in the global economy

No activity

$42.1 \%$

Little activity $23.0 \%$

Medium activity

$19.8 \%$

Medium-high activity

$9.5 \%$

High activity

$5.6 \%$

h. Working with neighboring cities to improve your position in the global economy

No activity $46.0 \%$

Little activity $23.8 \%$

Medium activity

$17.5 \%$

Medium-high activity

$9.5 \%$

High activity

$3.2 \%$

i. Working with state officials to improve your position in the global economy No activity $42.4 \%$

Little activity $23.2 \%$

Medium activity $20.0 \%$

Medium-high activity

$8.8 \%$

High activity

$5.6 \%$

2. How much of an impact do you think the increased competition of the global economy has had on the following aspects of your municipality?

a. City's unreserved fund balance

Low impact $66.4 \%$

Low-medium impact $18.9 \%$

Medium impact

$10.7 \%$

Medium-High impact

$3.3 \%$

High impact

$0.8 \%$ 
b. City's economic competitiveness

Low impact $\quad 36.9 \%$

Low-medium impact $\quad 22.1 \%$

Medium impact $\quad 26.2 \%$

Medium-High impact $\quad 13.9 \%$

High impact $\quad 0.8 \%$

c. City residents' income distribution

Low impact $\quad 32.2 \%$

Low-medium impact $\quad 28.1 \%$

Medium impact $\quad 26.4 \%$

Medium-High impact $\quad 9.1 \%$

High impact $\quad 4.1 \%$

d. Economic status of the poor

Low impact $\quad 43.4 \%$

Low-medium impact $\quad 23.8 \%$

Medium impact 20.5\%

Medium-High impact $\quad 9.0 \%$

High impact $\quad 3.3 \%$

e. City residents' job security

Low impact $\quad 33.1 \%$

Low-medium impact $\quad 22.9 \%$

Medium impact $\quad 32.2 \%$

Medium-High impact $\quad 6.8 \%$

High impact $\quad 5.1 \%$

3. The following issues may be viewed as positive or negative repercussions of globalization. How do you perceive these issues in the context of your city?

a. A more competitive global economy
No effect
$19.7 \%$
Very negative
$2.5 \%$
Negative
$11.5 \%$
Positive
$51.6 \%$
Very positive
$14.8 \%$ 
b. Entrepreneurship among immigrants

No effect $\quad 17.2 \%$

Very negative $\quad 1.6 \%$

Negative $\quad 4.9 \%$

Positive $\quad 54.1 \%$

Very positive $\quad 22.1 \%$

c. Local establishment of multinational corporations

No effect $26.2 \%$

Very negative $\quad 0.8 \%$

Negative $\quad 2.5 \%$

Positive $\quad 41.0 \%$

Very positive $\quad 29.5 \%$

4. In managing your city's affairs, how would do you assess globalization's impact on the following aspects of municipal governance?

a. Stability of revenue streams

Low impact

$45.7 \%$

Low-medium impact $\quad 23.3 \%$

Medium impact $\quad 20.7 \%$

Medium-High impact $\quad 6.9 \%$

High impact $\quad 3.4 \%$

b. Residents' sense of neighborhood

Low impact $\quad 55.6 \%$

Low-medium impact $\quad 17.9 \%$

Medium impact $\quad 15.4 \%$

Medium-High impact $\quad 5.1 \%$

High impact $\quad 6.0 \%$

c. Provision of affordable housing

Low impact $\quad 53.0 \%$

Low-medium impact $\quad 22.2 \%$

Medium impact $\quad 16.2 \%$

Medium-High impact $\quad 3.4 \%$

High impact $\quad 5.1 \%$

d. Procurement and purchasing practices

Low impact $\quad 46.1 \%$

Low-medium impact $\quad 27.0 \%$

Medium impact $\quad 18.3 \%$

Medium-High impact $\quad 6.1 \%$

High impact $\quad 2.6 \%$ 
e. Variety of services delivered to specific demographics

Low impact $\quad 43.0 \%$

Low-medium impact $\quad 22.8 \%$

Medium impact $\quad 21.1 \%$

Medium-High impact $\quad 8.8 \%$

High impact $\quad 4.4 \%$

5. Some argue that globalization makes for more complex managerial decision-making. In your opinion, how complicated have the following decision-making duties become, due to globalization?

a. Assessing technical and "people" skills of prospective hires

No change

$42.7 \%$

Very little change $\quad 25.6 \%$

Moderate change $\quad 18.8 \%$

More complicated $\quad 10.3 \%$

Much more complicated $\quad 2.6 \%$

b. Deploying economic development incentives

No change $\quad 46.2 \%$

Very little change $\quad 21.4 \%$

Moderate change $\quad 18.8 \%$

More complicated $\quad 11.1 \%$

Much more complicated $\quad 2.6 \%$

c. Branding your community's image

No change $\quad 37.1 \%$

Very little change $\quad 23.3 \%$

Moderate change $\quad 17.2 \%$

More complicated $\quad 15.5 \%$

Much more complicated $\quad 6.9 \%$

d. Setting operating budget priorities

No change $\quad 48.7 \%$

Very little change $\quad 22.2 \%$

Moderate change $\quad 20.5 \%$

More complicated $\quad 7.7 \%$

Much more complicated $\quad 0.9 \%$ 
e. Making capital budget decisions

$\begin{array}{lr}\text { No change } & 53.4 \% \\ \text { Very little change } & 19.8 \% \\ \text { Moderate change } & 16.4 \% \\ \text { More complicated } & 8.6 \% \\ \text { Much more complicated } & 1.7 \%\end{array}$

f. Benchmarking with other municipalities

No change $\quad 53.0 \%$

Very little change $\quad 17.1 \%$

Moderate change $\quad 17.9 \%$

More complicated $\quad 9.4 \%$

Much more complicated $\quad 2.6 \%$

6. Please indicate your level of agreement with the following statements.

Access and participation in the global economy lowers operating costs for my municipality

No opinion

$34.5 \%$

Strongly disagree $\quad 5.2 \%$

Disagree $\quad 27.6 \%$

Agree $\quad 29.3 \%$

Strongly agree $\quad 3.4 \%$

Increased racial/ethnic diversity in my municipality complicates policymaking

No opinion $\quad 12.1 \%$

Strongly disagree $\quad 12.1 \%$

Disagree $\quad 38.8 \%$

Agree $\quad 31.9 \%$

Strongly agree $\quad 5.2 \%$

Globalization raises wages in my municipality

No opinion

$26.7 \%$

Strongly disagree $\quad 6.0 \%$

Disagree $\quad 47.4 \%$

Agree $\quad 18.1 \%$

Strongly agree $\quad 1.7 \%$ 
Globalization increases job opportunities in my municipality

No opinion

Strongly disagree

Disagree

Agree

Strongly agree
$16.4 \%$

$6.0 \%$

$26.7 \%$

$44.8 \%$

$6.0 \%$

Globalization improves quality of life standards in my municipality

No opinion

Strongly disagree

Disagree

Agree

Strongly agree
$36.2 \%$

$3.4 \%$

$19.0 \%$

$36.2 \%$

$5.2 \%$ 


\section{APPENDIX}

\section{B. FACTOR ANALYSIS TABLES}

Table A1. Total Variance Explained (questions 3 \& 6)

\begin{tabular}{|l|r|r|r|r|r|r|}
\hline Component & \multicolumn{3}{|c|}{ Initial Eigenvalues } & \multicolumn{2}{c|}{ Rotation Sums of Squared Loadings } \\
\hline & Total & $\begin{array}{c}\text { \% of } \\
\text { Variance }\end{array}$ & $\begin{array}{c}\text { Cumulative } \\
\text { \% }\end{array}$ & Total & $\begin{array}{c}\text { \% of } \\
\text { Variance }\end{array}$ & $\begin{array}{c}\text { Cumulative } \\
\%\end{array}$ \\
\hline 1 & 3.223 & 40.282 & 40.282 & 2.453 & 30.665 & 30.665 \\
3 & 1.379 & 17.232 & 57.514 & 2.148 & 26.849 & 57.514 \\
4 & .879 & 10.982 & 68.496 & & \\
5 & .827 & 10.339 & 78.835 & & \\
6 & .601 & 7.516 & 86.351 & & & \\
7 & .434 & 5.429 & 91.780 & & & \\
8 & .373 & 4.656 & 96.437 & & & \\
\hline
\end{tabular}

Extraction Method: Principal Component Analysis.

Table A2. Total Variance Explained (questions 2 \& 4)

\begin{tabular}{|l|r|r|r|r|r|r|}
\hline \multirow{2}{*}{ Component } & \multicolumn{3}{|c|}{ Initial Eigenvalues } & \multicolumn{2}{c|}{ Rotation Sums of Squared Loadings } \\
\hline & Total & $\begin{array}{c}\text { \% of } \\
\text { Variance }\end{array}$ & $\begin{array}{c}\text { Cumulative } \\
\text { \% }\end{array}$ & Total & $\begin{array}{c}\text { \% of } \\
\text { Variance }\end{array}$ & $\begin{array}{c}\text { Cumulative } \\
\%\end{array}$ \\
\hline 1 & 5.378 & 53.784 & 53.784 & 3.616 & 36.158 & 36.158 \\
3 & 1.247 & 12.467 & 66.251 & 3.009 & 30.092 & 66.251 \\
4 & .873 & 8.725 & 74.976 & & \\
5 & .588 & 5.880 & 80.856 & & \\
6 & .501 & 5.008 & 85.864 & & \\
7 & .400 & 3.998 & 89.862 & & \\
8 & .323 & 3.233 & 93.095 & & \\
9 & .278 & 2.782 & 95.878 & & \\
10 & .235 & 2.346 & 98.224 & & \\
\end{tabular}

Extraction Method: Principal Component Analysis. 
Table A3. Total Variance Explained (questions 1, 7, 8)

\begin{tabular}{|c|c|c|c|c|c|c|}
\hline Component & \multicolumn{3}{|c|}{ Initial Eigenvalues } & \multicolumn{3}{|c|}{ Rotation Sums of Squared Loadings } \\
\hline & Total & $\begin{array}{c}\% \text { of } \\
\text { Variance }\end{array}$ & $\begin{array}{c}\text { Cumulative } \\
\%\end{array}$ & Total & $\begin{array}{c}\% \text { of } \\
\text { Variance }\end{array}$ & $\begin{array}{c}\text { Cumulative } \\
\%\end{array}$ \\
\hline 1 & 6.233 & 31.167 & 31.167 & 5.071 & 25.353 & 25.353 \\
\hline 2 & 2.025 & 10.125 & 41.292 & 2.414 & 12.070 & 37.423 \\
\hline 3 & 1.781 & 8.906 & 50.198 & 2.172 & 10.861 & 48.283 \\
\hline 4 & 1.205 & 6.023 & 56.222 & 1.402 & 7.008 & 55.291 \\
\hline 5 & 1.048 & 5.241 & 61.463 & 1.234 & 6.172 & 61.463 \\
\hline 6 & .941 & 4.706 & 66.169 & & & \\
\hline 7 & .912 & 4.560 & 70.729 & & & \\
\hline 8 & .737 & 3.684 & 74.414 & & & \\
\hline 9 & .712 & 3.558 & 77.972 & & & \\
\hline 10 & .673 & 3.366 & 81.337 & & & \\
\hline 11 & .625 & 3.126 & 84.463 & & & \\
\hline 12 & .563 & 2.817 & 87.281 & & & \\
\hline 13 & .492 & 2.460 & 89.740 & & & \\
\hline 14 & .422 & 2.111 & 91.851 & & & \\
\hline 15 & .389 & 1.945 & 93.796 & & & \\
\hline 16 & .368 & 1.840 & 95.635 & & & \\
\hline 17 & .313 & 1.566 & 97.201 & & & \\
\hline 18 & .266 & 1.330 & 98.531 & & & \\
\hline 19 & .151 & .757 & 99.288 & & & \\
\hline 20 & .142 & .712 & 100.000 & & & \\
\hline
\end{tabular}

Extraction Method: Principal Component Analysis. 


\section{APPENDIX}

C. Interview schedule used with city managers, economic development, planning and zoning, parks and recreation directors and police chiefs

\section{BACKGROUND}

1. What is your official job title?

2. How long have you served in this position?

3. Prior to serving in this position, did you serve in another public service or government position?

a. If yes, which one?

b. If no, from which sector/industry did you come to public service?

\section{VIEWS ON GLOBALIZATION GENERALLY}

4. When you hear the word 'globalization', what comes to mind?

5. How do you view its relevance in relation to public management activities?

6. In your opinion, how has globalization affected public management in this municipality?

7. Do you think it is a challenge or an opportunity for city management officials to bring a global perspective to their activities?

\section{VIEWS ON GLOBALIZATION SPECIFICALLY}

8. Does globalization affect your work directly? If so, how?

9. How do you handle these effects? 
10. In light of what you know about globalization, what would you say is the major challenge it poses for your position?

\section{FOR MAYORS AND CITY MANAGERS}

11. What approach do you take towards decision-making for the city?

12. Has globalization affected this approach? If yes, how?

13. In your opinion, what would you say is the major challenge that globalization poses for the practice of public management? 


\section{APPENDIX}

D. Survey on globalization and public management

1. City's global activity. For each of the following activities, please indicate the level of activity carried out on behalf of your city by municipal administration/government.

\begin{tabular}{|c|c|c|c|c|c|}
\hline & $\begin{array}{l}\text { No } \\
\text { Activity }\end{array}$ & 2 & 3 & 4 & $\begin{array}{l}\text { High } \\
\text { Activity }\end{array}$ \\
\hline Attracting foreign direct investment & 0 & O & o & o & o \\
\hline Promoting exports of local products & O & $\mathrm{O}$ & O & O & O \\
\hline $\begin{array}{l}\text { Investing with international capital } \\
\text { markets }\end{array}$ & O & o & o & o & O \\
\hline Attracting foreign tourists & o & o & O & ○ & O \\
\hline $\begin{array}{l}\text { Conducting trade missions } \\
\text { abroad/overseas }\end{array}$ & O & O & o & O & O \\
\hline $\begin{array}{l}\text { Exchanging ideas about city government } \\
\text { and management with foreign cities }\end{array}$ & o & o & o & 0 & 0 \\
\hline $\begin{array}{l}\text { Working with the private sector to } \\
\text { improve your position in the global } \\
\text { economy }\end{array}$ & o & o & o & o & o \\
\hline $\begin{array}{l}\text { Working with neighboring cities to } \\
\text { improve your position in the global } \\
\text { economy }\end{array}$ & o & o & o & 0 & 0 \\
\hline $\begin{array}{l}\text { Working with state officials to improve } \\
\text { your position in the global economy }\end{array}$ & 0 & 0 & 0 & 0 & 0 \\
\hline
\end{tabular}

\section{Global economy's effect on city's demography}

2. How much of an impact do you think the increased competition of the global economy has had on the following aspects of your municipality?

\begin{tabular}{|lccccc|}
\hline & $\begin{array}{c}\text { Low } \\
\text { Impact }\end{array}$ & 2 & 3 & 4 & $\begin{array}{c}\text { High } \\
\text { Impact }\end{array}$ \\
\hline City's unreserved fund balance & $\circ$ & $\circ$ & $\circ$ & $\circ$ & $\circ$ \\
\hline City's economic competitiveness & $\circ$ & $\circ$ & $\circ$ & $\circ$ & $\circ$ \\
\hline City residents' income distribution & $\circ$ & $\circ$ & $\circ$ & $\circ$ & $\circ$ \\
\hline Economic status of the poor & $\circ$ & $\circ$ & $\circ$ & $\circ$ & $\circ$ \\
\hline City residents' job security & $\circ$ & $\circ$ & $\circ$ & $\circ$ & $\circ$ \\
\hline Other (please specify) & & & & & \\
& & & & & \\
& & & & & \\
\end{tabular}


3. The following issues may be viewed as positive or negative repercussions of globalization. How do you perceive these issues in the context of your city?

\begin{tabular}{|lccccc|}
\hline & $\begin{array}{c}\text { Very } \\
\text { Negative }\end{array}$ & Negative & Positive & $\begin{array}{c}\text { Very } \\
\text { Positive }\end{array}$ & $\begin{array}{c}\text { No } \\
\text { Effect }\end{array}$ \\
\hline $\begin{array}{l}\text { A more competitive } \\
\text { global economy }\end{array}$ & 0 & 0 & 0 & 0 & 0 \\
\hline $\begin{array}{l}\text { Entrepreneurship } \\
\text { among immigrants }\end{array}$ & 0 & 0 & 0 & 0 & 0 \\
\hline $\begin{array}{l}\text { Local establishment of } \\
\text { transnational } \\
\text { corporations }\end{array}$ & 0 & 0 & 0 & 0 & 0 \\
\hline
\end{tabular}

\section{Globalization impact levels}

4. In managing your city's affairs, how would do you assess globalization's impact on the following aspects of municipal governance?

\begin{tabular}{|lccccc|}
\hline & $\begin{array}{c}\text { Low } \\
\text { Impact }\end{array}$ & 2 & 3 & 4 & $\begin{array}{c}\text { High } \\
\text { Impact }\end{array}$ \\
\hline Stability of revenue streams & $\circ$ & $\circ$ & $\circ$ & $\circ$ & $\circ$ \\
\hline Residents' sense of neighborhood & $\circ$ & $\circ$ & $\circ$ & $\circ$ & $\circ$ \\
\hline Provision of affordable housing & $\circ$ & $\circ$ & $\circ$ & $\circ$ & $\circ$ \\
\hline Procurement and purchasing practices & $\circ$ & $\circ$ & $\circ$ & $\circ$ & $\circ$ \\
\hline $\begin{array}{l}\text { Variety of services delivered to specific } \\
\text { demographics }\end{array}$ & $\circ$ & $\circ$ & $\circ$ & $\circ$ & $\circ$ \\
\hline Please add any other comments & & & & & \\
& & & & & \\
\end{tabular}

5. Some argue that globalization makes for more complex managerial decision-making. In your opinion, how complicated have the following decision-making duties become, due to globalization?

\begin{tabular}{|lccccc|}
\hline & $\begin{array}{c}\text { No } \\
\text { Change }\end{array}$ & 2 & 3 & 4 & $\begin{array}{c}\text { More } \\
\text { complicated }\end{array}$ \\
\hline $\begin{array}{l}\text { Assessing the technical and "people" } \\
\text { skills of prospective hires }\end{array}$ & $\circ$ & $\circ$ & $\circ$ & $\circ$ & $\circ$ \\
\hline $\begin{array}{l}\text { Deploying economic development } \\
\text { incentives }\end{array}$ & $\circ$ & $\circ$ & $\circ$ & $\circ$ & $\circ$ \\
\hline Branding your community's image & $\circ$ & 0 & $\circ$ & $\circ$ & $\circ$ \\
\hline Setting operating budget priorities & $\circ$ & $\circ$ & $\circ$ & $\circ$ & $\circ$ \\
\hline Making capital budget decisions & $\circ$ & $\circ$ & $\circ$ & $\circ$ & $\circ$ \\
\hline
\end{tabular}




\begin{tabular}{|llllll|}
\hline $\begin{array}{l}\text { Benchmarking with other } \\
\text { municipalities }\end{array}$ & 0 & $\circ$ & $\circ$ & 0 & $\circ$ \\
\hline
\end{tabular}

Perceptions about multi-dimensional impact of globalization

6. Please indicate your level of agreement with the following statements.

\begin{tabular}{|c|c|c|c|c|c|}
\hline & $\begin{array}{l}\text { Strongly } \\
\text { Disagree }\end{array}$ & Disagree & Agree & $\begin{array}{c}\text { Strongly } \\
\text { Agree }\end{array}$ & $\begin{array}{c}\text { No } \\
\text { Opinion }\end{array}$ \\
\hline $\begin{array}{l}\text { Access to and } \\
\text { participation in the } \\
\text { global economy lowers } \\
\text { operating costs for my } \\
\text { municipality }\end{array}$ & O & O & 0 & O & O \\
\hline $\begin{array}{l}\text { Increased racial/ethnic } \\
\text { diversity in my } \\
\text { municipality } \\
\text { complicates } \\
\text { policymaking }\end{array}$ & O & O & 0 & O & O \\
\hline $\begin{array}{l}\text { Globalization raises } \\
\text { wages in my } \\
\text { municipality }\end{array}$ & O & o & O & O & o \\
\hline $\begin{array}{l}\text { Globalization increases } \\
\text { job opportunities in my } \\
\text { municipality }\end{array}$ & O & o & O & ○ & o \\
\hline $\begin{array}{l}\text { Globalization improves } \\
\text { quality of life standards } \\
\text { in my municipality }\end{array}$ & O & ○ & O & O & ○ \\
\hline
\end{tabular}

\section{Municipality's administrative response to globalization}

7. In your opinion, which of the following activities have been undertaken in your municipality, as a consequence of globalization? You may check more than one.

$\square$ Teaching cultural competencies of city employees

$\square$ Improving technological competencies of city employees

$\square$ Hiring individuals who communicate in languages other than English

$\square$ "Marketing" the city internationally

$\square$ Hosting/promoting multicultural community events

$\square$ Other (please specify) 
8. Which of the following holds true for your municipality? You may check more than one.

$\square$ The city provides foreign language training for its employees.

$\square$ The city requires second-language competencies for certain employment positions.

$\square$ The city provides cultural diversity training for its employees.

$\square$ The city uses translation services for non-English speakers at its public meetings.

$\square$ City signage appears in English and at least one language other than English throughout the community.

$\square$ City publications are presented in English and at least one language other than English.

9. Some people feel that globalization is positive, others see it as negative. Please use the space provided below to add any comments you may have on the issue of globalization and how it impacts your work as a public service practitioner.

10. What is your highest level of education?

$\square$ High School

$\square$ Some College

$\square$ Bachelor's Degree

$\square$ Master's Degree

$\square$ Doctoral Degree

11. Have you ever worked outside the U.S. for at least one year during your professional life?

$\square$ Yes

$\square$ No

12 . What is your age category?

$\square 25-39$ years

$\square$ 40-54 years

$\square 55$ years and over 
13. Are you a native-born citizen of the U.S.?

$\square$ Yes $\square$ No 
VITA

NADINE VANESSA WEDDERBURN

1990-1995

B.S. Civil Engineering Technology

Rochester Institute of Technology

Rochester, New York

1995-1997

Project Engineer

CFC Construction Company, Ltd.

St. Ann, Jamaica, W.I.

1997-1999

M.S. Engineering Management

Florida Institute of Technology

Melbourne, Florida

1999-2002

Assistant Project Manager

Morse Diesel International

Fort Lauderdale, Florida

$2002-2003$

Owner's Representative, ChristWay Baptist Church

Miramar, Florida

2003-2004

Enrolled, Latin American and Caribbean Studies

Florida International University

Miami, Florida

2004-2010

Doctoral Candidate in Public Affairs

Florida International University

Miami, Florida 